

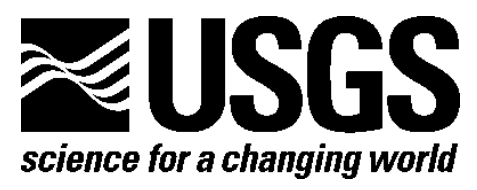

\title{
Hydraulic and Geomorphic Assessment of the Merced River and Historic Bridges in Eastern Yosemite Valley, Yosemite National Park, California
}

\author{
By J. Toby Minear and Scott A. Wright
}

Open-File Report 2013-1016

U.S. Department of the Interior

U.S. Geological Survey 


\section{U.S. Department of the Interior \\ KEN SALAZAR, Secretary}

\section{U.S. Geological Survey \\ Marcia K. McNutt, Director}

U.S. Geological Survey, Reston, Virginia: 2013

Revised and reprinted: 2013

For more information on the USGS-the Federal source for science about the Earth,

its natural and living resources, natural hazards, and the environment-visit

http://www.usgs.gov or call 1-888-ASK-USGS

For an overview of USGS information products, including maps, imagery, and publications,

visit $h$ ttp://www.usgs.gov/pubprod

To order this and other USGS information products, visit $h$ ttp://store.usgs.gov

Suggested citation:

Minear, J.Toby, Wright, Scott A., 2013, Hydraulic and Geomorphic Assessment of the Merced River and Historic Bridges in Eastern Yosemite Valley, Yosemite National Park, California: Sacramento, California, United States Geological Survey, Open-File Report 2013-1016, 74 p.

Any use of trade, firm, or product names is for descriptive purposes only and does not imply endorsement by the U.S. Government.

Although this information product, for the most part, is in the public domain, it also may contain copyrighted materials as noted in the text. Permission to reproduce copyrighted items must be secured from the copyright owner. 


\section{Contents}

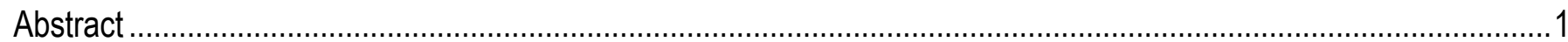

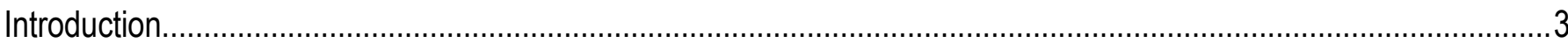

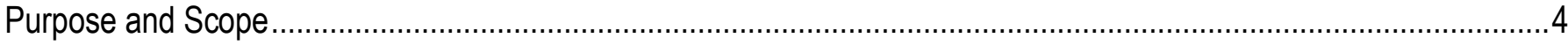

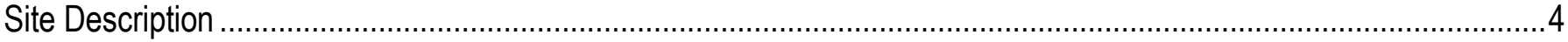

Methods

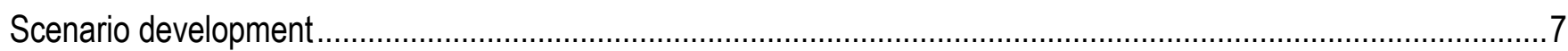

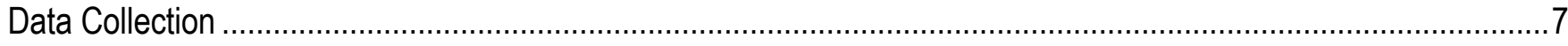

Present-day topography

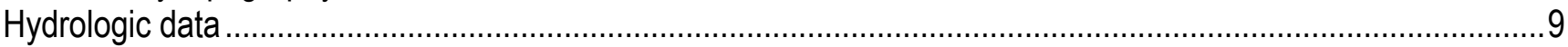

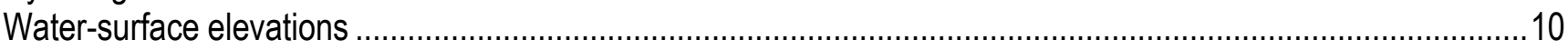

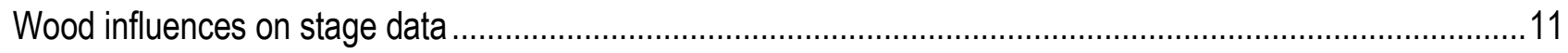

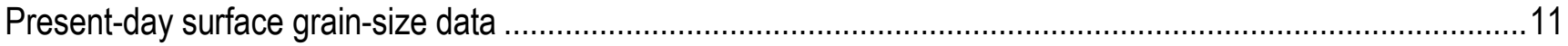

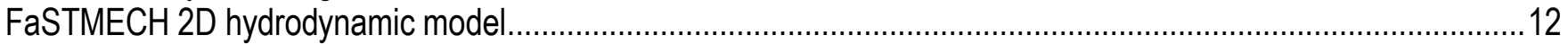

Development of the present-day topographic surface model...................................................................12

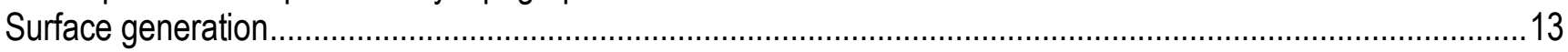

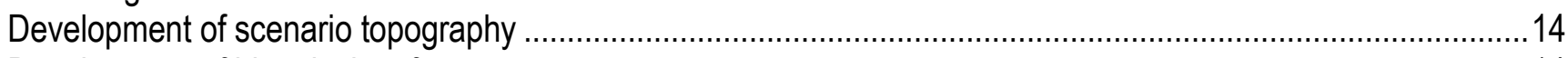

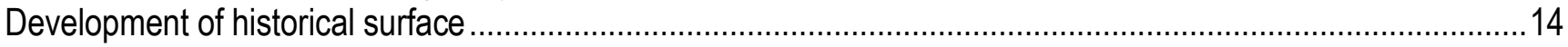

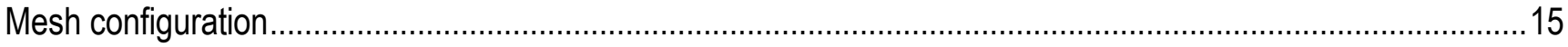

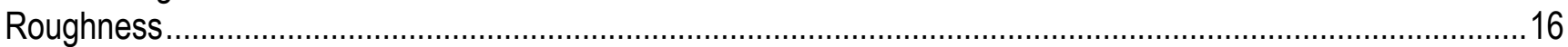

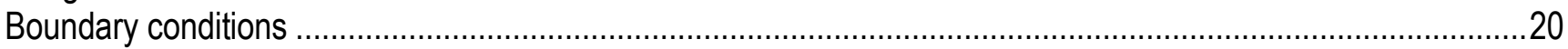

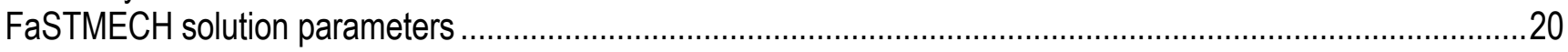

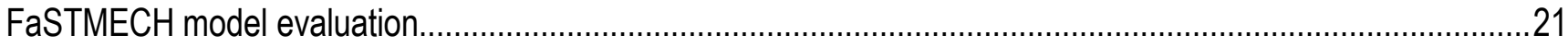

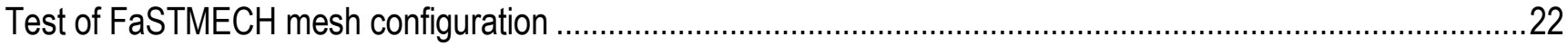

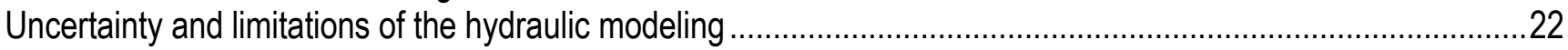

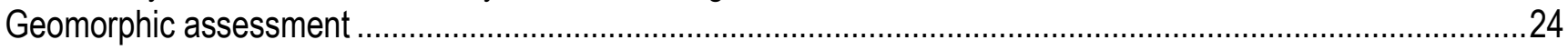

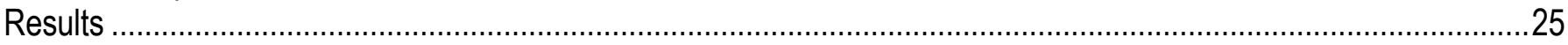

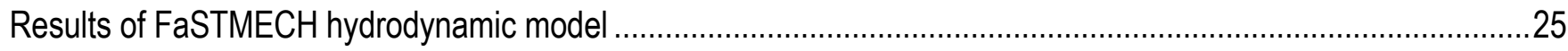

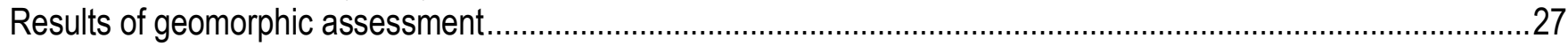

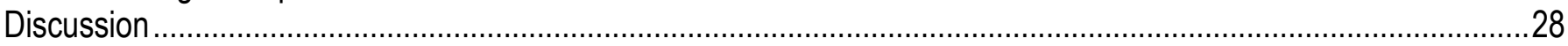

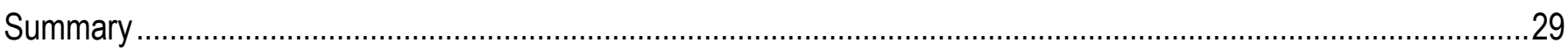

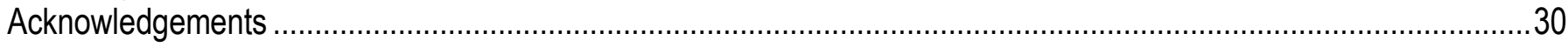

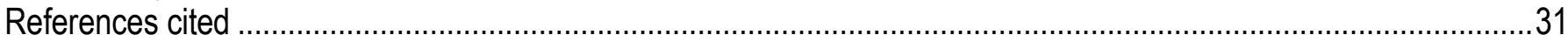




\section{Figures}

Figure 1. Overview map of the watersheds of eastern Yosemite Valley and the project site.

Figure 2. Photograph of ground-based LiDAR unit on river left streambank approximately $100 \mathrm{~m}$ downstream of Ahwahnee Bridge at site of the previous Lower Pines Campground..

Figure 3. Map of bridge locations in eastern Yosemite Valley....

Figure 4. Longitudinal profile of the Merced River through Yosemite Valley (modified from Eagan 1998)...............37

Figure 5. Digital elevation model of the Merced River study reach, with evaluation cross-sections marked............38

Figure 6. Comparison of flow data for the historical gage on Tenaya Creek (USGS gage 11265000) and Merced River at Happy Isles (USGS gage 11264500).

Figure 7. Photograph of flow through river right equestrian tunnel at Clark's Bridge, taken looking upstream.

Figures 13 and 14 show the main bridge spans for Clark's and Ahwahnee Bridges.

Figure 8. Map of Merced River in eastern Yosemite Valley, showing the locations of study cross-sections established by the YNP as part of an ongoing streambank monitoring program.

Figure 9. Photograph of the side channel and the ground-based LiDAR unit, Maptek I-Site 4400, looking upstream into the side channel between Sugar Pine and Ahwahnee Bridges.

Figure 10. Map of the project site on the Merced River in eastern Yosemite Valley..

Figure 11. Stage-discharge relation developed by YNP for Tenaya Creek from discharge measurements collected by Balance Hydrologics in WY2006 and YNP in WY2009-2010.

Figure 12. Flood probability plotted for the Merced River, using peak discharge data collected at the USGS Merced River at Happy Isles gage, 11264500.

Figure 13. Photograph of a "tape-down" measurement of river stage during WY2010 on the downstream side of Clark's Bridge..

Figure 14. Photograph of water stage measurements during WY2010 showing wood accumulation at Ahwahnee Bridge during WY2010 snowmelt runoff.

Figure 15. Photograph of water flowing several centimeters deep through North Pines Campground..

Figure 16. Graph of measured discharge for peak snowmelt runoff during WY2010 at Tenaya Creek (YNP gage), Merced River at Happy Isles (USGS gage 11264500) and the estimated discharge below the confluence of the Merced River and Tenaya Creek.

Figure 17. Photograph of the logjam at the head of the side channel cutoff between Sugar Pine and Ahwahnee Bridges immediately after it formed in January 1997.

Figure 18. Photograph of large wood accumulated on El Capitan Crossover Bridge immediately following the 1997 flood. The large wood blocks most of the river right $1 / 3$ side of the bridge.

Figure 19. Map showing the location of Wolman pebble counts (black triangle, labeled with site name initial) and field-mapped geomorphic facies of D65 grain size.

Figure 20. Graph of grain-size distributions from Wolman pebble counts for sampled locations in summer 2010.

Figure 21. Photographs showing the variation of bed material size along the study reach during the ground-based LiDAR survey, September 20-24, 2007. 
Figure 22. Longitudinal profile of the Merced River through eastern Yosemite Valley, showing the 1997 flood highwater marks and grain sizes measured from Wolman counts in WY2010.

Figure 23. Cross-section view of an example of bank smoothing by the iRIC template compared to a triangulated irregular network (TIN) for a streambank downstream of Ahwahnee Bridge (view is looking upstream), using ground-

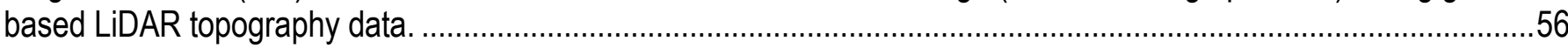

Figure 24. Topography used in the present-day and scenario FaSTMECH model runs.....................................57

Figure 25. Map of 1919 USGS maps (published in 1921) and estimated historical D65 grain size......................58

Figure 26. Comparison of cross-sections of the present-day-conditions surface used in FaSTMECH and the historical surface digital elevation model created from the 1919 USGS map...

Figure 26. (Continued) Comparison of cross-sections of the present-day-conditions surface used in FaSTMECH and the historical surface digital elevation model created from the 1919 USGS map.

Figure 27. Map of the location of the stem plot of trees used in the estimate of floodplain roughness from large diameter trees.61

Figure 28. Oblique view of ground-based LiDAR point data at the site used to estimate floodplain roughness. The trees have been fitted with horizontal circles to estimate diameter at breast height.

Figure 29. View of FaSTMECH velocity vector outputs downstream of Stoneman Bridge for the evaluation flow of $130.9 \mathrm{~m}^{3} \mathrm{~s}^{-1}$ using the $1 \mathrm{~m} \times 1 \mathrm{~m}$ grid.

Figure 30. Predicted versus observed water-surface elevations for FaSTMECH evaluation runs at $130.9 \mathrm{~m}^{3} \mathrm{~s}^{-1}$ compared to measured water-surface elevations from June 8, 2010.

Figure 31. FaSTMECH model results of depth for the present-day full-reach model runs for 50-, 20-, 10-, and 5percent annual exceedance probability floods.

Figure 32. FaSTMECH model results of velocity for the present-day full-reach runs for 50-, 20-, 10-, and 5percent annual exceedance probability floods.

Figure 33. Cross-section view of FaSTMECH model results for present-day conditions and the scenarios evaluated at Sugar Pine Bridge.

Figure 34. Cross-section view of FaSTMECH model velocity and depth results for present-day conditions and the scenarios evaluated at Ahwahnee Bridge..

Figure 35. Cross-section view of FaSTMECH model velocity and depth results for present-day conditions and the scenarios evaluated at the side channel..

Figure 36. Cross-section view of FaSTMECH model velocity and depth results for present-day conditions and the Removed Stoneman Bridge scenario evaluated at Stoneman Bridge ....

Figure 37. Summary graphs of FaSTMECH velocity results for the modeled scenarios evaluated at Ahwahnee and Sugar Pine cross-sections

Figure 38. Summary graphs of FaSTMECH velocity results for the side channel and Stoneman cross-sections (see fig. 5 for the cross-section location).

Figure 39. Maps of FaSTMECH model results of depth for historical conditions in the study reach for 50-, 20-, 10-, and 5-percent annual exceedance probability floods

Figure 40. Maps of FaSTMECH model results of velocity for historical conditions in the study reach for 50-, 20-, 10-, and 5-percent annual exceedance probability floods (panels a, b, c, and d, respectively). 
Figure 41. Cross-section view of YNP study cross-section XS 13 (see fig. 8 for location).

Figure 42. Calculated magnitude-frequency of bedload and suspended-sediment transport at YNP study crosssection 13

\section{Tables}

Table 1. Description of model scenarios developed for this study .76

Table 2. Gaging stations used in this study. .76

Table 3. Accuracy assessment of YNP 2007 topographic survey data. .76

Table 4. Results of flood frequency analysis for eastern Yosemite Valley. . .77

Table 5. YNP WY2010 water stage survey data. .78

Table 6. Downstream stage elevations used as inputs to the FaSTMECH 2D model. .78

Table 7. Input parameters for bedload transport calculations. .79

Table 8. Evaluation of equestrian tunnels at Stoneman Bridge for two flows, the 50- and 5-percent annual exceedance probability floods.

Table 9. Change through time at YNP Merced River study cross-section 13 at "Tenaya Bar". 


\section{Conversion Factors}

SI to Inch/Pound

\begin{tabular}{|c|c|c|}
\hline Multiply & By & To obtain \\
\hline \multicolumn{3}{|c|}{ Length } \\
\hline centimeter $(\mathrm{cm})$ & 0.3937 & inch (in.) \\
\hline millimeter $(\mathrm{mm})$ & 0.03937 & inch (in.) \\
\hline meter $(\mathrm{m})$ & 3.281 & foot $(\mathrm{ft})$ \\
\hline kilometer (km) & 0.6214 & mile (mi) \\
\hline meter $(\mathrm{m})$ & 1.094 & yard (yd) \\
\hline \multicolumn{3}{|c|}{ Area } \\
\hline square meter $\left(\mathrm{m}^{2}\right)$ & 0.0002471 & acre \\
\hline square kilometer $\left(\mathrm{km}^{2}\right)$ & 247.1 & acre \\
\hline square meter $\left(\mathrm{m}^{2}\right)$ & 10.76 & square foot $\left(\mathrm{ft}^{2}\right)$ \\
\hline square kilometer $\left(\mathrm{km}^{2}\right)$ & 0.3861 & square mile $\left(\mathrm{mi}^{2}\right)$ \\
\hline \multicolumn{3}{|c|}{ Volume } \\
\hline cubic meter $\left(\mathrm{m}^{3}\right)$ & 264.2 & gallon (gal) \\
\hline cubic meter $\left(\mathrm{m}^{3}\right)$ & 35.31 & cubic foot $\left(\mathrm{ft}^{3}\right)$ \\
\hline cubic meter $\left(\mathrm{m}^{3}\right)$ & 1.308 & cubic yard $\left(\mathrm{yd}^{3}\right)$ \\
\hline cubic meter $\left(\mathrm{m}^{3}\right)$ & 0.0008107 & acre-foot (acre-ft) \\
\hline \multicolumn{3}{|c|}{ Flow rate } \\
\hline cubic meter per second $\left(\mathrm{m}^{3} / \mathrm{s}\right)$ & 70.07 & acre-foot per day (acre-ft/d) \\
\hline meter per second $(\mathrm{m} / \mathrm{s})$ & 3.281 & foot per second (ft/s) \\
\hline cubic meter per second $\left(\mathrm{m}^{3} / \mathrm{s}\right)$ & 35.31 & cubic foot per second $\left(\mathrm{ft}^{3} / \mathrm{s}\right)$ \\
\hline \multicolumn{3}{|c|}{ Mass } \\
\hline kilogram (kg) & 2.205 & pound avoirdupois (lb) \\
\hline metric ton per day & 1.102 & ton per day (ton/d) \\
\hline metric ton per year & 1.102 & ton per year (ton/yr) \\
\hline \multicolumn{3}{|c|}{ Pressure } \\
\hline kilopascal (kPa) & 0.009869 & atmosphere, standard (atm) \\
\hline kilopascal (kPa) & 0.01 & bar \\
\hline \multicolumn{3}{|c|}{ Density } \\
\hline kilogram per cubic meter $\left(\mathrm{kg} / \mathrm{m}^{3}\right)$ & 0.06242 & pound per cubic foot $\left(\mathrm{lb} / \mathrm{ft}^{3}\right)$ \\
\hline \multicolumn{3}{|c|}{ Hydraulic conductivity } \\
\hline meter per day $(\mathrm{m} / \mathrm{d})$ & 3.281 & foot per day $(\mathrm{ft} / \mathrm{d})$ \\
\hline \multicolumn{3}{|c|}{ Hydraulic gradient } \\
\hline meter per kilometer $(\mathrm{m} / \mathrm{km})$ & 5.27983 & foot per mile ( $\mathrm{ft} / \mathrm{mi})$ \\
\hline
\end{tabular}


Temperature in degrees Celsius $\left({ }^{\circ} \mathrm{C}\right)$ may be converted to degrees Fahrenheit $\left({ }^{\circ} \mathrm{F}\right)$ as follows:

${ }^{\circ} \mathrm{F}=\left(1.8 \times{ }^{\circ} \mathrm{C}\right)+32$.

Vertical coordinate information is referenced to the North American Vertical Datum of 1988 (NAVD 88).

Horizontal coordinate information is referenced to the North American Datum of 1983 (NAD 83).

\section{Abbreviations}

\begin{tabular}{ll} 
1D & one-dimensional \\
2D & two-dimensional \\
3D & three-dimensional \\
AEP & annual exceedance probability \\
BAGS & Bedload Assessment for Gravel-bed Streams \\
CBA & Cella Barr and Associates \\
DEA & David Evans and Associates \\
DEM & digital elevation model \\
FaSTMECH & Flow and Sediment Transport with Morphological Evolution of Channels \\
GIS & geographic information system \\
HEC-RAS & Hydrologic Engineering Center - River Analysis System \\
HEC-SSP & Hydrologic Engineering Center - Statistical Software Package \\
iRIC & Internationl River Interface Cooperative \\
LEV & lateral eddy viscosity \\
LiDAR & light detection and ranging \\
NAD83 & North American Datum, 1983 \\
NAVD88 & North American Vertical Datum, 1988 \\
NCALM & National Center for Airborne Laser-swath Mapping \\
NPS & National Park Service \\
RMSE & root mean square error \\
RR & river right (looking downstream) \\
RL & river left (looking downstream) \\
TIN & triangulated irregular network \\
USA & United States of America \\
USACE & United States Army Corps of Engineers \\
USGS & United States Geological Survey \\
UTM & Universal Transverse Mercator \\
WY & water year \\
YNP & Yosemite National Park \\
& \\
\hline
\end{tabular}




\title{
Hydraulic and Geomorphic Assessment of the Merced River and Historic Bridges in Eastern Yosemite Valley, Yosemite National Park, California
}

\author{
By J. Toby Minear and Scott A. Wright
}

\begin{abstract}
The Merced River in the popular and picturesque eastern-most part of Yosemite Valley in Yosemite National Park, California, USA, has been extensively altered since the park was first conceived in 1864. Historical human trampling of streambanks has been suggested as the cause of substantial increases in stream width, and the construction of undersized stone bridges in the 1920s has been suggested as the major factor leading to an increase in overbank flooding due to deposition of bars and islands between the bridges. In response, the National Park Service at Yosemite National Park (YNP) requested a study of the hydraulic and geomorphic conditions affecting the most-heavily influenced part of the river, a 2.4-km reach in eastern Yosemite Valley extending from above the Tenaya Creek and Merced River confluence to below Housekeeping Bridge. As part of the study, present-day conditions were compared to historical conditions and several possible planning scenarios were investigated, including the removal of an elevated road berm and the removal of three undersized historic stone bridges identified by YNP as potential problems: Sugar Pine, Ahwahnee and Stoneman Bridges. This Open-File Report will be superseded at a later date by a Scientific Investigations Report.

A two-dimensional hydrodynamic model, the USGS FaSTMECH (Flow and Sediment Transport with Morphological Evolution of Channels) model, within the USGS International River Interface Cooperative (iRIC) model framework, was used to compare the scenarios over a range of discharges with annual exceedance probabilities of 50-, 20-, 10-, and 5- percent. A variety of topographic and hydraulic data sources were used to create the input conditions to the hydrodynamic model, including aerial LiDAR (Light Detection And Ranging), ground-based LiDAR, total station survey data, and grain size data from pebble counts. A digitized version of a historical topographic map created by the USGS in 1919, combined with estimates of grain size, was used to simulate historical conditions, and the planning scenarios were developed by altering the present-day topography. Roughness was estimated independently of measured water-surface elevations by using the mapped grain-size data and the Keulegan relation of grain size to drag coefficient. The FaSTMECH hydrodynamic model was evaluated against measured water levels by using a $130.9 \mathrm{~m}^{3} \mathrm{~s}^{-1}$ flow (approximately a 33-percent annual exceedance probability flood) with 36 water-surface elevations measured by YNP personnel on
\end{abstract}


June 8, 2010. This evaluation run had a root mean square error of $0.21 \mathrm{~m}$ between the simulated- and observed water-surface elevations (less than 10 percent of depth), though the observed water-surface elevations had relatively high variation due to the strong diurnal stage changes over the course of the 4.4-hour collection period, during which discharge varied by about 15 percent. There are presently no velocity data with which to test the model. A geomorphic assessment was performed that consisted of an estimate of the magnitude and frequency of bedload and suspended-sediment transport at "Tenaya Bar", an important gravel-cobble bar located near the upstream end of the study site that determines the amount of flow across the floodplain at the Sugar Pine - Ahwahnee bend. An analysis of select repeat cross-sections collected by YNP since the late 1980s was done to investigate changes in channel crosssectional area near the Tenaya Bar site.

The results of the FaSTMECH models indicate that the maximum velocities in the present-day channel within the study reach are associated with Stoneman and Sugar Pine Bridges, at close to $3.0 \mathrm{~m}$ $\mathrm{s}^{-1}$ for the 5-percent annual exceedance probability flood. The modeled maximum velocities at Ahwahnee Bridge are comparatively low, at between 1.5 and $2.0 \mathrm{~m} \mathrm{~s}^{-1}$, most likely due to the bridge's orientation parallel to down-valley floodplain flows. The results of the FaSTMECH models for the bridge removal scenarios indicate a reduction in average velocity at the bridge sites for the range of flows by approximately 23-38 percent (Sugar Pine Bridge), 32-42 percent (Ahwahnee Bridge), and 3339 percent (Stoneman Bridge), though a side channel of concern to YNP management did not appear to be substantially affected by the removal scenarios. In comparison to the historical data, the FaSTMECH results suggest that flows for present-day conditions do not inundate the floodplain until between the 50and 20-percent annual exceedance probability flood, whereas historically, a large portion of the floodplain was inundated during the 50-percent annual exceedance probability flood. Modeled maximum velocities in the present-day channel commonly exceed $2.0 \mathrm{~m} \mathrm{~s}^{-1}$, whereas with the historical scenario, modeled maximum in-channel velocities rarely exceeded $2.0 \mathrm{~m} \mathrm{~s}^{-1}$. The geomorphic analysis of the magnitude-frequency of bedload and suspended-sediment transport suggests that at the important Tenaya Bar site, the majority of bed sediment is mobile during most snowmelt-dominated floods. In contrast to sediment transport capacity, the analysis of repeat cross-sections suggests that bedload sediment supply into the eastern Yosemite Valley may be quite different between rain-on-snow floods and snowmelt-dominated floods, potentially with most sediment supply occurring during rain-on-snow floods, such as the 1997 flood. In contrast, the magnitude-frequency analysis of bedload and suspendedsediment transport suggests that long-term bedload sediment transport is likely dominated by snowmelt floods, and suspended-sediment transport is relatively low compared to bedload transport.

Obtaining measured velocity data throughout the study reach would aid in model calibration, and thus would improve confidence in model results. Improved confidence in the model velocity results would allow additional substantial analyses of reach-scale effects of the planning scenarios and would enable the development of geomorphic models to evaluate the long-term geomorphic responses of the site. In addition, the collection of watershed sediment-supply data, about which little is presently known, would give planners helpful tools to plan restoration scenarios for this nationally important river. 


\section{Introduction}

Yosemite National Park is one of the most well-known and popular National Parks in the USA, with current annual visitation levels approaching 3.9 million (National Park Service, 2011). Whereas Yosemite National Park as a whole includes a large portion of wilderness and unimproved areas, the primary tourist interest and access point for visitors is the majestic Yosemite Valley along the Merced River located near an elevation of 1,200 m (fig. 1). Partly as a result of the heavy tourism pressure, Yosemite Valley has been extensively developed with numerous buildings, campgrounds, roads, and bridges built by the park management and concessionaires since the formation of the Yosemite Grant in 1864 (Milestone, 1978). The National Park Service at Yosemite National Park (YNP) has been responsible for the management of the park since 1916 and is mandated to maintain both the natural and historic aspects of the park "unimpaired for the enjoyment of future generations" as required in the National Park Service Organic Act of 1916.

The heavy tourism pressure and historical management actions in Yosemite Valley, particularly in the eastern parts of the valley, have contributed to adverse effects to the Merced River and its floodplains, including substantial erosion of streambanks, extensive loss of riparian vegetation, and increases in channel width (Madej and others, 1991 and 1994). The overall trend of stream geomorphology from 1919 to 1989 has been that channel widths of the Merced River in eastern Yosemite Valley increased an average of 27 percent with some cross-sections increasing more than 120 percent, likely due to human trampling of streambanks and riparian vegetation (Madej and others, 1991 and 1994). At the same time, stream areas near the bridges have decreased channel widths 38 percent, on average, owing to the undersized bridge design (Madej and others, 1991 and 1994). In addition to alteration of the Merced River streambanks, the majority of original floodplain meadows and oak woodlands adjacent to the river have been altered, as they were converted first to campgrounds and later invaded by conifer forest that now includes hundreds of mature trees dozens of meters in height and more than $1 \mathrm{~m}$ in diameter (Cooper and Wolf 2008) (fig. 2). Many of these conifers are now being undercut by bank erosion and enter the channel as large wood (Milestone 1978, Madej and others, 1994). Much of the floodplain area is hydrologically connected to the channel such that in-channel water-surface elevations partially determine depths to groundwater, soil formation, and floodplain vegetation, with some effects occurring far from the channel itself (Cooper and Wolf 2008).

YNP is currently involved in a process to update their General Management Plan to incorporate a comprehensive plan for the Merced River, called the Merced River Wild and Scenic Comprehensive Management Plan, and an associated Environmental Impact Statement ("Merced River Plan"). In 1987, the Merced River was designated as a Wild and Scenic River, and the current Merced River Plan is a requirement of the Wild and Scenic Rivers Act. As part of the plan update, YNP is actively investigating the current and historical conditions of the Merced River as well as options for restoration. In particular, YNP is interested in the potentially adverse effects of three historic stone bridges in the eastern portion of the Yosemite Valley: Sugar Pine, Ahwahnee, and Stoneman Bridges (fig. 3). Whereas there have been several previous flood-flow studies in Yosemite Valley (Eagan, 1998; Cella Bar and Associates, 1998; Stantec, 2000), these studies have primarily utilized one-dimensional flow models to investigate large flooding events, particularly following the 1997 flood (1-percent annual exceedance probability flood - the "100-year" flood). Presently, there is a need for an investigation of the hydraulics that occur at the bridge sites for a variety of situations, including current conditions, historical conditions, and potential bridge removal scenarios. The flows of particular interest are relatively frequent flooding events (50- to 5-percent annual exceedance probability floods) that are more common 
than the 1997 flood event and are expected to dominate long-term geomorphic processes and stream conditions.

\section{Purpose and Scope}

The purpose of this report, prepared in cooperation with Yosemite National Park (YNP), is to develop and evaluate a two-dimensional hydrodynamic model, and then to use that model to investigate various planning scenarios being considered by YNP concerning bridges, including possible bridge and berm removal, along a 2.4-km reach of the Merced River in eastern Yosemite Valley. Of particular interest are the effects of the bridges on local river hydraulics and geomorphology, particularly whether increased velocities are associated with the bridges for a range of discharges from moderate annual exceedance probability (AEP) discharges (50-percent AEP) up to floods of 5-percent AEP. Seven different scenarios of interest to YNP were investigated by using the 2D hydraulic model, including present-day conditions, five hypothetical planning scenarios, and a historical condition that uses data from the early 1900s. It was hypothesized by YNP that there are increased velocities associated with bridges, particularly those bridges that are oriented perpendicular to flood flows on the floodplain, and that removing these bridges will reduce local in-channel velocities. Two secondary objectives of this study were to evaluate the accuracy and quality of the topographic records of the YNP and to perform an initial assessment of the modern geomorphology of the Merced River in the study reach.

\section{Site Description}

Yosemite National Park is located in the central Sierra Nevada in eastern California, USA (fig. 1). The majestic walls that have made the Yosemite area famous are formed by bedrock of sparselyjointed and resistant granite-granodiorite-tonalite rocks (henceforth simplified to "granite") (Huber, 1987). The granitic bedrock was emplaced as a series of plutons over the course of the Cretaceous, from approximately 80 to 120 million years ago (Huber, 1987). These plutons were well underground until the Sierra Nevada underwent an orogenic uplift event beginning approximately 25 million years ago (Huber, 1987). In addition to granitic rocks, small bands of metamorphic and volcanic rocks can be found in the highlands, and alluvial and colluvial deposits in low-land areas.

The dramatic topography of Yosemite Valley was carved through the granitic batholith by glaciers during the Pleistocene beginning approximately 2 to 3 million years ago, but there is evidence of only the last three glaciation events in the vicinity of Yosemite Valley (Huber, 1987). The mostrecent and relatively small glaciation event that occurred during the Last Glacial Maximum-15,000 to 20,000 years ago - is known as the Tioga advance in the Yosemite region (Huber, 1987). The Tioga advance of the Merced and Tenaya Glaciers either re-excavated or created pre-historic Yosemite Lake in the current Yosemite Valley, as well as leaving a large recessional moraine at the downstream end of the valley and a medial moraine at the upstream end of the valley (Huber, 1987) (fig. 3). A portion of the recessional moraine, which historically created a more substantial backwater in lower Yosemite Valley during floods, was lowered approximately 1 to $1.5 \mathrm{~m}$ by Galen Clark using dynamite in 1879 (Milestone, 1978). The medial moraine, deposited at the confluence between the Tenaya and Merced Glaciers, continues to influence the geomorphology of the river by constricting flows near Clark's Bridge at the upper end of the valley (fig. 3). The pre-historic Yosemite Lake has since filled with alluvium and now forms the base for the alluvial deposits created by the present-day Merced River and 
Tenaya Creek (Huber, 1987) (fig. 4). Depths to bedrock at the head of the valley are approximately 600 $\mathrm{m}$ (Gutenberg and others, 1956), which is supported by the later drilling of deep alluvial wells of approximately this depth in Yosemite Valley.

The 2.4-km-long project reach for this study is located at the eastern end of Yosemite Valley, and includes the confluence of the two major streams - the Merced River, and Tenaya Creek (figs. 3 and 5). With a relatively small watershed of $121 \mathrm{~km}^{2}$ (table 2), Tenaya Creek is dammed immediately upstream of the Yosemite Valley floor by Mirror Lake, a small, natural seasonal lake originally formed by a landslide (Huber, 1987), that was augmented with a small seasonal dam in the early 1900's (Milestone, 1978). Sediment deposited in Mirror Lake was repeatedly dredged by early park managers to maintain the lake's visual appeal (Milestone, 1978). The Merced River watershed is much larger, with a drainage area of $469 \mathrm{~km}^{2}$ at the USGS Merced River at Happy Isles Bridge gage, and consequently the Merced River produces larger mean daily flows and larger peak flows than Tenaya Creek (fig. 6).

One of the main issues affecting the Merced River through eastern Yosemite Valley is the historic landmark stone-arch bridges, which are (listed in downstream order): Clark's, Sugar Pine, Ahwahnee, and Stoneman (figs. 3 and 4). The bridges were built during the period of 1928 to 1938 by the Civilian Conservation Corps (Milestone, 1978). Some of the stone bridges replaced wooden structures that had previously occupied the bridge sites (for example, Stoneman and Clark's Bridges), whereas other bridges were entirely new (Milestone, 1978). Housekeeping Bridge, the fifth bridge in the study reach, is a foot bridge that was built later than the other four. All of the stone-arch bridges were built much shorter than the present stream width, and as a result, cause a constriction of flow during high flow events that has likely resulted in the deep pools observed immediately downstream of the bridges, with the exception of Ahwahnee Bridge. Two of the bridges, Clark's and Stoneman, have equestrian tunnels on either side of the main bridge opening that pass a small amount of water during floods (fig. 7). Two separate bridges, Ahwahnee and Housekeeping, have footings that help maintain the streambed elevation at the location of the bridge and do not allow substantial scouring of bed material immediately under the bridge, though Housekeeping has a large pool immediately downstream of the footings. Of particular importance historically and to the present study, Sugar Pine Bridge and the protection of its associated namesake Sugar Pine tree just downstream on the river-right bank have been the objects of extensive effort by the park management, with substantial efforts to protect the tree with riprap beginning as early as 1893 (Milestone, 1978). As a result, the present configuration of Sugar Pine Bridge is less than optimal for passing flood flows. Interestingly, the bridge currently appears to direct flows towards the tree and its associated riprap, possibly due to the effects of the scour hole that has formed downstream of the bridge and adjacent to the riprap protecting the tree.

Management concern about the condition of the Merced River in Yosemite Valley is not a new subject. Bank erosion has been a topic of concern to park managers since the formation of the Yosemite Grant in 1864, according to historical documents cited in Milestone (1978). In response, past park managers have tried a variety of different techniques, including extensive riprapping of streambanks, removal of large wood, blasting, and dredging (Milestone, 1978). According to Milestone (1978), by the late 1960s more than $4.4 \mathrm{~km}$ of riprap (some with stones larger than $1 \mathrm{~m}$ in diameter) was installed in Yosemite Valley, much of it in the eastern portion of the valley. Additionally, more than $15,000 \mathrm{~m}^{3}$ of gravel was excavated historically from the Merced River channel in eastern Yosemite Valley for construction purposes (Milestone, 1978). More recently, YNP has removed numerous pipelines that 
crossed the bed of the Merced River, which historically had been maintained at or near river-level, maintaining the elevation of the streambed in those areas. Legacy effects of these stream alterations are still present in the channel and likely are affecting current channel processes, but the extent of their effects is not known and was not addressed in the current study, which is primarily concerned with the hydraulic effects of the three middle bridges.

Since the last major geomorphic studies in Yosemite Valley (Madej and others, 1991,1994, and 1998), there have been two substantial events in Yosemite Valley - the January 1997 flood, and the subsequent closing of three major campgrounds in the eastern part of Yosemite Valley. The January 1997 flood is not the largest flood on record (the December 1867 flood was likely as much as 25 percent larger (United States Army Corps of Engineers, 1997) but the 1997 flood is the largest in the recent record and the only major flood since December 1964. The 1997 flood did substantial damage to park infrastructure, including campgrounds, some of which were flooded by 1-2 m deep, high velocity water that uprooted much of the campground infrastructure (Madej and others, 1998). Partially in response, three campgrounds - Lower Pines, Upper River, and Lower River-were closed and the remaining campground infrastructure in these campgrounds was removed by YNP.

In the years since 1997, riparian vegetation has become established on streambanks near the three closed campgrounds, though riparian trees and saplings continue to be relatively sparse and the ground surface of the streambanks is largely in the same position as in 1997, according to the study cross-section data collected by YNP (J. Roche, YNP, written commun., 2010) (fig. 8). The previous Upper River campground, downstream and river right of Ahwahnee Bridge, had been used by the YNP as a project staging area with large soil piles that can be seen in the 2006 aerial LiDAR images (fig. 5), but have since been mostly removed (J. Roche, YNP, written commun., 2010). In streambank areas adjacent to operating campgrounds, YNP has increased efforts to restrict human access to sensitive streambanks to help protect these resources (J. Roche, YNP, oral commun., 2010). An unforeseen effect of the campground closures in 1997 has been that some of the floodplain conifer forests that were previous campgrounds have become covered in dense stands of conifer saplings 1-3 m high, particularly at the lower end of the study reach, which has increased floodplain roughness in those locations.

One of the main river management concerns following the 1997 flood event was the enlargement of a side channel cutoff from the upstream side of Sugar Pine Bridge to below Ahwahnee Bridge (figs. 5 and 9). Park management was concerned that the cutoff channel might continue to enlarge and would eventually supplant the main channel. The cause of the extra flow in the cutoff was thought to be the undersized construction of Sugar Pine Bridge and flow confinement caused by the road berm connecting Sugar Pine and Ahwahnee Bridges. Since 1997, YNP has reinforced the side channel with riprap drop structures (fig. 9) as well as bio-engineering using plant stakings to prevent additional scour from occurring. This side channel is one of the main areas of concern for the YNP and was included in the flow modeling scenarios. 


\section{Methods}

\section{Scenario development}

The different model scenarios were developed in conjunction with YNP for the study reach. The YNP scenarios of interest are listed in table 1, and consist of seven different scenarios: present-day conditions; historical conditions based on a detailed USGS map made in 1919; removal of Sugar Pine Bridge; removal of Ahwahnee Bridge; removal of Stoneman Bridge; removal of Sugar Pine Bridge and the elevated road berm; and lastly, removal of Sugar Pine and Ahwahnee Bridges as well as the elevated road berm. The annual exceedance probabilities of the evaluation flows identified by YNP are the 50-, 20-, 10-, and 5-percent annual exceedance probability floods, which are discussed in further detail below.

\section{Data Collection}

\section{Present-day topography}

Three different topographic datasets were evaluated and used for this study: aerial LiDAR, ground-based LiDAR, and total station survey data. All data were converted into Universal Transverse Mercator (UTM) coordinates (Zone 11), by using the North American Datum of 1983 (NAD83) and the North American Vertical Datum of 1988 (NAVD88) with the U.S. Army Corps of Engineers (USACE) software, CorpsCon (version 6.0). The aerial LiDAR data were collected and processed in 2006 by the National Center for Airborne Laser Mapping (NCALM). The final aerial LiDAR product has point spacing of $1 \mathrm{~m}$, with RMS error of $0.2 \mathrm{~m}$ compared to GPS ground-points (NCALM, 2006). A portion of the 2006 aerial LiDAR just upstream of the Tenaya Creek and Merced River confluence was affected by a survey error as the plane flew too close to Half-Dome (NCALM, 2006). A subsequent aerial LiDAR flight in 2008 corrected the error and was merged to the 2006 aerial LiDAR by Bill Kuhn at YNP.

The ground-based LiDAR topographic data were collected as part of the YNP Streambank Assessment program during low water from September 20-24, 2007, by J.T. Minear (then at U.C. Berkeley), E.D. Andrews (USGS), J. Roche (YNP) and other YNP staff. A Maptek I-Site 4400 scanner (fig. 9) was chosen for the field work due to its capability for quick scans, light weight, and compatibility with a total station. The scanner collects 4,400 points per second in a 360 degree horizontal radius, within an 80 vertical degree range (40 degrees up, 40 degrees down). Due to the steep canyon walls, GPS coverage and accuracy is poor in the majority of Yosemite Valley, necessitating the use of the total station surveys for nearly all types of surveying. The center-point location of the Maptek scanner was located by using a total station and a prism mounted on a survey screw at the top of the scanner. The optical backsighting ability was utilized for every scan, typically sighting onto a plumbbob attached to the total station, but several times backsighting was performed by using a survey rod on other known points if the plumb-bob on the total station was not visible. The self-leveling procedure within the Maptek unit was utilized for every scan. During the course of 5 days, 71 ground-based LiDAR scans were taken, for a total of approximately 42.6 million points (fig. 10).

Bathymetric survey data were collected by using a total station at the same time as the groundbased LiDAR scans because the ground-based LiDAR instrument is not able to penetrate water. Several 
permanent benchmarks were utilized in the bathymetric survey, including one established by the USGS and a series that were established by David Evans and Associates (DEA, 2004) by total station. These USGS and DEA benchmarks were used by YNP to survey additional control points (typically rebar rods) associated with the YNP cross-section monitoring efforts. The bathymetric survey was performed by YNP with a Topcon GTS-210 total station (all portions of the channel were accessible by foot), and post-processing was performed by YNP in the TopCon Links software version 7. The 2007 YNP total station survey data were not adequately evaluated for survey error during the survey period (specifically, the survey was not closed out and no repeat surveys were performed to evaluate survey error). A subsequent survey effort to evaluate error was undertaken by YNP staff in fall 2010. In the 2010 survey evaluation, the same total station instrument utilized in the 2007 survey was used to survey the elevation of permanent cross-section benchmarks in a closed survey loop, as well as several of the temporary benchmarks from the 2010 water-surface surveys (next section). According to YNP staff, most of the 2007 benchmarks were still in place in 2010. In addition, during the installation of the water-stage monitoring points, an auto-level and rod were used to check elevations at many of the same benchmarks and several points were surveyed for elevation that had not been resurveyed with the total station.

The accuracy of the 2007 YNP survey data is an important check on the error in the measurements because both the bathymetric survey data and ground-based LiDAR data were based on the 2007 survey. The 2007 YNP survey data were assessed using accuracy guidelines by the USACE (United States Army Corps of Engineers, 2007). There were three primary survey loops in the original 2007 survey: Loop 1 covering from Clark's Bridge down to the Tenaya Creek confluence, Loop 2 covering from the Tenaya Creek confluence downstream to Ahwahnee Bridge, and Loop 3 from Ahwahnee Bridge down to below Housekeeping Bridge (distances and number of stations are shown in table 3). Overall, the horizontal accuracy was relatively good, ranging from a 1:1000 to 1:2500 level of accuracy (table 3), which is suitable for coarse surveying operations (United States Army Corps of Engineers, 2007). This level of horizontal accuracy corresponds to horizontal error of less than $1 \mathrm{~m}$ every $1,000 \mathrm{~m}$ to less than $0.4 \mathrm{~m}$ every $1,000 \mathrm{~m}$. The vertical accuracy was less accurate than the horizontal accuracy, ranging from less than 1:1000 to 1:2500 (table 3). This level of vertical accuracy corresponds to a vertical error of greater than $1 \mathrm{~cm}$ for every $10 \mathrm{~m}$ of elevation to less than $0.4 \mathrm{~cm}$ for every $10 \mathrm{~m}$ of elevation (10 $\mathrm{m}$ is roughly the range of elevation present in the channel). In general, Loop 3 was the least accurate of the three survey loops, partially due to its greater distance (over 1,600 m) between benchmarks.

Average and maximum distances between total station locations for all loops (for example, total station shooting distance) were $94 \mathrm{~m}$ and $213 \mathrm{~m}$, respectively. Loop 3 included a number of long shots, with several shots between total station locations that were greater than $100 \mathrm{~m}$. In addition, Loop 3 was an overly long survey loop, extending from Ahwahnee Bridge past Housekeeping Bridge, the length of which and the number of total station setups served to exacerbate the survey error due to the large distance between benchmarks (United States Army Corps of Engineers, 2007). For all loops, the 58 individual control points resurveyed in 2010 (most of which were surveyed twice in 2010) had a mean error of $0.47 \mathrm{~m}$ in the horizontal direction and mean error of $0.05 \mathrm{~m}$ in the vertical direction. The accuracy of the vertical measurements were of particular interest due to the nature of this study, with some vertical measurement error of up to $0.29 \mathrm{~m}$ in the total station resurvey, and up to $0.6 \mathrm{~m}$ error from the auto-level and rod resurvey in 2010. In particular, some of the larger error occurred at the survey points near the downstream end of the reach in Loop 3, which is a key boundary location for 
determining the input stages for the hydrodynamic model. Future survey efforts and accuracy could be improved by re-locating the additional DEA benchmarks in the study reach (there are more than twenty in the survey area), particularly in the least reliable survey loop, Loop 3.

For scaling between ground and grid coordinates, all topographic data were kept in ground scale for steps leading up the hydrodynamic model to ensure that proper conservation (for example, mass) was maintained. For subsequent analyses of the topographic data and hydrodynamic results, the data were converted to grid scale for comparison in the geographic information system (GIS).

\section{Hydrologic data}

There are two main stream gages operating in eastern Yosemite Valley: the USGS at Merced River at Happy Isles Bridge gage (\#11264500), and the YNP Tenaya Creek gage, operated by YNP (table 2). The USGS Pohono gage (hereafter USGS Happy Isles Gage) (\#11266500) is located approximately $11 \mathrm{~km}$ downstream of the study site and collects an additional $362 \mathrm{~km}^{2}$ of the watershed; hence, it was used as a rough check on the estimated flows but was not used directly. The USGS Happy Isles gage has an excellent flow record (1916 to present), including some suspended sediment samples for medium and low flows but no bedload transport or bed material samples (see review in Madej and others, 1994). In addition, the Happy Isles gage is part of the USGS Hydrologic Benchmark Network, a network of long-term hydrologic monitoring sites in the U.S.

A gage on Tenaya Creek was originally established by the USGS in 1912 (\#1126500), discontinued in 1958, and then a nearby gage site was established in 2006 by YNP and Balance Hydrologics (J. Roche, YNP, written commun., 2010). Since 2006, the YNP Tenaya Creek gage has been operated and maintained by YNP (J. Roche, YNP, written commun., 2010). The Tenaya Creek gage has not been operational as long nor as consistently as the USGS Happy Isles Gage. Stagedischarge measurements at the new YNP Tenaya Creek gage are available for WY2006, and for WY2009-2010. Unfortunately for this study, the maximum measured discharge for the YNP Tenaya Creek gage is only $29 \mathrm{~m}^{3} \mathrm{~s}^{-1}$ (the peak flow for WY2010 was estimated at $54.5 \mathrm{~m}^{3} \mathrm{~s}^{-1}$ ). As such, an extrapolation of the present rating curve used by the YNP (fig. 11) was used to estimate the flow from Tenaya Creek during the 2010 snow melt period.

The U.S. Army Corps of Engineers software program, HEC-SSP (version 2.0), was used to estimate annual exceedance probabilities of flood discharges for the USGS Merced River at Happy Isles gage and for the historical USGS Tenaya Creek gage (no post-2006 Tenaya Creek discharge data were used to estimate annual exceedance probabilities). USGS Bulletin 17-B procedures were followed (USGS, 1982) and Weibull plotting positions were used for the flood frequency estimates. The four discharges of interest identified by the YNP for this study are the 50-, 20-, 10-, and 5-percent annual exceedance probability floods. The corresponding discharges estimated from the HEC-SSP analysis are listed in table 4. The most defining feature of the flood-frequency curves for the Merced River and Tenaya Creek are the disparate winter high-flow peaks, which are distinct from the more common and lower discharge snowmelt-dominated peaks (figs. 6 and 12). The highest peak flows occur from rain-onsnow floods during the early winter months (typically December and January) and occur above an annual exceedance probability between 5- and 4-percent. As such, the discharges evaluated in this study (table 4) represent the more common snowmelt peaks and are below the cutoff for the largest rain-onsnow floods, which have caused most of the flooding issues in Yosemite Valley and that have been the focus of previous modeling efforts (Eagan, 1998, Cella Bar Associates, 1998, Stantec, 2000). 
Subsequent to the completion of our flood frequency analysis and model runs, but before publication of this report, Gotvald and others (2012) published an extensive analysis of numerous USGS gages in California, including an analysis of the Merced River at Happy Isles Bridge USGS gage and the Tenaya Creek near Yosemite Village USGS gage. The annual exceedance probabilities for flood discharges calculated by Gotvald and others (2012) is close to but not the same as the results of the analysis presented here, though similar methods were used. The main difference between the two studies is that Gotvald and others utilized records through WY2006, whereas the present study utilized a longer period of record through WY2010.

\section{Water-surface elevations}

Water-surface elevations for evaluating the flow model were collected with two methods: continuous water-stage recorders (YNP Hobo and Solinst installations), and YNP stage measurements made during WY2010 at established cross-sections and from "tape down" measurements at the upstream and downstream edges of the bridges (figs. 13 and 14). Four continuous water-stage recorders were located between major bridges, with one additional below Housekeeping Bridge on the Merced River. Most of the stage recorders were operational over the period WY2006-2010. Unfortunately, the separate elevation survey of the continuous stage recorders was not considered accurate enough to confidently use the continuous stage data (J. Roche, YNP, written commun., 2011). To supplement the continuous water-stage recorders during WY2010, temporary cross-sections were established by YNP in the vicinity of the bridges (10 $\mathrm{m}$ and $20 \mathrm{~m}$ upstream and downstream, as well as at the upstream and downstream edges of the bridges). These temporary stage measurements were tied to existing benchmarks by using an auto-level and rod, with the approximate latitude and longitude locations of the measurements determined from the ground-based LiDAR scans (for example, tied to the water-surface measurement location, not the location of the rebar benchmarks). Additional water stages were observed at several of the previously established long-term study cross-sections within the study reach. In all, water stage was measured by YNP personnel at a maximum of 68 sites in the project area for 7 days during the spring snowmelt peak (table 5), though measurements at all sites were not collected during each day. Observations of floodplain inundation depths for WY2010 during which the peak discharge was an approximately 20-percent annual exceedance probability flow, indicated that flooding was local, not widespread, and floodplain depths tended to be relatively shallow on the order of several centimeters in most locations (fig. 15).

Despite the large spring snowmelt in WY2010, the water stage measurements did not capture the peak flow because of its strong diurnal timing and the timing of measurement collection (fig. 16). The peak flows on Tenaya Creek occurred just before midnight and the largest flows on the Merced River occurred near midnight and into the early morning, similar to the pattern observed at other snowmeltdominated areas (Lundquist and Cayan, 2002). By the time YNP personnel were able to get to the river and begin stage measurements (as early as 6:30 am) the flows had already dropped 15 percent or more from their nightly peak. Discharge fluctuated by as much as 40 percent through the day and night, which is a strong diurnal signal but is typical of other snowmelt-dominated regions (Lundquist and Cayan, 2002). 
Wood influences on stage data

An important issue with the water stage data is that several of the bridges have been known to accumulate large wood, which can locally elevate water stage and affect upstream stage data. Two reviews were performed to evaluate the effects of wood in the study reach: a review of the flood photos taken by YNP personnel during water-surface elevation measurements in WY2010, and a review of the 1997 photo archive at the Yosemite National Park Research Archive. From the review of WY2010 photos, only marginal amounts of wood were present near the bridges during the WY2010 snowmelt, suggesting that large wood had a relatively minor influence on observed water stages. One possible exception is Ahwahnee Bridge (fig. 14), which had several pieces of accumulated wood that might have created a slight increase in local water level. The logjam created during the 1997 flood at the head of the side channel likely affected water stages in the side channel in WY2010 (shown in fig. 17) by creating locally higher floodplain roughness values, and might have blocked water from entering the side channel due to relatively large logs $(1.2 \mathrm{~m})$ sitting on the ground.

From the photo archive at the Yosemite National Park Research Archive, large wood had a relatively small influence on historical water levels at the bridges within the study site during the 1997 flood. One bridge downstream, however, called the El Capitan Crossover, had substantial wood accumulation, blocking up to one third of the passage under the bridge (fig. 18). It is possible that the large wood accumulation at El Capitan Crossover substantially influenced upstream water levels given the low slope (see fig. 4), although this possibility was dismissed by Eagan (1998). The conclusions of Eagan (1998) might be suspect in this case because the 1D HEC-RAS model used in the study was calibrated to the 1997 flood. Eagan had observed $+0.6 \mathrm{~m}$ higher flood stages in the 1997 flood relative to four similar-sized floods from 1950-1964. To best model the 1997 flood and account for the $0.6 \mathrm{~m}$ increase in stage, Eagan greatly increased channel and floodplain roughness in the model, though more reasonable roughness values fit the other four floods to within $0.03 \mathrm{~m}$ (Eagan 1998). In summary, large wood, particularly its accumulation at the bridges, likely does play a substantial role in the water stages of the Merced River in Yosemite Valley, but the evidence is not conclusive.

\section{Present-day surface grain-size data}

Surface grain sizes were measured by the USGS during low flow in October 2010 by using the Wolman count technique (Wolman 1954), from immediately upstream of the Happy Isles gage down to below Housekeeping Bridge (figs. 19, 20 and 21). Wolman samples were measured by using a gravelometer down to $4 \mathrm{~mm}$ grain size, the lower limit of optical estimation. For facies with more than approximately 75 percent of the unit area consisting of less than 4-mm particles, the estimated grain-size diameter was set at $3 \mathrm{~mm}$ because these small grain sizes have marginal effects on overall channel roughness in the absence of dunes and the facies were relatively small in areal extent. On the other end of the spectrum, the grain sizes of riprap placed at the apices of several of the bends in the study reach were too large to measure by using the gravelometer. Instead, the approximate grain size of the riprap was estimated by using the ground-based LiDAR data at a site upstream of Ahwahnee Bridge, and was mapped by using a "Riprap map" supplied by the YNP (YNP internal records, dated September 1994) and by field-observation by the USGS in fall 2010. 


\section{FaSTMECH 2D hydrodynamic model}

One of the initial constraints on the choice of hydrologic model centered on the effects of the five historic bridges during high flows: were they acting simply as constrictions or were the arches of the bridges coming into play causing the bridges to act more like culverts? By using the ground-based LiDAR scans of the bridges, the upstream edges of the bridges were compared to water surface elevations measured during the 1997 flood, a 1-percent annual exceedance probability flood and the flood of record (fig. 22). This analysis suggested only a small proportion of the bridge arches were coming into play even during large flows, such as the 1997 flood. Because this study is concerned with smaller floods than the 1997 flood, a 2D flow model that could treat the bridges as constrictions was deemed sufficient.

The USGS iRIC model framework (International River Interface Cooperative) and one of its hydrodynamic models, FaSTMECH (Flow and Sediment Transport with Morphological Evolution of Channels), was chosen for the 2D flow modeling of this study because of its fast run times, ease of use, and proven track record with difficult sites similar to the Merced River site. iRIC is the upgrade of the previous USGS multi-dimensional flow model, MD-SWMS (Multi-Dimensional-Surface Water Modeling System). iRIC implements the Computational Fluid Dynamics General Notation System, originally developed at NASA for stable and computationally-fast modeling of complex 2D+ fluid dynamics (McDonald and others, 2005). There are a number of plug-in nodes that can be used within iRIC, including flow simulation, sediment transport, landform evolution, and habitat modeling. For this study, we only elected to use the 2D flow simulation within iRIC known as FaSTMECH (Nelson and McDonald, 1996; Nelson and others, 2003). The iRIC flow simulation modules SToRM and Morpho2D were also evaluated for this study, but for its consistency and speed given the large number of scenario conditions, FaSTMECH was employed for all the model runs. For a detailed description of the iRIC modeling interface and the numerical solutions in FaSTMECH, the reader is referred to Nelson and McDonald (1996), Nelson and others (2003), and McDonald and others (2005).

\section{Development of the present-day topographic surface model}

After a thorough evaluation of the quality of the aerial LiDAR, ground-based LiDAR, and total station bathymetric survey data, it was determined that a surface utilizing the strengths of each dataset would be the best representation of the topography in the study reach. In particular, the ground-based LiDAR did a much better job estimating streambank dimensions than did the aerial LiDAR because the filtered aerial LiDAR had smoothed out the streambanks and erroneously included elevated in-channel points and possibly water surface points. The high quality portion of the ground-based LiDAR dataset, however, was limited in extent to approximately $10 \mathrm{~m}$ from the top-of-bank and included the channel area, even though there were numerous ground points more than $100 \mathrm{~m}$ beyond the top of bank. Neither the aerial LiDAR nor the ground-based LiDAR were able to capture topographic points underwater, which necessitated the use of a total station to collect bathymetric data.

When they were attained by this study, the aerial LiDAR and total station bathymetric datasets were relatively well-processed compared to the ground-based LiDAR. To get the ground-based LiDAR prepared for input into the hydrodynamic model, additional post-processing was performed by using 3D manipulation software, Maptek I-Site Studio (version 4.3), which was developed for ground-based LiDAR processing. In general, the ground-based LiDAR data were excellent where there was sufficient overlap between scans (specifically, $2+$ scans), and the data were poor where there was insufficient 
overlap of scans due to shadows cast by objects in the field of view. The ground-based LiDAR data also needed to be cleaned of reflected points where the laser beam had bounced off of still water, reflecting a mirror image of the topography. Because the reflected points had much reduced laser intensity, they were easy to locate and correct by using an intensity filter. The remaining points in the ground-based LiDAR dataset were then filtered by using an iterative process of filtering that uses a block filter (initially $4 \mathrm{~m}$ ), creating a Triangulated Irregular Network (TIN) surface from the remaining points; additional ground-based LiDAR points were added back to the filtered data by using a proximity-tosurface filter, then the process was repeated using a smaller block filter. The final filter used in the iterative process was $0.5 \mathrm{~m}$, resulting in 261,288 ground-based LiDAR points.

For the final steps in the filtering process, two polygons were created: a "top-of-bank" polygon, which began approximately $10 \mathrm{~m}$ from the top-of-bank of the streambank (determined from the aerial LiDAR and ground-based LiDAR datasets) and a water edge polygon for the survey period in WY2007 (from the ground-based LiDAR and bathymetric survey datasets) (fig. 10). The top-of-bank polygon was used to filter the aerial LiDAR data, limiting them to points located outside the top-of-bank polygon (specifically, points on the floodplain). This "floodplain" aerial LiDAR subset was then filtered from a regular $1 \mathrm{~m} \mathrm{x} 1 \mathrm{~m}$ grid to an irregular grid with 75 percent less points, but which accurately represented the original TIN surface to within $0.01 \mathrm{~m}$. The ground-based LiDAR data were filtered with the top-ofbank polygon, retaining the points close to the channel, and all points within the water edge polygon were excluded. No filtering was performed on the bathymetric survey data points - they were all used in this study. Later, a small portion of aerial LiDAR points were added on the river left side of the side channel to enhance the coverage of ground-based LiDAR points in that vicinity.

It should be noted here that having the ability to manipulate and visualize 3D topographic data was crucial for comparing and combining the different datasets. We initially attempted these steps by using a 2D software package, but the software limitations introduced a number of errors and the final product was inferior to that produced from the 3D software. In this study, we used the Maptek I-Site Studio software, but other manipulation software would probably perform as well.

\section{Surface generation}

One important issue arose early in the modeling process, whereby the less dense bathymetric points and the dense bank and floodplain points created difficulties with accurately representing the bed, with TIN interpolation being coarse and extending large artifact wedges well out into the channel bed (fig. 23). Several different methods of topographic interpolation of the bathymetric points were evaluated to determine one that best preserved relevant in-channel features, including mapping with Delaunay triangulation (a TIN), and nearest-neighbor template searches using the template mapper within iRIC. Of particular interest to this study were the deep pools located next to riprap and near the bridge abutments (such as the scour hole downstream of Sugar Pine Bridge - see fig. 8). In general, we found that neither the TINs of the raw data nor a variety of different-sized nearest-neighbor template searches using the iRIC tool could ameliorate the problem. Instead, we found that the scour holes were best preserved by using an interpolated bathymetric dataset, where breaklines were incorporated primarily at the base of the banks by using the interpolate function in the iRIC interface (for example, breaklines with interpolated points between vertices). These interpolated base-of-bank breaklines effectively cut down on the size of the artifact TIN wedges projecting into the channel, making a more realistic topographic surface and preserving the representation of the deeply scoured pools. 
To best represent the bridge abutments and equestrian tunnels in the created surface, a separate point-dataset was created for the corners of the important structures. The ground-based LiDAR data were excellent for this task, allowing the determination of the coordinates for the relevant points. Because the bridges would not be overtopped by the modeled flows and for ease in locating the points once they were within iRIC, all the corner points for a particular bridge were set at the maximum height of the bridge, determined from the ground-based LiDAR data. Once this bridge point dataset was imported into iRIC, a series of 40+ breaklines were employed within the iRIC modeling interface to further define the edges of the bridge structures. Breaklines at the base of the bridge abutments and equestrian tunnels were assigned the elevation of the ground surface at the base of the structure.

\section{Development of scenario topography}

The topographic files for the different scenarios were generated by removing the relevant bridge and equestrian tunnel points and creating ground points that were graded to the same elevation as the surrounding topography (fig. 24). No attempt was made to artificially fill in the pools downstream of the bridges given the uncertainty regarding the pool formation. For example, in the scenario of the removal of Ahwahnee Bridge, the topographic points and breaklines used to create the two bridge abutments within the channel and the bank abutments were removed and replaced with topographic points at the same elevation as nearby topography (within 2-3 m, horizontally). For the scenario with the removal of the road berm between Sugar Pine and Ahwahnee Bridges, the elevation within the post-removal area ranged from $1210.0 \mathrm{~m}$ to $1210.7 \mathrm{~m}$, which was the same height as the area surrounding the berm. There was one exception to the above rules for the development of the scenario topography. For the left-bank abutment of Sugar Pine Bridge, which extends out into the channel, a single elevation was used, centered near an elevation of $1209.6 \mathrm{~m}$, because the abutment was originally built at bank height at that elevation according to the 1919 USGS topographic map. Overall, the simulated topography created for the scenario runs was relatively conservative (for example, width was only moderately reduced compared to some potential designs). It is likely that using a more dramatic topography (for example, using a wider channel) at the bridge locations would result in additional reductions in velocity in the study reach.

\section{Development of historical surface}

The historical surface used in the FaSTMECH model was developed by using a series of USGS 1919 maps (topographic survey in 1919, map edition of 1921) that were scanned, rectified, and stitched together by Eleanor Griffith, USGS, in 2009 (J. Roche, YNP, written. commun., 2010) (fig. 25). The contour lines (at increments of 2-ft elevations; 0.61-m spacing) were then digitized by YNP (J. Roche, YNP, written commun., 2011). The original 1919 map produced by the USGS shows a few individual topographic measurements within the channel (at approximately 20 points within the project reach), which are presumably bed points. The digital elevation model (DEM) surface created by YNP in 2009 from the historical 1919 USGS map does not contain the individual point measurements within the channel because the DEM was created solely from contours digitized from the original map.

To test if there was a substantial difference between the in-channel 1919 DEM created from the contours and the individual bed points, the two datasets were compared at the locations of the individual bed measurements. The average difference between the two datasets was $0.3 \mathrm{~m}$ with a standard 
deviation of $0.36 \mathrm{~m}$ (some individual bed points were higher than the created DEM surface), suggesting that though the DEM created from the 1919 contours was slightly higher than the bed, it was not higher by a large amount. This finding suggests that the contour data (and hence the YNP-created DEM) for the 1919 map represent the channel bed and not just the above-water portions of the channel. Figure 26 shows plots of the topography at selected YNP study cross-sections of the present-day scenario surface compared to the historical channel. Given the sparse individual bed points and the large changes in nearby land-use and riverine features now present in the channel, it was deemed inadvisable to attempt to re-create historical in-channel topography by using the individual bed points. Instead, the DEM created from the 1919 contours was deemed adequate for representing the channel bed and for modeling the historical condition.

Late in the development of the historical surface, a discrepancy was discovered in the 1919 digitized maps, whereby the farthest upstream map (covering Clark's Bridge area and upstream), is shifted at an angle (approximately 3-5 degrees) relative to the downstream maps (visible in fig. 25). The discrepancy would affect YNP cross-sections XS10, XS11, and XS12 in Figure 8. This shift would create issues with reach-scale surface differencing between the historical surface and present-day (specifically, for topographic change detection), but it appears to have no effect or only a minor effect on the FaSTMECH hydrodynamic model results. As such, no correction was made for the discrepancy.

\section{Mesh configuration}

Two types of curvilinear mesh grids were used in the model runs: a reach-scale $1.85 \mathrm{~m} \times 2.4 \mathrm{~m}$ cell-dimension grid to determine water-surface elevation inputs for the bridge scenarios (fig. 10), and finer-scale $1 \mathrm{~m}$ x $1 \mathrm{~m}$ cell-dimension grids centered on the bridges of interest. The results of the $1.85 \mathrm{~m}$ x 2.4 m full-reach FaSTMECH model were used to create the water-surface elevation inputs to the finescale mesh $(1 \mathrm{~m} \times 1 \mathrm{~m})$ FaSTMECH model runs. The $1.85 \mathrm{~m}$ x $2.4 \mathrm{~m}$ grid was deemed too coarse for the bridge scenarios because the region of interest under the bridges contained too few points (approximately 6-8) across the channel for the shortest bridges, Sugar Pine and Stoneman. In addition, the streamwise spacing of the reach-scale grid points, particularly under the bridges, was too coarse to adequately resolve the flow field given the relatively short bridges, most of which are around $10 \mathrm{~m}$ wide. The $1 \mathrm{~m} \mathrm{x} 1 \mathrm{~m}$ fine-scale grids that were used for the scenarios contained at least 10 cross-stream points and 10 streamwise points under the bridges of interest, including 1-2 points in the equestrian tunnels. The fine-mesh grid was used for all runs of each bridge (specifically, all flows and all scenarios) to minimize errors associated with different meshes. With the exception of Sugar Pine Bridge, the ends of the fine-scale grids were located several hundred meters away from the bridges of interest (distances between the areas of interest and the edge of the grid ranged from 300-500 $\mathrm{m}$ ). The close proximity (145 m) of Sugar Pine Bridge to the confluence of Tenaya Creek and the Merced River made it difficult to move the edge of the grid farther away (fig. 10).

The amount of flow across the river left floodplain at the head of the full-reach grid between Clark's Bridge and Sugar Pine Bridge is of particular concern because it determines the amount of flow in the channel through the important Sugar Pine - Ahwahnee bend (fig. 10). To optimize the main FaSTMECH models used for the scenario testing and to adequately estimate the amount of flow across the river left floodplain, an initial FaSTMECH model was created to model flows upstream, coming through the Clark's Bridge area and into the Tenaya Creek and Merced River confluence area (fig. 10). The flows used in the upstream FaSTMECH simulation were determined by using the annual 
exceedance probability discharges only for the Merced River at the USGS Merced River at Happy Isles Bridge gage (\#11264500), and roughness and topography were generated using the same methods as the main study reach. From the results of the upstream FaSTMECH model, the entry conditions for the downstream full-reach grid were optimized to cover the full width of water extent for the different modeled flows. The upstream FaSTMECH simulation was used only to evaluate the entry conditions for the downstream FaSTMECH models, and further results of the upstream model will not be presented here.

\section{Roughness}

Roughness in the FaSTMECH model was determined separately for in-channel and floodplain points. Roughness in the channel was calculated by using the Keulegan resistance equation (equation 1) (Keulegan, 1938):

$$
\frac{U}{u_{*}}=\left(\frac{1}{k}\right) \ln \left(11 \frac{d}{k_{s}}\right)
$$

where $\quad U \quad$ is mean channel velocity $(\mathrm{m} / \mathrm{s})$,

$u^{*}$ is shear velocity calculated as $(g d S)^{1 / 2}$,

$g$ is gravitational acceleration $\left(\mathrm{m} \mathrm{s}^{-2}\right)$,

$d$ is water depth $(\mathrm{m})$,

$S$ is friction slope $\left(\mathrm{m} \mathrm{m}^{-1}\right)$,

$k$ is von Karmen's constant (0.407), and

$k s$ is the roughness length scale in this case with $k_{s}=2\left(D_{65}\right)$ where $D_{65}(\mathrm{~m})$ is the surface grain size at which $65 \%$ of the grains are finer (Wilcock et al. 2009).

The value of $k_{s}$ may be slightly lower than other estimates (for example, using $2\left(D_{84}\right)$ or other values see discussion in Whiting and Dietrich (1990)). Lower values of $k_{s}$ result in slightly higher estimates of velocity and lower estimates of the coefficient of drag, however, the difference is not large. For example, increasing values of $k_{s}$ by 28 percent (the average difference between $D_{65}$ and $D_{84}$ for the study reach) results in a 12 percent increase in the coefficient of drag (see below). In addition to grain-scale resistance, other sources of roughness, such as bar resistance (for example, Prestegaard, 1983), also influence reach-average values, some of which can be incorporated into 2D models through topography and lateral eddy viscosity.

The relation of the dimensionless coefficient of drag $\left(C_{d}\right)$ to shear velocity and mean velocity (equation 2):

$$
C_{d}=\left(\frac{u_{*}}{U}\right)^{2}
$$

where $C d \quad$ is the coefficient of drag (dimensionless).

Equation (2) was combined with the Keulegan resistance equation (equation 1) to create a relationship between the dimensionless coefficient of drag, depth, and $k_{s}$ (equation 3): 


$$
C_{d}=\left[\left(\frac{1}{k}\right) \ln \left(11 \frac{d}{k_{s}}\right)\right]^{(-2)}
$$

where all units are as described above.

Floodplain roughness was calculated using equation 4 (Froehlich 1989):

$$
C_{d}=\frac{g(n)^{2}}{d^{(1 / 3)}}
$$

where $C d \quad$ is the dimensionless drag coefficient,

$g \quad$ is gravity $\left(\mathrm{m} \mathrm{s}^{-2}\right)$,

$n \quad$ is Manning's $n$, and

$d \quad$ is depth (m).

Due to the lack of sufficient data with which to independently test or calibrate the estimates of floodplain roughness, a Manning's $n$ value of 0.085 was chosen as an input into equation 4 , which is a value similar to that found for similarly wooded areas (Chow 1959, Barnes 1967, Arcement and Schneider 1989). The Manning's $n$ input of 0.085 into equation 4 is similar to the floodplain Manning's $n$ values found by Eagan (1998) to fit the four large pre-1997 floods (ranging from 0.09 to 0.1 ), though in the same runs, Eagan used relatively high values of in-channel Manning's $n(0.055)$ to be able to fit observed water-surface elevations. In their study, Cella Bar and Associates (1998) also used a similar range of Manning's $n$ values to estimate floodplain roughness (ranging from 0.05 to 0.1 ), but did not discuss how the value was derived or how well the modeled roughness fit observed water-surface elevations. For this study, to avoid spuriously high drag coefficients for points with relatively low relative submergence in equation 4 (for example, where grain size approaches flow depth), $C_{d}$ was set at 0.071 for flow depths less than $1 \mathrm{~m}$. For comparison, at a coefficient of drag of 0.071 and a depth of 1 $\mathrm{m}$, Manning's $n$ is approximately 0.085 (using equation 4).

As a test of the floodplain roughness due to trees, one of the most apparent sources of floodplain roughness, a subset of the ground-based LidAR data was analyzed to estimate the density and diameter of the trees at a 60 -m-wide $\mathrm{x} 80$-m-long site $\left(4,800 \mathrm{~m}^{2}\right)$ on the river left bank downstream of Ahwahnee Bridge near the entry of the side channel (fig. 27). All trees within the floodplain site were estimated for diameter at breast-height (DBH) by fitting the ground-based LiDAR points of the trunk with a horizontal circle at breast-height (about $1.3 \mathrm{~m}$ ) (fig. 28). The floodplain site had 103 trees in it, most of which were large diameter conifers (fig. 2 is a photograph taken nearby), with a mean diameter of 0.71 $\mathrm{m}$, a total plan-view wood area of $40.8 \mathrm{~m}^{2}$, and average tree spacing of one tree every $46.6 \mathrm{~m}^{2}$. Because the flow in the floodplain is hydraulically rough (Reynold's number, $\operatorname{Re}=\rho U d / \mu$, where $\rho$ is the density of water $\left(\mathrm{kg} \mathrm{m}^{-3}\right)$, and $\mu$ is the viscosity of water $\left(\mathrm{kg} \mathrm{m}^{-1} \mathrm{~s}^{-1}\right)$; in this case Re is about $\left.10^{6}\right)$, the area-scaling direction was chosen to be in the down-flow direction (see Kean and Smith, 2004, for a discussion), which is down valley for this floodplain site and for most of the floodplains in Yosemite Valley. In the case of the floodplain site used for estimating roughness, the down-valley flow is east to west, heading towards the main channel, rather than parallel to the main channel. 
To get an estimate of the site-scale drag coefficient due to the trees (for example, not just drag for one tree), the drag coefficient for an individual tree (modeled here as a cylinder, with a drag coefficient of about 1.1) was combined with the effective blockage area of the trees in the down-valley direction (Shields and Gippel, 1995; Manga and Kirchner, 2000) by using the relation: $\mathrm{C}_{\mathrm{d}}{ }^{\text {app }}=\mathrm{C}_{\mathrm{d}} /(1-$ $\beta)^{2}$ (following the symbology of Manga and Kirchner (2000)), where $\mathrm{C}_{\mathrm{d}}{ }^{\text {app }}$ is the coefficient of drag scaled to the cross-section, $C_{d}$ is the drag coefficient for a singular element (a cylinder has a $C_{d}=$ about $1.1)$, and $\beta$ is the blockage ratio $\left(\mathrm{m}^{2} \mathrm{~m}^{-2}\right)$ calculated as the ratio of the area of the obstruction to the total flow area in the downstream direction $(0.061$ in the case for depth at $1 \mathrm{~m})$. For this floodplain site, the value of $\mathrm{C}_{\mathrm{d}}$ app of 1.11 is similar to the original $\mathrm{C}_{\mathrm{d}}$ because the trees are spaced relatively far apart. An estimate of site-scale drag due to trees is then: $\tau_{\mathrm{lwd}}=(1 / 2) \rho\left(\mathrm{C}_{\mathrm{d}}{ }^{\mathrm{app}} n_{t} \mathrm{D}_{\mathrm{t}}\right) U^{2}$, where $\tau_{\mathrm{lwd}}$ is the shear stress due to large wood, $n_{t}$ is the number of stems per unit area $\left(0.0215\right.$ stems $\mathrm{m}^{-2}$ for this site), and $\mathrm{D}_{\mathrm{t}}$ is the average diameter of the tree $(0.71 \mathrm{~m}$ for this site) (Manga and Kirchner, 2000; Kean and Smith, 2004). A theoretical estimate of the average coefficient of drag from the large wood can then be calculated by using the middle terms in brackets - in this case, this calculated coefficient value is relatively low at 0.017 . Note that in addition to drag from trees, the flow over the floodplain also experiences drag from other sources such as the ground, leaves, and shrubs, all of which influence the drag experienced by floodplain flows. At this particular site, there are none of the stands of dense, young conifer trees that are typical of other parts of the floodplain (see note below). Without additional velocity data, however, it is difficult to parameterize the additional roughness elements of the floodplain. The main point of interest from this independent estimate of floodplain roughness is that the large, mature conifer species appear to contribute only slightly to overall floodplain roughness.

There are two other distinct floodplain features: the two large meadows in the floodplain area, and the logjam located just southwest of Sugar Pine Bridge (fig. 3). For the two meadows, there are only marginal amounts of water flowing over them at the modeled flows. As such, and because there are no velocity data with which to compare model results, the floodplain roughness for all meadow sites were treated equally with equation 4, with a Manning's $n$ value of 0.085 (the same as the other floodplain sites). This value is slightly higher than the Manning's $n$ value (0.07) used in meadows by Eagan (1998), but that study also did not have sufficient calibration data in the meadow areas. A Manning's $n$ value of 0.085 is close to the value obtained by using an estimate of floodplain roughness at a depth of 1 $\mathrm{m}$ for these sites, given the large height of the meadow floodplain (Kundu and Cohen, 2004). The large extent and size of the logjam (some logs in the jam have diameters greater than $1.2 \mathrm{~m}$ ) near Sugar Pine Bridge at the head of the side channel (fig. 17) suggested that water velocities entering the side channel likely would be substantially reduced. As such, a drag coefficient of 0.25 was chosen for the logjam area to adequately slow the simulated water velocities entering the side channel, which is an intermediate value of drag for this type of site (Manga and Kirchner, 2000; Fischenich and Dudley, 2000).

The depth input to the roughness equations was calculated for each node of the FaSTMECH model by using the full-reach grid (1.85 m x $2.4 \mathrm{~m})$ FaSTMECH model and a constant drag coefficient of 0.01165 , the approximate average drag coefficient for the reach. These constant-roughness FaSTMECH runs were kept to the same standards as the final variable-roughness FaSTMECH runs (see section below). For example, for the evaluation flow of $130.9 \mathrm{~m}^{3} \mathrm{~s}^{-1}$, a drag coefficient value of 0.01165 is approximately equivalent to a Manning's $n$ of 0.039 for the average flow depth of $2.1 \mathrm{~m}$ (using equation 4). Limerinos (1970) in a study of roughness in natural-bed channels, found a similar Manning's $n$ value of 0.035 for a $52.1 \mathrm{~m}^{3} \mathrm{~s}^{-1}$ flow in the rougher Clark's Bridge reach $\left(D_{50}\right.$ of $\left.122 \mathrm{~mm}\right)$. 
For the FaSTMECH constant-drag-coefficient runs, the resulting grids of depth solutions for each flow were approximately 230,000 points. These points were exported to ESRI's software, ArcMap, combined with a GIS coverage of grain size (including $D_{65}$ ), and exported to a spreadsheet where roughness was calculated by using equations 3 and 4 (note that equation 4 does not utilize grain size). There was only a marginal difference in depth (maximum of 2 percent) between the FaSTMECH runs using a constant drag coefficient to calculate roughness and the final variable-roughness FaSTMECH runs using the depth-dependent variable drag coefficient, indicating that the initial constant roughness runs were sufficiently accurate to calculate reasonable depth values for use in the roughness estimates.

The drag-coefficient input files for the fine-scale grid $(1 \mathrm{~m} \mathrm{x} 1 \mathrm{~m})$ scenarios were calculated using the same values of drag coefficients calculated for the full-reach (1.85 m x 2.4 m) FaSTMECH inputs by using equations 3 and 4. For the portions of the bridge areas that were altered in the scenarios, roughness values from immediately adjacent locations were used to create the scenario roughness (for example, following bridge removal). Only points with similar topography to that created in the simulated scenario topography were used in the estimates of scenario roughness. Several tests of the final scenario roughness generated in this manner were relatively consistent between scenarios, most likely due to the slight variations in topography for the different scenarios.

For historical grain sizes present in the reach, there is no information besides anecdotal evidence of grain size. Historical grain size was estimated as a longitudinally-variable parameter rather than choosing a single constant grain size throughout the study site because a single constant grain size would be highly unlikely given the large change in slope along the longitudinal channel profile. The historical grain size (fig. 25) was estimated by assigning current grain size distributions to similar types and locations of geomorphic features present in the detailed 1919 USGS map. For example, the grain size distribution at present-day Wolman pebble count site "L" on the bar just downstream of Ahwahnee Bridge (fig. 19) was assigned to a similar bar on the 1919 map (fig. 25). No riprap values were assigned to the 1919 map, although there was some riprap already in place by the time the original 1919 map was made (Milestone, 1978).

An important point about roughness in the study reach is that there have been substantial changes to roughness on the floodplain over time. Historically, the Merced River floodplain in Yosemite Valley was primarily wet meadow with a scattering of oak trees and a healthy riparian corridor (Cooper and Wolf, 2008). With the advent of fire suppression in the park and the construction of permanent campgrounds, conifers invaded the meadows and oak savannah, such that much of the floodplain is now mostly mature conifer cover (Cooper and Wolf, 2008). The floodplains in these maturing conifer forests had relatively low roughness due to the wide-spacing of the conifer trees and the lack of undergrowth from the high-density human use. Subsequent to the closure of three campgrounds in the upper Yosemite Valley after the 1997 flood, there has been substantial growth of mid- and under-story trees in the lower part of the study site. In particular, there are patches with a dense growth of young conifers approximately 1-3 m high in some locations of the lower parts of the study reach, which would increase roughness compared to pre-1997 conditions, however, these effects are not well quantified and as such, are not incorporated into the floodplain roughness of the historical scenario. 


\section{Boundary conditions}

To determine the stage elevations for the modeled flows at the downstream-most position of the FaSTMECH grid, a 1D USACE HEC-RAS model was constructed by using cross-sections from the downstream end of the study site. For the current conditions, the cross-sections of the HEC-RAS model at the downstream boundary of the FaSTMECH mesh grid were taken from the topographic measurements in this study. For the historical conditions runs, the cross-sections were taken from the 1919 DEM created by the USGS. The uppermost cross-section of the 1D HEC-RAS model, which was used as the downstream stage control for the FaSTMECH grid, was approximately at the same location as the CBA cross-section 22 (Cella Bar and Associates 1998). Results from the HEC-RAS model for the various modeled flows were similar to the CBA results for cross-section 22 (though the discharges used in the CBA report were slightly different than those used here) as well as the measured stages for flows during WY2010 (table 6).

\section{FaSTMECH solution parameters}

Individual FaSTMECH model runs were required to run for 800-2,000 iterations until the model was considered stable and representative. Each individual model run (for example, the Removed Ahwahnee Bridge scenario at $165 \mathrm{~m}^{3} \mathrm{~s}^{-1}$ ) was only considered representative and stable if errors in discharge remained at less than 3 percent for the final approximately 300-400 iterations (R. McDonald, USGS, written commun., 2011). Typically, however, individual runs stabilized at a lower level of discharge error, between 0.5 percent to 2.5 percent. Computation instabilities most commonly arose due to wetting and drying complications on the shallow floodplain. Hence, for all runs, wetting and drying was calculated periodically, ranging from every $7^{\text {th }}$ to $67^{\text {th }}$ iteration, depending on the run. Drying depth was set at zero, and wetting depth at $0.05 \mathrm{~m}$.

Partially to account for the initial difficulties with solution stability, lateral eddy viscosity (LEV) was calculated variably at between $0.3-0.5 \mathrm{~m}^{2} \mathrm{~s}^{-1}$ for the first few hundred iterations, then relaxed to $0.05 \mathrm{~m}^{2} \mathrm{~s}^{-1}$ for the final several hundred iterations. Using the equation, LEV $=0.6 d\left(u_{*} / U\right)$, where $d$ is mean channel depth, $u_{*}$ is shear velocity (defined above), and $U$ is mean channel velocity (Fischer and others, 1979), the value of LEV utilized here $\left(0.05 \mathrm{~m}^{2} \mathrm{~s}^{-1}\right)$ is within the realm of reasonable values and did produce realistic eddy circulation lengths (shown as ' $a$ ' and ' $b$ ' in fig. 29). Varying LEV from 0.01 to $0.1 \mathrm{~m}^{2} \mathrm{~s}^{-1}$ for the evaluation flow $\left(130.9 \mathrm{~m}^{3} \mathrm{~s}^{-1}\right)$ had no effect on water-surface elevations (less than $0.01 \mathrm{~m}$ ) but did affect the recirculation pattern and strength of eddies. A single intermediate value of $\operatorname{LEV}\left(0.05 \mathrm{~m}^{2} \mathrm{~s}^{-1}\right)$ was chosen for all flows here to minimize potential differences in results caused solely by LEV and because there were no velocity data with which to test the assumptions. In general, calculated values of LEV varied only slightly with different discharge values, owing to the small relative changes in velocity (about 25 percent) and depth (about 30 percent). Another important factor affecting LEV is the more than ten-fold decrease in slope across the model domain, which would vary calculated LEV values by a factor of three using the Fischer and others (1979) equation. The final value of calculated LEV chosen here represented a mid-point value of the possible LEV values, given the variation in discharge and the variation in slope across the model domain. 


\section{FaSTMECH model evaluation}

The accuracy of the FaSTMECH model was evaluated primarily by using measured watersurface elevations because no velocity data have been measured in this reach. The term "evaluation" is used here instead of "calibration" because the in-channel roughness values were calculated independently of the measured water-surface elevations (by using equation 3), and no subsequent calibration was performed on the roughness values. Owing to the lack of additional velocity data and the presence of survey errors in the water-stage measurements, calibration of the roughness estimates was not pursued, but it could certainly be pursued if velocity data were collected. An important point is that the evaluation flows in WY2010 did not sufficiently inundate the floodplain to be able to adequately evaluate the floodplain roughness beyond that which was independently estimated from the groundbased LiDAR data.

The water-stage data from June 8, 2010, were used to evaluate the FaSTMECH model because June $8^{\text {th }}$ had the highest flows for which stage was recorded during WY2010 (table 5). Whereas the June $7^{\text {th }}, 2010$ flow was higher than on June $8^{\text {th }}$, stage measurements on June $7^{\text {th }}$ did not begin until the water had dropped substantially (fig. 16). In addition, for the June $8^{\text {th }}$ flow, there was a large number of quality stage observations made (38) compared to other days. There are some issues, however, with the observed stage measurements, given the large diurnal flux of snowmelt discharge and the inaccuracies of the survey data, particularly at the downstream end of the site (in survey Loop 3). The estimated combined flow below the confluence of the Merced River and Tenaya Creek was $130.9 \mathrm{~m}^{3} \mathrm{~s}^{-1}$ at the mid-point time of the water-stage measurements on June $8^{\text {th }}$ (fig. 16), and this was the value used in the FaSTMECH evaluation runs. Yet, over the course of the 4.4 hours of stage measurements on June $8^{\text {th }}$, the estimated discharge at the confluence varied from 140 to $119 \mathrm{~m}^{3} \mathrm{~s}^{-1}$ (-15 percent). Stage at the USGS Happy Isles gage fluctuated by $0.13 \mathrm{~m}$ during the same period. In addition, the stage survey on June $8^{\text {th }}$ started at the downstream-most stage station and generally, though not consistently, worked upstream as discharge dropped over the course of the morning. Hence, there is likely error included in the observed water-stage measurements on the order of one- to two-decimeters in addition to the onedecimeter survey error (see earlier section). In addition, two separate survey estimates of the benchmark (XS29R) were as much as $28 \mathrm{~cm}$ off - this benchmark was used as a control point for measuring the lowest water-surface elevation. These variations in the observed water-surface elevation are important because they determine the relevancy of the FaSTMECH error estimate. The elevated stage measured at the downstream boundary (because it was measured first when flow was highest), is particularly influential for the study reach because it may have caused the model to simulate artificially high downstream river stages at the same time that flows were decreasing.

The observed water surface elevations, simulated water-surface elevations and their associated residuals for the $1.85 \mathrm{~m}$ x $2.4 \mathrm{~m}$ full-reach FaSTMECH model, as well as the results of the $1 \mathrm{~m} \mathrm{x} 1 \mathrm{~m}$ FaSTMECH models used in the scenarios are plotted in figure 30. Overall root mean square error (RMSE) for the FaSTMECH evaluation run for the $1.85 \mathrm{~m} \mathrm{x} 2.4 \mathrm{~m}$ was initially $0.24 \mathrm{~m}$. After investigation of the observed water-stage measurements, it was noticed that the two most deviatory stage locations (exceeding $0.3 \mathrm{~m}$ ) were affiliated with the side channel (fig. 30). The measured stages in the side channel are also low relative to points in the main channel and hence may be erroneous due to survey error. Another possibility is that the logs at the logjam are effectively blocking flow down the side channel at moderately low flows, such as the $130.9 \mathrm{~m}^{3} \mathrm{~s}^{-1}$ evaluation flow. From the ground-based LiDAR dataset, some of the larger downed logs exceed $1.2 \mathrm{~m}$ in height above ground level, an elevation slightly higher than the measured water stage in the upstream channel. The logs therefore may be 
preventing flows from entering the side channel. If the side channel points are removed, the RMSE for the $1.85 \mathrm{~m}$ x $2.4 \mathrm{~m} \mathrm{FaSTMECH}$ run drops to $0.21 \mathrm{~m}$. The evaluation runs (also at $130.9 \mathrm{~m}^{3} \mathrm{~s}^{-1}$ ) of the two finer grids $(1 \mathrm{~m} \mathrm{x} 1 \mathrm{~m})$ had RMSEs of $0.10 \mathrm{~m}$ and $0.06 \mathrm{~m}$ for the grids centered around Stoneman Bridge and Ahwahnee / Sugar Pine Bridges, respectively (again excluding the side channel points). The reason for the smaller RMSE values of the finer-grids models compared to the coarse-grid model is not fully known, though it most likely is due to the increased number of nodes under the relatively short bridges (for example, greater than 15 nodes across the channel width for the fine grids, whereas the coarse grid had approximately 6-8 nodes). Overall, the model fits for the evaluation runs were considered adequate owing to the fact that the river decreases in elevation by approximately $3 \mathrm{~m}$ over the length of the model domain (for example, model water-surface-elevation error for the evaluation flow is less than 7 percent of total elevation drop) and that average depth for this flow is approximately $2.3 \mathrm{~m}$ (for example, FaSTMECH model water-surface-elevation error is less than 10 percent of average depth), particularly given the uncertainties in the measurements of observed water-surface elevations.

\section{Test of FaSTMECH mesh configuration}

Two separate $2 \mathrm{~m} \times 2 \mathrm{~m}$ curvilinear grids were compared to evaluate the reach-scale effects of the influence of mesh configuration on the simulated hydraulics of the reach given the disparate nature of medium floods (for example, a 50-percent annual exceedance probability flow that remains in the low-flow channel) compared to larger floods (for example, a lesser than 10-percent annual exceedance probability flow that is partially in the low-flow channel and partially moving in the floodplain directly down valley). Both grids extended from the confluence of Tenaya Creek downstream to below Housekeeping Bridge. The first grid had a width of $300 \mathrm{~m}$ and a centerline that closely followed the low-flow stream centerline; and, the second grid had a width of $570 \mathrm{~m}$ and a centerline that still followed low-flow stream channel but also captured the down-valley path of larger flood events. The two centerlines were tested on the evaluation flow of $130.9 \mathrm{~m}^{3} \mathrm{~s}^{-1}$. Whereas the root mean square error of the simulated water-surface elevations for the narrow grid versus the observed stage measurements was better than that of the wide grid ( $0.14 \mathrm{~m}$ compared to $0.24 \mathrm{~m}$ for 38 water-surface points), the narrow grid is not wide enough to adequately represent flows across the floodplains that occur during flows higher than a 10-percent annual exceedance probability discharge. Hence, the wide grid was chosen for its applicability to the larger flow events.

\section{Uncertainty and limitations of the hydraulic modeling}

There are a number of uncertainties with the input conditions that are not well-quantified, such as the downstream stage and discharge, and it is important to point out that there are no velocity data available to fully evaluate the model. As such, the results of the FaSTMECH hydrodynamic model should be viewed with caution. For velocity, there is one historical assessment of velocity in the Clark's Bridge region by Limerinos (1970), made while studying the effects of roughness in natural channels. Limerinos measured a velocity of 1.0 to $2.15 \mathrm{~m} \mathrm{~s}^{-1}$ for a $17.6 \mathrm{~m}^{3} \mathrm{~s}^{-1}$ and a $52.1 \mathrm{~m}^{3} \mathrm{~s}^{-1}$ flow, respectively, at the site with a D50 grain size of $122 \mathrm{~mm}$. The velocity values found by Limerinos (1970) are similar to the velocities results of the FaSTMECH model in the present study. Lacking suitable velocity data, however, the precision of the models in simulating velocity is not known.

The downstream stage elevations are not well known owing to the uncertainties in survey accuracy in the lowest few control points and because the stage estimates from previous 1D modeling 
reports are based on out-of-date topography (pre-1997 flood topography). Because of the strong decrease in slope across the study reach and downstream, small changes in downstream stage have the potential to influence upstream results (see Eagan, 1998). To investigate the effects of differences in downstream stage, two stages were tested by using the $1.85 \mathrm{~m}$ x $2.4 \mathrm{~m}$ grid FaSTMECH model and the evaluation flow of $130.9 \mathrm{~m}^{3} \mathrm{~s}^{-1}$, the highest flow for which observed stage data exist. In these two FaSTMECH runs, downstream stage was set at $1208.68 \mathrm{~m}$ and $1208.91 \mathrm{~m}$ (the measured stage values based on the control point coordinates at study cross-section 29 (XS29) determined in the 2010 and 2007 surveys, respectively) and all other parameters were kept the same. The two models have RMSEs of $0.21 \mathrm{~m}$ and $0.25 \mathrm{~m}$, respectively, but differences between the two stages exceed $0.1 \mathrm{~m}$ until a location $300 \mathrm{~m}$ upstream near study cross-section 27 (XS27), approximately 25 percent of the lower length of the full study reach. The affected portion of the reach is still well away $(400+\mathrm{m})$ from the most downstream bridge of interest, Stoneman, but it does highlight the importance of the stage data given the low slope at the downstream end of the site.

Another possible source of uncertainty is the estimate of discharge. Whereas the Merced River at Happy Isles USGS gage has a reliable and long-standing gage record, the gage on Tenaya Creek recently has been re-installed and has had discharge measured only to approximately half the discharge that was estimated for the evaluation runs. As such, the modeled discharge for the evaluation flow (taken as a sum of the flows from the Merced River and Tenaya Creek) could be off by some amount. In addition, the strong diurnal fluctuations in stage over the course of the water-stage measurements may be introducing error into the discharge estimates of the evaluation runs (the estimated discharge at the mid-point in time of the stage measurements was used for the evaluation runs). To compound issues, the FaSTMECH model stabilizes at solutions with discharges that were 1 percent to 3 percent larger than the modeled flow. Though not evaluated here, another possible source of discharge error is that the historical USGS Tenaya gage record that was used to estimate annual exceedance probabilities for discharge does not adequately represent present-day flows.

To evaluate these possible errors in discharge, the FaSTMECH evaluation model was run with a variety of different discharges, ranging from 115 to $140 \mathrm{~m}^{3} \mathrm{~s}^{-1}$ for the assessment of diurnal discharge errors (the estimated ending and starting discharge on the day of water-stage measurements for the evaluation flow), keeping other parameters the same. In addition, several test runs were performed by decreasing the discharge values by up to 3 percent of the discharge used for the evaluation run (specifically, subtracting up to 3 percent from $130.9 \mathrm{~m}^{3} \mathrm{~s}^{-1}$ ) to estimate the effects of the FaSTMECH model stabilizing at slightly higher discharges than the input discharge. The results of the diurnal discharge error assessment have RMSEs that are smaller for lower discharge flows (for example, the $115 \mathrm{~m}^{3} \mathrm{~s}^{-1}$ flow had RMSE of $0.11 \mathrm{~m}$, whereas the $140 \mathrm{~m}^{3} \mathrm{~s}^{-1}$ flow had RMSE of $0.30 \mathrm{~m}$ ). The average stage difference between the 115 and $140 \mathrm{~m}^{3} \mathrm{~s}^{-1}$ flows is $0.22 \mathrm{~m}$ and is relatively constant throughout the model domain. There are several explanations for the improved fit between observed and simulated water stages at lower flows, including the possibility that the estimates of roughness are too high, or that the downstream stage elevations are incorrect. The test of the effects of increases in discharge due to stable discharge FaSTMECH solutions occurring at +1 to +3 percent of discharge indicate that only a small amount of the variation seen in stage is likely due to this effect (average of $+0.04 \mathrm{~m}$ decrease in stage with 3 percent decrease in discharge).

Owing to the lack of velocity data for full evaluation of the FaSTMECH models and the uncertainties with the input data, the comparison of the results of the scenarios focused primarily on 
changes in depths and velocities at the cross-sections directly beneath the bridges. This type of analysis was chosen because the bridge openings are relatively straight (Sugar Pine Bridge might be an exception) and would be expected to be less affected by other model input errors as compared to areabased analyses (for example, May and others, 2009). In addition, the highest velocities in the reach are associated with the bridges. One down-side to using the cross-section approach is that it is not able to characterize reach-scale effects, which would be useful for comparing bridge-related effects that are not proximal to the bridge sites. For example, one potential effect of bridge removal could include upstream effects or increased velocities at upstream riffles, but these results would not be fully apparent with the evaluation method chosen here. Because the cross-sections under the bridges are relatively straight, though the modeled velocities may be off from actual velocities, the relative differences between velocity results from the models should be more robust. If additional velocity data were collected and the models were sufficiently vetted with the velocity data, additional area-based analyses could be applied to estimate reach-scale effects of the different scenarios. Also, analyses of parameters could be conducted in addition to depth and velocity, such as shear stress and the potential for sediment transport.

\section{Geomorphic assessment}

The geomorphic assessment performed here comprises initial results from an ongoing study of the geomorphic effects of the modern geomorphology of the Merced River in Yosemite Valley by the USGS in cooperation with the NPS. For the initial geomorphic assessment presented here, the YNP study cross-section topographic data were analyzed for changes through time, and the magnitude and frequency of sediment transport was calculated at one important cross-section location, "Tenaya Bar", at YNP study cross-section 13, located on the Merced River just upstream of the confluence with Tenaya Creek (XS13 in fig. 8). This cross-section is a key site because when overbank flooding occurs at this location, water is directed across the meander bend that contains both the Sugar Pine and Ahwahnee Bridges, often flowing through the side channel of concern.

For the sediment transport magnitude-frequency analysis, the U.S. Forest Service BAGS model (Bedload Assessment for Gravel-bed Streams) was chosen because it contains a variety of sediment transport equations that are specifically developed for gravel-bed river systems such as the Merced River (Pitlick and others, 2009, Wilcock and others, 2009). Though the Wilcock and Crowe (2003) sediment transport equation was evaluated for use, the primary sediment transport equation utilized here is from Parker (1990). The equation from Parker was utilized primarily owing to uncertainty in the Yosemite study area sand fraction data that are a required input for the Wilcock and Crowe (2003) equation. For all of the relevant equations, see Parker (1990) and Pitlick and others, (2009). The inputs used for the BAGS model runs are listed in table 7. By using the BAGS model, bedload transport is calculated for 27 equal-spaced discharge "bins" $\left(10 \mathrm{~m}^{3} \mathrm{~s}^{-1}\right.$ in each bin) spanning the full range of daily flows. After a review of the literature, more than fifteen bins were chosen, and the mid-point of each bin is used for calculations and plotting, though guidance on these issues is relatively sparse for bedload flux calculations. Suspended-sediment transport is calculated by using the fitted relationship found by Andrews (2012) using suspended-sediment data from the USGS Merced River at Happy Isles Bridge gage (\#11264500), with bins of $2.8 \mathrm{~m}^{3} \mathrm{~s}^{-1}$. The guidelines of Crowder and Knapp (2005), developed for suspended sediment, were adhered to for the bedload and suspended-sediment calculations (specifically, less than 10 percent of total load in the first bin). The frequencies of each bin were calculated from the historical record of mean daily discharges at the USGS Merced River at Happy Isles Bridge gage. In addition to the above geomorphic analyses, a GIS-based geomorphic watershed assessment was 
performed to investigate possible disruptions in sediment supply continuity owing to glacially-caused low-slope reaches in the upstream catchments. The primary topographic data utilized in the watershed geomorphic assessment were the 10-m USGS National Elevation Dataset.

\section{Results}

\section{Results of FaSTMECH hydrodynamic model}

The depth and velocity results of the FaSTMECH present-day full-reach flow models are presented in figures 31-32, with cross-section results presented in figures 33-36. Summarized results for all model runs are presented in figures 37 and 38. The FaSTMECH depth-results agree with field observations that much of the present-day varied topography within the channel (for example, pools and islands) is associated with either the bridges or riprap (for example, see fig. 31). In general, modeled velocities are highest in the vicinity of the bridges and riprap compared to the rest of the channel and floodplain (fig. 32). The highest simulated velocities in the reach are associated with the Stoneman and Sugar Pine Bridges at the highest modeled flows, approaching $3.0 \mathrm{~m} \mathrm{~s}^{-1}$ for the 5- percent annual exceedance probability flood (fig. 32). Sugar Pine Bridge, however, has higher maximum velocities at smaller floods, at over $2.4 \mathrm{~m} \mathrm{~s}^{-1}$ for the 50- and 20-percent annual exceedance probability floods (fig. 33a), whereas Stoneman Bridge has lower velocities for the 50- and 20-percent annual exceedance probability floods, at between 1.8 and $2.5 \mathrm{~m} \mathrm{~s}^{-1}$ (fig. 36a). In contrast to the other two bridges, maximum velocities at Ahwahnee Bridge are relatively low, between 1.5 and $1.9 \mathrm{~m} \mathrm{~s}^{-1}$, likely due to the relatively wide design and the orientation of the bridge parallel to the down-valley floodplain path of the larger floods (fig. 34a). Whereas maximum velocities at the bridge sites are high relative to the overall channel velocities, the average velocities at the three bridge sites $-1.0 \mathrm{~m} \mathrm{~s}^{-1}, 1.4-1.6 \mathrm{~m} \mathrm{~s}^{-1}$, and $1.2-1.9$ $\mathrm{m} \mathrm{s}^{-1}$ for Ahwahnee, Sugar Pine and Stoneman Bridges, respectively (figs. 37 and 38) - are closer to the overall channel velocities.

The FaSTMECH results for depth and velocity of the various scenarios are shown in crosssection view in figures 33-36, and summarized in figures 37 and 38. Water-surface elevations are relatively constant at the bridge sites and the side channel between the present-day and bridge-removal scenarios, despite the alteration of the model grid topography to develop the scenarios (figs. 33-36). The maximum absolute difference in water-surface elevations between two scenarios occurs at Stoneman Bridge and is $0.09 \mathrm{~m}$, less than 2 percent of average present-day depth (specifically, comparing the "Present-day" scenario to the "Removed Stoneman Bridge" scenario) (fig. 36). This reduction in stage in the simulation with the removal of Stoneman Bridge was also found in a 1D model of the much larger 100-year flood event (CBA 1998), which similarly did not find substantial reductions in water-surface elevations with the simulated removal of either the Ahwahnee or Sugar Pine Bridges. Overall, the majority of the other bridge removal scenarios produce simulated water-surface elevations within 0.05 $\mathrm{m}$ of the present-day scenarios.

The FaSTMECH results at the bridge sites indicate that the scenarios of bridge and road-berm removals primarily affect velocity and the direction of flow. For all the bridge sites, the largest reductions in velocity occur in the immediate vicinity of the "removed" bridge (specifically, removal of Ahwahnee Bridge has the greatest effect on flows for the Ahwahnee Bridge cross-section; figs. 34 and 37). Slight additional reductions in velocity (typically less than 5 percent) were observed with the simulated removal of the road-berm and additional bridges, though these are secondary to removal of 
the nearest bridge (figs. 37 and 38). For the range of modeled flows, the simulated removal of Stoneman Bridge results in reductions in average and maximum cross-sectional velocity at that site by 33-39 percent and 17-26 percent, respectively (fig. 37 and 38). At Sugar Pine Bridge, the cross-sectional velocity for the scenarios "Removed Sugar Pine Bridge" and "Removed Ahwahnee and Sugar Pine Bridges and Berm" are reduced by 33-38 percent and 23-29 percent, respectively, for average velocity, and 7-11 percent and 10-12 percent, respectively, for maximum velocity (fig. 37). At Sugar Pine Bridge, the reductions in velocity for the scenario "Removed Sugar Pine Bridge and Berm" are intermediate between the previous two scenarios (fig. 37). The already low average velocities at Ahwahnee Bridge are reduced by 32-37 percent and 35-42 percent for the scenarios "Removed Ahwahnee Bridge" and "Removed Ahwahnee and Sugar Pine Bridges and Berm", respectively, and maximum velocities are reduced by 12-18 percent and 15-19 percent, respectively (fig. 37).

The depths and velocities in the side channel of concern between the Sugar Pine and the Ahwahnee Bridges are only slightly affected by the scenarios modeled here, with most depths within $0.05 \mathrm{~m}$ of the present-day modeled water-surface elevation (fig. 35). Present-day average and maximum velocities are $0.8-0.85 \mathrm{~m} \mathrm{~s}^{-1}$ and $1.2-1.6 \mathrm{~m} \mathrm{~s}^{-1}$, respectively (fig. 38). The various scenarios only slightly affect average and maximum velocity at the side-channel cross-section, with average velocity decreasing by 0-12 percent, and maximum velocity decreasing by 1-15 percent. The scenarios that include removing the berm are the most effective at reducing velocity, particularly at the two lower flows, with percent-velocity reductions greater than 10 percent (for 50- and 20-percent annual exceedance probability floods) (fig. 37), though the overall reduction is not large at less than $0.1 \mathrm{~m} \mathrm{~s}^{-1}$. It is not entirely clear why the model results at the side channel cross-section are relatively unaffected in the scenarios, though it is most likely due either to the cross-floodplain orientation of the mainstem channel downstream from the side channel or possibly to the logjam dynamics at the head of the side channel. If the modeled logjam is removed, simulated velocities and depths increase in the side channel. In addition, several riprap and engineering projects have been constructed in the side channel, which were incorporated into the topography used in the FaSTMECH model, and may be reducing flow velocity in the side channel.

The FaSTMECH model results for the historical 1919 scenario indicate that the historical floodplain likely was already becoming inundated at the 50-percent annual exceedance probability flood (figs. 39 and 40), whereas for the present-day scenario, the FaSTMECH model did not show floodplain inundation occurring until larger flows were reached, such as the 20-percent annual exceedance probability flood. For the present-day FaSTMECH results of the 50-percent annual exceedance probability flood, the flow remains well contained in the channel, suggesting that discharges closer to the 20-percent annual exceedance probability flood cause overbank flooding. In the historical FaSTMECH model simulations, velocities rarely exceeded $2.0 \mathrm{~m} \mathrm{~s}^{-1}$, but in the present-day simulations, velocities commonly exceeded $2.0 \mathrm{~m} \mathrm{~s}^{-1}$ (figs. 37 and 38). This result may be partially due to the shallower channel estimated by the historical surface used for the FaSTMECH simulations (specifically, the digitized contours most likely did not include points in the channel). Yet, the average difference in depth between the historical surface that was used in the FaSTMECH simulations and the individual point measurements on the bed in the historical map was small relative to the channel depth (approximately 10 percent of average channel depth), suggesting that even if additional historical bed points were available, depths and velocities in the historical simulations would be considerably less than in present-day simulations. 
One important factor affecting present-day conditions relative to historical conditions is the Stoneman Bridge access road berm, which approaches Stoneman Bridge from the river right (north) side, and perpendicularly crosses the entire floodplain (visible in fig. 5). For flows as frequent as the 20percent annual exceedance probability flood, the access berm forces the floodplain flow towards Stoneman Bridge, as shown in figures 31 and 32. It is likely that this effect persists for lower annual exceedance probability flows as well, though flows begin to overtop the berm for flows exceeding the 20-percent annual exceedance probability flood high-flow event. These results at the Stoneman Bridge access road berm are similar to those found by Eagan (1998), who estimated that a flow of $169.9 \mathrm{~m}^{3} \mathrm{~s}^{-1}$ was needed to inundate the access berm, which is slightly larger than the 20-percent annual exceedance probability flood modeled here. The floodplain flows affected by the access berm likely were an important historical factor influencing the flows in the main channel, as the reduction in historical velocities with increasing discharge seen in figure 38, occurs primarily as more water cuts across the floodplain, bypassing the Stoneman Bridge area, rather than being directed back into the channel as it does presently.

The results of the FaSTMECH model indicate that the equestrian tunnels at Stoneman Bridge pass only 2.7 percent to 3.7 percent of the overall discharge at the bridge site (table 8 ), and therefore, do not provide much additional capacity. It has been proposed to YNP that a tunnel, similar in size to the equestrian tunnels at Stoneman, be installed at Sugar Pine to relieve the high velocities there. From the present analysis, it does not appear that one or even two equestrian tunnels would contribute enough capacity to substantially reduce velocities at the bridge, though this particular scenario was not modeled.

\section{Results of geomorphic assessment}

A review of the YNP study cross-section 13 (XS13 in fig. 8) in the upper part of the study reach, near the nicknamed "Tenaya Bar", found that there have been substantial changes over time in the channel cross-sectional area at that site (fig. 41; table 9). The Tenaya Bar is important because it determines the channel capacity just upstream of the confluence with Tenaya Creek, and hence, determines the amount of water crossing the floodplain and bypassing the Sugar Pine and Ahwahnee Bridges bend (fig. 2). Following the 1997 flood, the cross-sectional channel area was reduced to 55 percent of the channel area surveyed in 1989. Since 1997, the channel area has been increasing but has not yet returned to the 1989 value (fig. 41; table 9), with the last available survey in 2006 having a channel area equal to 77 percent of the 1989 survey. These results suggest that the snowmelt-dominated flows following the 1997 flood are able to mobilize sediment found at Tenaya Bar.

The magnitude-frequency assessment of sediment transport at Tenaya Bar (cross-section 13, XS13 in fig. 8) indicates that the majority of bedload sediment at Tenaya Bar is mobile during relatively moderate flows (less than a 50-percent annual exceedance probability flood event) (fig. 42) and that the largest snowmelt-dominated flood peaks are just able to move the largest sediment found in the channel (up to 256-mm diameter). The peak in the magnitude-frequency bedload curve occurs at approximately $60 \mathrm{~m}^{3} \mathrm{~s}^{-1}$ (approximately a 66-percent annual exceedance probability flood) suggesting that the most geomorphically important discharges for bedload sediment are relatively frequent and are capable of moving the majority of the sediment found in the bed, despite the large bed-sediment size (fig. 21a). These results are consistent with the YNP cross-section survey data, showing a mobilization of sediment at Tenaya Bar for snowmelt-dominated flows. In contrast, suspended-sediment transport is low, as has been pointed out in other studies (Madej and others, 1994; Andrews, 2012), though it should be noted 
that suspended-sediment data for the Happy Isles gage have been collected only up to discharges of 75 $\mathrm{m}^{3} \mathrm{~s}^{-1}$ (specifically, there are no high-flow suspended-sediment data).

The results of the watershed analysis suggest that sediment supply to the study reach, particularly for bedload, is limited and likely temporally irregular owing to the upstream watershed characteristics. In the Tenaya Creek watershed, the low-gradient reach of Tenaya Creek upstream of Mirror Lake (slope of about 0.0015) and the low-gradient reach immediately upstream of the confluence with the Merced River (slope of about 0.003 ) likely limit the supply of sediment larger than sand from being transported to the Merced River. The Merced River above the Tenaya Creek confluence has a larger watershed than Tenaya Creek (table 2) and is steeper, with an average gradient of 0.011 from Clark's Bridge to Happy Isles Gage, and a gradient of 0.107 from Happy Isles Gage to the base of Nevada Falls. Upstream of Nevada Falls, however, the Merced River decreases in gradient (slope of about 0.0015) as it flows through Little Yosemite Valley, making it unlikely that sediment larger than sand exits Little Yosemite Valley. A little-studied but major tributary to the Merced River, called Illilouette Creek (158- $\mathrm{km}^{2}$ drainage area), joins the Merced below Nevada Falls just before it enters Yosemite Valley and is the only consistently steep-gradient stream with substantial potential to transport large bedload-sized sediment to Yosemite Valley (slope of about 0.25 just above confluence with the Merced River, leveling off to about 0.06). On the basis of anecdotal evidence, Illilouette Creek was believed to be a substantial sediment source in the 1997 flood.

\section{Discussion}

The results presented above focus on velocity primarily because shear stress, the primary driver affecting sediment transport, is a function of the square of velocity. Shear stress in turn is exponentially related to sediment transport; as such, a small change in velocity (and hence, shear stress) can be a major driver influencing the erosion of the bed and banks of the stream. Even slight reductions in velocity can result in substantially less shear stress and sediment transport. For example, a reduction in velocity by 25 percent results in a 44 percent reduction in shear stress (see equation 2) and a potential reduction in bedload sediment transport of nearly 60 percent [assuming the critical shear stress has been exceeded, $q=\tau^{3 / 2}$ (where, $q=$ width-normalized sediment transport, and $\tau$ is shear stress)]. Not all shear stress, however, is used for mobilizing sediment grains, as a large fraction of the overall energy can be lost to friction with other elements of the channel, including banks, bedforms, bars (for example, Prestergaard, 1983), or large wood (for example, Manga and Kirchner, 2000). In general, however, reducing velocity will result in a reduction in shear stress and the ability of the stream to mobilize sediment.

The FaSTMECH hydrodynamic model run within the USGS iRIC model interface was chosen for this study primarily because of its fast run times and stability given the large number of required simulations. One limitation that was encountered while using FaSTMECH is its curvilinear grid structure that necessitated tight grid spacing at the interior of bends to have sufficiently dense channel grid points, due to the wide floodplain and sinuous main channel of the study site. For the moderate flows modeled here, the edge of water towards the inside of the bend was still relatively far away from these interior bends; however, with larger flows, the tight grid spacing at the interior of bends could become problematic with the grid spacing utilized. For larger flows, a wider grid spacing could be used with FaSTMECH, though an unstructured grid model also could work well. In addition, a model capable of allowing lateral inputs (for example, from Tenaya Creek) would permit the upstream 
boundary to be moved farther upstream away from Sugar Pine Bridge and might allow the incorporation of the reach near Clark's Bridge into a single model.

To help facilitate future planning and restoration efforts, one of the main data needs for the Merced River is suitable velocity data with which to evaluate restoration effectiveness and to calibrate the hydrodynamic models. In this study, the various scenarios were evaluated by using the existing datasets; however, substantial additional analyses of sediment transport and shear stress would be possible if suitable velocity data were collected. Given the national importance of the Merced River site in Yosemite National Park, further study of the planned scenarios might be warranted following collection of velocity calibration data, or once more-refined planning scenarios are completed. In addition to the collection of velocity data, geomorphic modeling of the long-term effects of various planning scenarios, including pool filling and scour, and an investigation of sediment sources would give planners valuable tools to help plan effective restoration strategies as well as estimate the long-term evolution of the river channel for this nationally important river.

\section{Summary}

In response to Yosemite National Park planning alternatives, a series of 2D hydrodynamic flow models were developed for a 2.4-km-long study reach of the Merced River in eastern Yosemite Valley, Yosemite National Park, USA. Flood discharges with 50-, 20-, 10, and 5-percent annual exceedance probabilities were tested with the USGS FaSTMECH 2D hydrodynamic model for several different conditions including: present-day conditions; historical conditions; and five bridge removal scenarios involving Sugar Pine, Ahwahnee, and Stoneman Bridges, as well as a road berm that connects Sugar Pine and Ahwahnee Bridges. This Open-File Report will be superseded at a later date by a Scientific Investigations Report.

The FaSTMECH model utilized topographic inputs that originated from a variety of sources, including aerial LiDAR, ground-based LiDAR, and total station surveys, which were used to develop a detailed present-day (circa 2007) topographic surface. Geomorphic facies mapping combined with Wolman grain-size counts from WY2010 and estimates of floodplain roughness were used to prepare a comprehensive roughness map of the reach. A digitized historical 1919 USGS map was used to simulate historical topography, and roughness was interpreted onto the historic map by using present-day values of grain size. An evaluation of the FaSTMECH model for a moderate-sized flood $\left(130.9 \mathrm{~m} \mathrm{~s}^{-1}\right)$ resulted in a relatively good match between observed and simulated water-surface elevations, given the uncertainty accompanying the observed water-surface elevations, with the evaluation runs having a root mean square error of $0.21 \mathrm{~m}$ for average flow depths of about $2.3 \mathrm{~m}$. No measured velocity data were available to test the model. A geomorphic assessment of sediment transport and possible watershed sediment supply was performed along with an assessment of channel change at the important "Tenaya Bar" site, which determines the amount of flow onto the floodplain at the critical Sugar Pine Ahwahnee bend.

The FaSTMECH model results indicate that maximum velocities in the present-day channel are associated primarily with the bridges and riprap areas. Maximum simulated velocities in the study reach, in some places approaching $3.0 \mathrm{~m} \mathrm{~s}^{-1}$, are associated with Stoneman and Sugar Pine Bridges, whereas Ahwahnee Bridge had lower maximum velocities, between $1.5 \mathrm{~m} \mathrm{~s}^{-1}$ to $2.0 \mathrm{~m} \mathrm{~s}^{-1}$, most likely owing to the orientation of the bridge parallel to down-valley floodplain flows. The FaSTMECH model results 
for the bridge removal scenarios indicate a reduction in average velocity at the bridge sites for the range of flows by approximately 23-38 percent (Sugar Pine Bridge), 32-42 percent (Ahwahnee Bridge), and 33-39 percent (Stoneman Bridge). In the side channel of interest to YNP management, the model simulated average velocities did not appear to be substantially effected by the removal scenario. The comparison of historical conditions indicates present-day topography and hydraulics are quite different than historically, with much more flow in the channel presently. In addition, analysis of the FaSTMECH model results suggests that during floods between the 50- and 5-percent annual exceendance probability, historical channel velocities rarely exceeded $2.0 \mathrm{~m} \mathrm{~s}^{-1}$, whereas with present-day conditions, modelderived channel velocities commonly exceed $2.0 \mathrm{~m} \mathrm{~s}^{-1}$.

An ongoing investigation of the geomorphology of the study reach suggests that sediment transport and supply likely differs between the high-magnitude winter rain-on-snow floods and the more moderate snowmelt-dominated floods. An assessment of study cross-sections near the Tenaya Creek confluence and the important Tenaya Bar site reveals a sizeable reduction in channel cross-sectional area associated with sediment deposition from the 1997 flood, the last major rain-on-snow flood. Since 1997, the channel cross-sectional area has been increasing to pre-1997 flood conditions, suggesting the snowmelt-dominated high flows that have occurred since 1997 are capable of transporting the bed sediment at this site. A magnitude-frequency analysis of bedload and suspended-sediment transport at the Tenaya Bar site, indicates a peak in bedload transport of about $60 \mathrm{~m}^{3} \mathrm{~s}^{-1}$ (about a 66-percent annual exceedance probability discharge), with the majority of the bed sediment being mobile at this flow. At the largest discharges modeled (5-percent annual exceedance probability flood), the largest sediment in the bed is mobile. In contrast to bedload transport, suspended-sediment transport is low, though no suspended-sediment measurements have been taken at high discharges.

Obtaining additional field measurements of velocity and discharge data in the study reach would enable further testing and calibration of the hydrodynamic models and would improve confidence in the model results. Improved confidence in the modeled velocity results would allow additional substantial analyses of reach-scale effects and would enable the development of geomorphic models to test longterm responses of the site to various planning scenarios. In addition, the collection of watershed sediment-supply data would give planners helpful tools to plan restoration scenarios for this nationally important river.

\section{Acknowledgements}

In particular, we would like to thank Jim Roche at the Yosemite National Park, National Park Service, for his extensive assistance, persistence, and patience with preparing this report. We also would like to thank the reviewers at USGS and the NPS external reviewers who helped to refine the manuscript. In addition, we would like to thank Brina Moscny at Yosemite National Park, who was instrumental in obtaining the topographic and water-stage field data. 


\section{References cited}

Andrews, E.D., 2012, Hydrology of the Sierra Nevada Network National Parks: Status and Trends, National Park Service, Natural Resource Report NPS/SIEN/NRR, 2012/500, 192 p.

Arcement, G. J., and Schneider, V.R., 1989, Guide for selecting Manning's Roughness Coefficients for natural channels and flood plains, United States.S. Geological Survey, Water-supply Paper 2339, 67 p.

Barnes, H. H., 1967, Roughness characteristics of natural channels, United States.S. Geological Survey. Water-Supply Paper 1849, 219 p.

Cella Barr Associates, 1998, Hydrologic and hydraulic investigation for proposed campgrounds in Yosemite National Park, CA, Report prepared for National Park Service, 120 p.

Chow, V.T., 1959, Open Channel Hydraulics, McGraw-Hill, New York, New York.

Cooper, D.J., and Wolf, E.C., 2008, Yosemite Valley: Hydrologic regime, soils, pre-settlement vegetation, disturbance, and concepts for restoration, Report submitted to Yosemite National Park, CA, $67 \mathrm{p}$.

Crowder, D.W., and Knapp, H.V., 2005, Effective discharge recurrence intervals of Illinois streams, Geomorphology, v. 64, p. 167-184.

David Evans and Associates, 2004, Survey data provided to Yosemite National Park, unpublished report.

Eagan, S.M., 1998, Modeling floods in Yosemite Valley, California, using Hydrologic Engineering Center's River Analysis System, Master's thesis submitted to Department of Hydrologic Science, University of California, Davis, $79 \mathrm{p}$.

Fischenich, C., and Dudley, S., 1999, Determining drag coefficients and area for vegetation, EMRRP Technical Notes Collection - (ERDC TN-EMRRP-SR-08), United StatesU.S. Army Engineer Research and Development Center, Vicksburg, MS, 14 p.

Fischer, H.B., List, J.E., Koh, C.R., Imberger, J., and Brooks, N.H., 1979, Mixing in Inland and Coastal Waters, Academic Press, New York, New York, 302 p.

Froehlich, D.C., 1989, Finite Element Surface-Water Modeling System: Two-dimensional flow in a horizontal plane-users manual, Federal Highway Administration Report, FHWA-RD-88-177, 285 p.

Gotvald, A.J., Barth, N.A., Veilleux, A.G., and Parrett, C., 2012, Methods for determining magnitude and frequency of floods in California, based on data through water year 2006: U.S. Geological Survey Scientific Investigations Report 2012-5113, 38 p., 1 pl., available online only at http://pubs.usgs.gov/sir/2012/5113/.

Gutenberg, B., J.P. Buwalda, and Sharp, R.P., 1956, Seismic explorations on the floor of Yosemite Valley, California, Bulletin of the Geological Society of America, v. 67, no. 1, p. 1051-1078.

Huber, N.K., 1987, The geologic story of Yosemite National Park, U.S. Geological Survey Bulletin $1595,64 \mathrm{p}$.

Kean, J. W., and Smith, J. D., 2004, Flow and boundary shear stress in channels with woody bank vegetation., in S. J. Bennett, and Simon, A., (eds.), Riparian Vegetation and Fluvial Geomorphology, Water Science Applications Series, v. 8, American Geophysical Union, Washington, D. C., p. 237252.

Keulegan, G. H., 1938, Laws of turbulent flow in open channels, Research paper 1151, United States National Bureau of Standards, Journal of Research, v. 21, no. 6, p. 707-741.

Kundu, P.K., and Cohen, I.M., 2004, Fluid Mechanics, (third edition), Academic Press, New York, New York, $759 \mathrm{p}$.

Limerinos, J. T., 1970, Determination of the Manning coefficient for measured bed roughness in natural channels, United States Geological Survey Water Supply Paper 1898-B, Washington, D.C., 53 p. 
Lundquist, J. D., and Cayan, D., 2002, Seasonal and spatial patterns in diurnal cycles in streamflow in the western United States, Journal of Hydrometeorology, v. 3, p. 591- 603.

Madej, M.A., Ozaki, V., Jones, C., and Gibbs, G., 1998, Channel changes in the Merced River following the January, 1997 flood, Report to Yosemite National Park, CA, 109 p.

Madej, M.A., Weaver, W.E., and Hagans, D.K., 1991, Analysis of bank erosion on the Merced River, Yosemite Valley, Yosemite National Park, Unpublished National Park Service report, Arcata, California, $161 \mathrm{p}$.

Madej, M.A., Weaver, W.E., and Hagans, D.K., 1994, Analysis of bank erosion on the Merced River, Yosemite Valley, Yosemite National Park, California, USA, Environmental Management, v. 18, no. 2, p. 235-250.

Manga, M., and Kirchner, J.W., 2000, Stress partitioning in streams by large woody debris, Water Resources Research, v. 36, no. 8, p. 2373-2379.

May, C.L., Pryor, B., Lisle, T.E., and Lang, M., 2009, Coupling hydrodynamic modeling and empirical measures of bed mobility to predict the risk of scour and fill of salmon redds in a large regulated river, Water Resources Research, v. 45, 22 p. W05402, doi:10.1029/2007WR006498.

McDonald, R.R., Nelson, J.M., and Bennett, J.P., 2005, Multi-dimensional surface-water modeling system user's guide: U.S. Geological Survey online documentation, accessed January 5, 2011 at http://wwwbrr.cr.usgs.gov/projects/GEOMORPH_Lab/WebHelp_Pro/MD_SWMS.htm

Milestone, J.F., 1978, The influence of modern man on the stream system of Yosemite Valley, Master's thesis, San Francisco State University, San Francisco, California, 227 p.

Nash, D.B., 1994, Effective sediment-transporting discharge from magnitude-frequency analysis, Journal of Geology, v. 102, p. 79-95.

National Center for Airborne Laser-Swathe Mapping, 2006, Yosemite National Park. Aerial LiDAR processing report submitted to Yosemite National Park, CA, $23 \mathrm{p}$.

National Park Service, 2011, National Park Service Public Use Statistics website: www.nature.nps.gov/stats, accessed February, 2011.

Nelson, J.M., and McDonald, R.R., 1996, Mechanics and modeling of flow and bed evolution in lateral separation eddies, USGS Director's approved report submitted to the USGS Grand Canyon Monitoring and Research Center and available at: http://www.gcmrc.gov/library/reports/GCES/Physical/hydrology/Nelson1996.pdf

Nelson, J.M., Bennett, J.P., and Wiele, S.M., 2003, Flow and sediment-transport modeling, in Kondolf, G.M., and Piegay, H., (eds.), Tools in fluvial geomorphology, England, Wiley, p. 539-576.

Parker, G., 1990, Surface-based bedload transport relation for gravel rivers, Journal of Hydraulic Research, v. 28, no. 4, p. 417-436.

Pitlick, J., Cui, Y., and Wilcock, P., 2009, Manual for computing bed load transport using BAGS (Bedload Assessment for Gravel-bed Streams) software, United States Forest Service General Technical Report RMRS-GTR-223, 45 p.

Prestegaard, K., 1983, Bar resistance in gravel bed streams at bankfull stage, Water Resources Research, v. 19 , p. 472-476.

Shields, F. D., and Gippel, C. J., 1995, Prediction of effects of woody debris removal on flow resistance, Journal of Hydraulic Engineering, v. 121, p. 341-354.

Stantec, 2000, Hydrologic and hydraulic analysis, Phase II, Yosemite National Park, CA, Report prepared for Yosemite National Park, National Park Service, CA, May 1, 2000, 46 p.

United States Army Corps of Engineers, 1997, Merced River near Yosemite, California, Hydrology, Sacramento District, Letter Report, 17 p. 
United States Army Corps of Engineers, 2007, Control and topographic surveying, Engineering and design manual, EM 1110-1-1005, 498 p.

United States Geological Survey, 1982, Guidelines for determining flood flow frequency, Bulletin 17-B of the Hydrological Subcommittee, Interagency Advisory Committee on Water Data, Reston, VA, $194 \mathrm{p}$.

Whiting, P.J., and Dietrich, W.E., 1990, Boundary shear stress and roughness over mobile alluvial beds, Journal of Hydraulic Engineering, v. 116, no. 12, p. 1495-1511.

Wilcock, P., Pitlick, J., and Cui, Y., 2009, Sediment transport primer estimating bed-material transport in gravel-bed rivers, United States Forest Service, General Technical Report, RMRS-GTR-226, 78 p. Wilcock, P.R. and Crowe, J.C., 2003, Surface-based transport model for mixed-size sediment, Journal of Hydraulic Engineering, v. 129, no. 2, p. 120-128.

Wolman, G.M., 1954, A method of sampling coarse riverbed material, Transactions of the American Geophysical Union, v. 35, no. 6. 


\section{Figures}

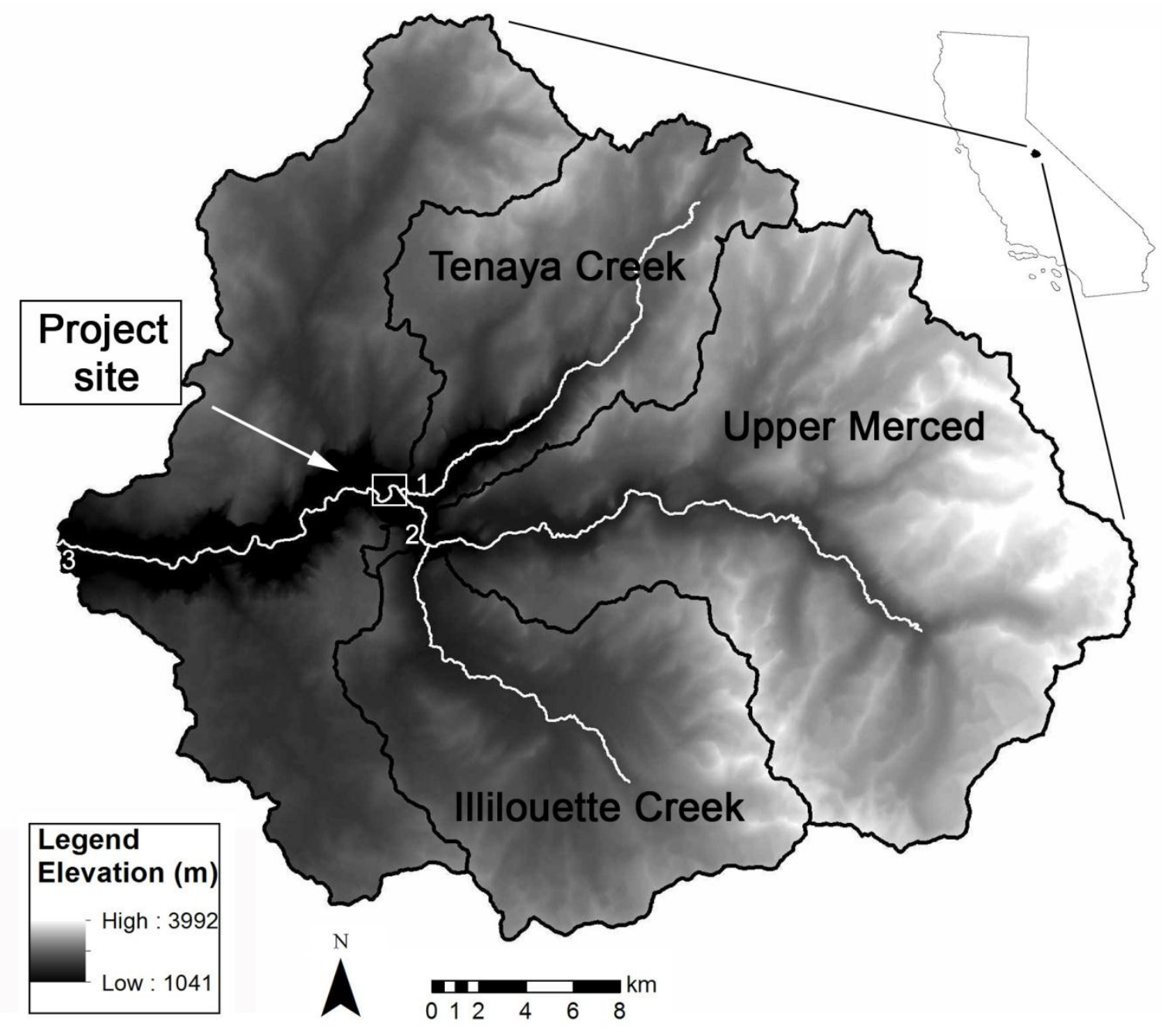

Figure 1. Overview map of the watersheds of eastern Yosemite Valley and the project site. Overall flow is right to left, with the three primary upstream stream channels highlighted in white, and watershed boundaries outlined in black. Note the large watershed contribution from the Merced River (consisting of the Upper Merced and Illilouette basins), relative to Tenaya Creek. The three surface-water gages near the project site are: the YNP maintained Tenaya Creek gage (1) near the location of the historical USGS gage \#11265000 - Tenaya Creek near Yosemite Village, the USGS gage \#11264500 - Merced River at Happy Isles Bridge near Yosemite (2), and USGS gage \#11266500 - Merced River at Pohono Bridge near Yosemite (3). The geographic coordinates of the center of the project site (outlined with a white square) are $37.7442 \mathrm{~N},-119.5743 \mathrm{~W}$. 


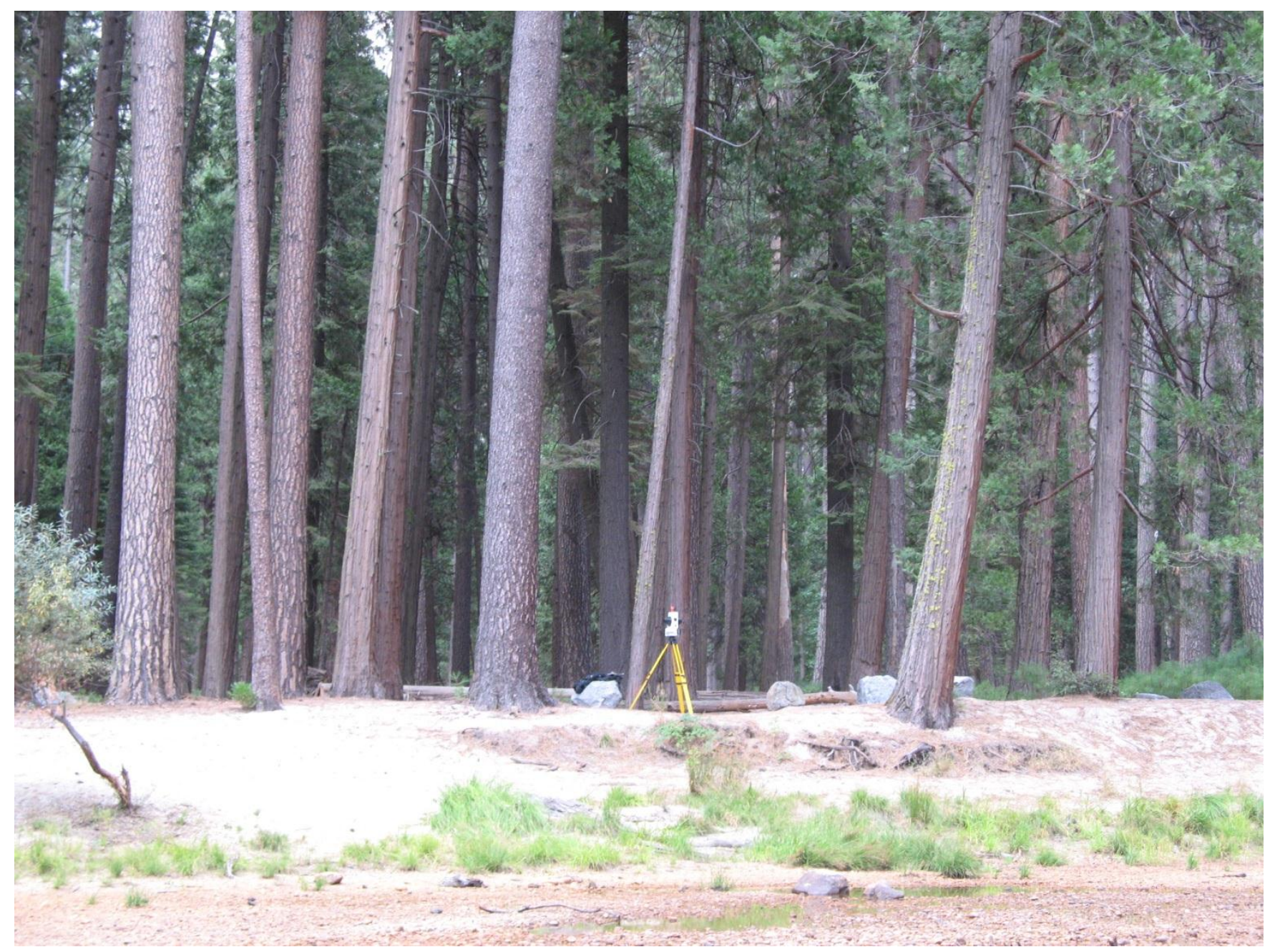

Figure 2. Photograph of ground-based LiDAR unit on river left streambank approximately $100 \mathrm{~m}$ downstream of Ahwahnee Bridge at site of the previous Lower Pines Campground. Note the extensive and large coniferous forest with relatively sparse riparian growth and exposed streambank sediments. Photograph taken by J.T. Minear, 9/21/2007. 


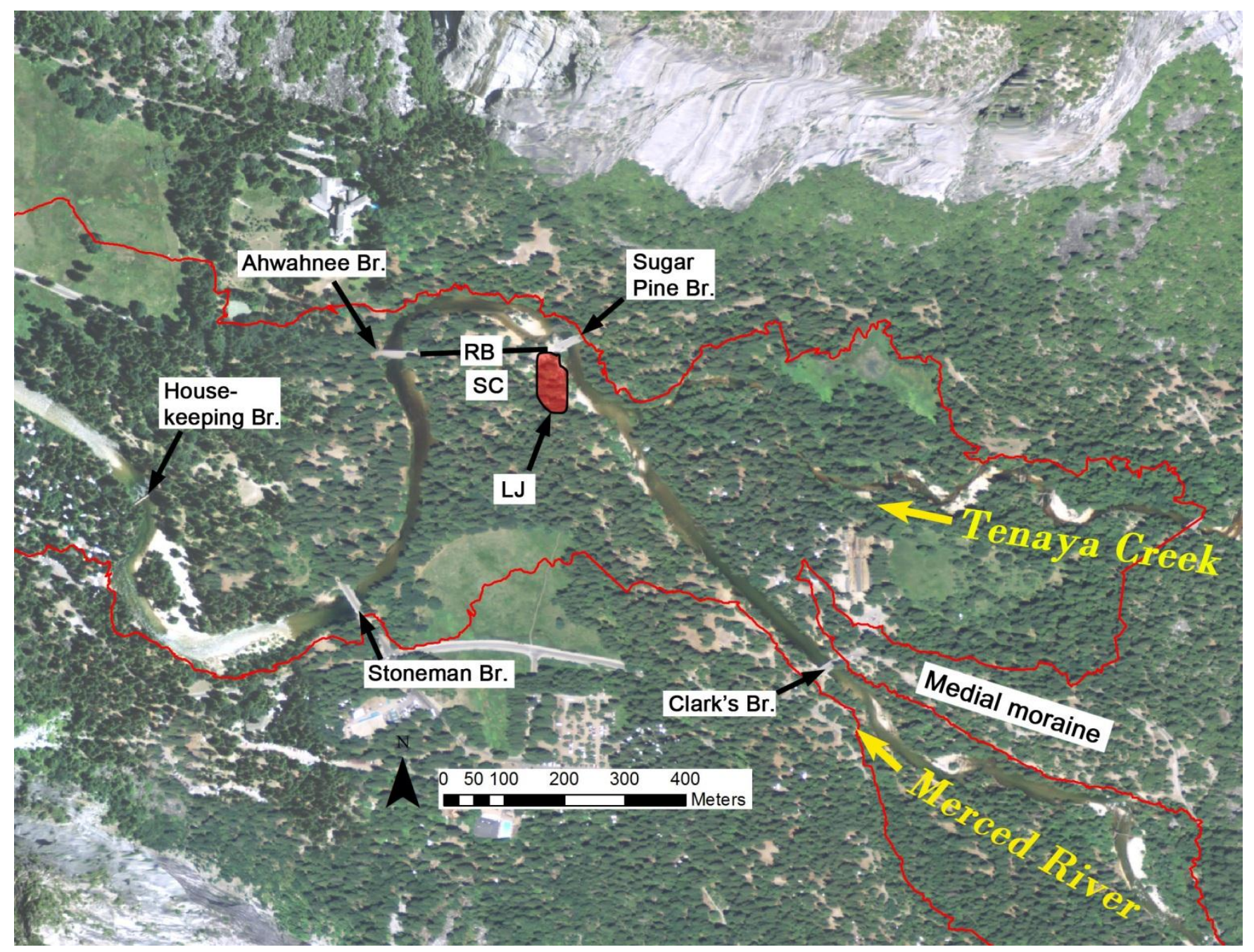

Figure 3. Map of bridge locations in eastern Yosemite Valley. Also shown are the elevated road berm (RB) connecting Sugar Pine and Ahwahnee Bridges, the side channel cutoff (SC) of interest in this study, and the log jam area (LJ) that formed during the 1997 flood at the entrance to the side channel. The measured water extent of the 1997 flood is shown in a red outline. Note that the medial moraine, remnant of the last glacial maximum, between Tenaya Creek and the Merced River acts to constrain high flows to the channel through the Clark's Bridge area. The extent of the 1997 flood shows the nearly valley-wide inundation that occurs during the largest flow events in Yosemite Valley below Clark's Bridge. 


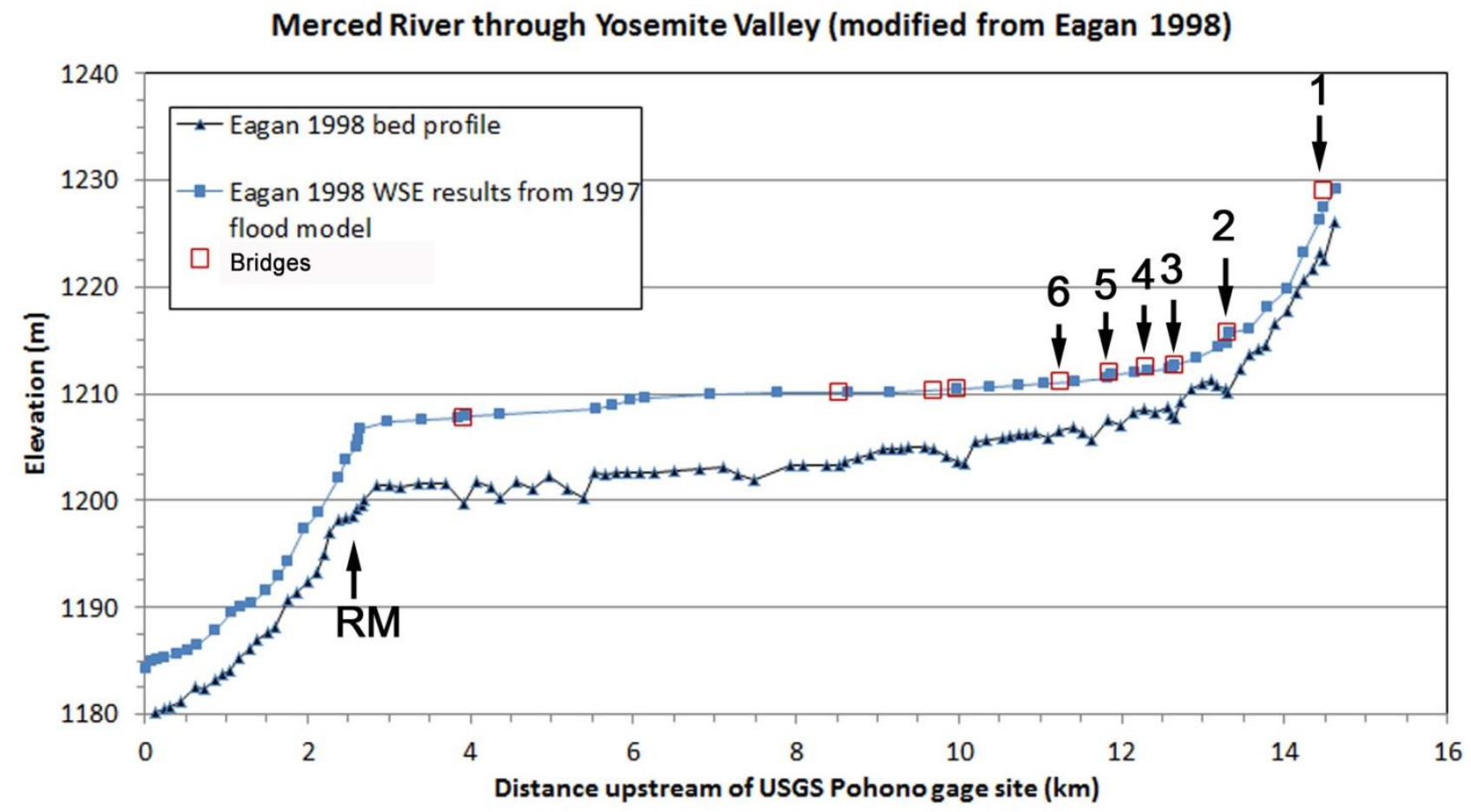

Figure 4. Longitudinal profile of the Merced River through Yosemite Valley (modified from Eagan 1998). Water surface elevations (WSE) are from Eagan (1998), modeling the 1997 flood. Note the rapid decrease in slope at the head of the valley and the relatively low slope until reaching the approximate location of the recessional moraine (RM). The locations of the bridges are: Happy Isles (1), Clark's (2), Sugar Pine (3), Ahwahnee (4), Stoneman (5), and Housekeeping (6). For perspective, the 1997 flood modeled here is the flood of record at the USGS Merced River at Happy Isles Bridge gage (1-percent annual exceedance probability). 


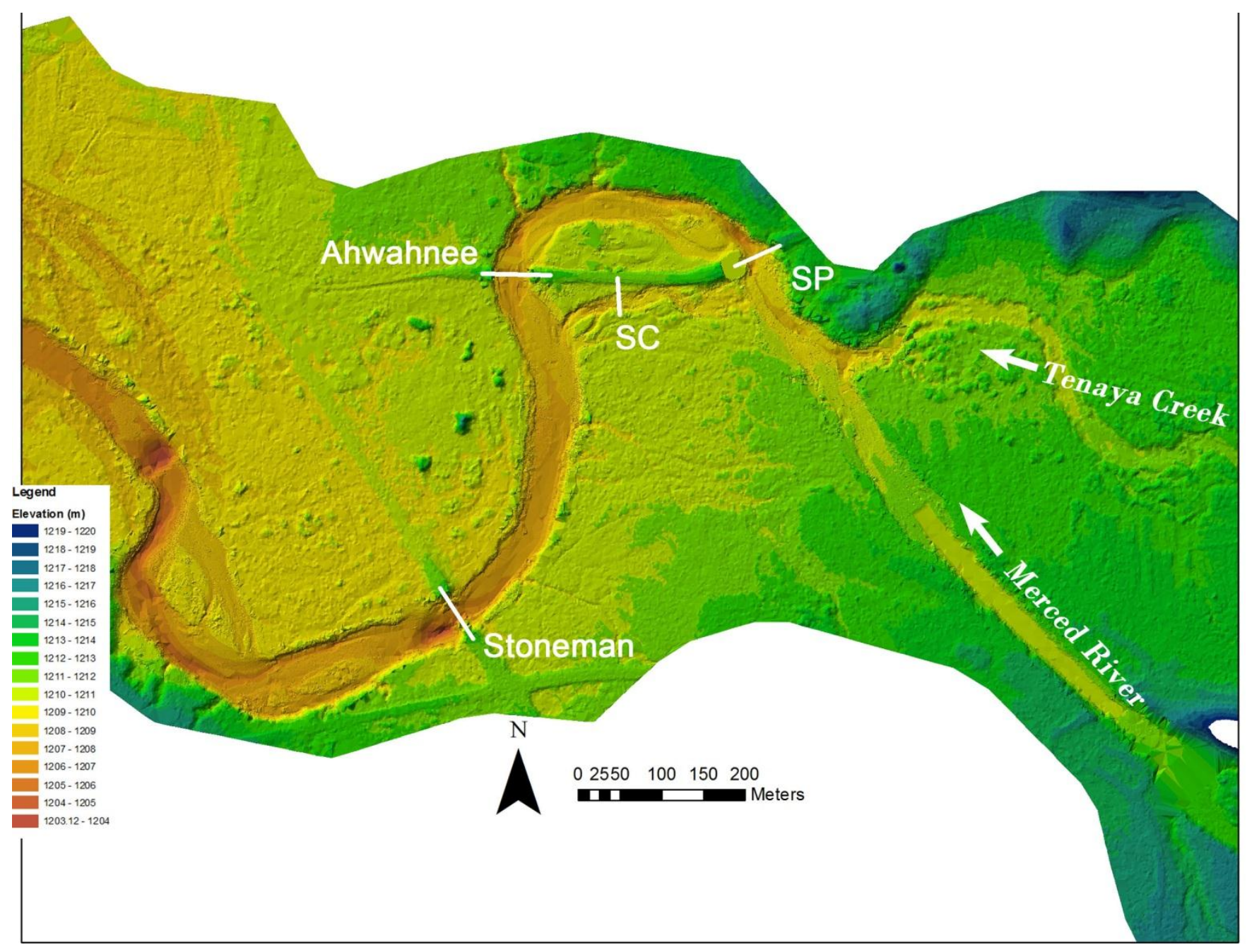

Figure 5. Digital elevation model of the Merced River study reach, with evaluation cross-sections marked. The topography shown in the figure is the final hybrid surface used in the FaSTMECH model, with aerial LiDAR, ground-based LiDAR, bathymetric points, bridge surfaces and interpolated channel points. "SC" marks the side channel cross-section, and "SP" marks the Sugar Pine cross-section. 


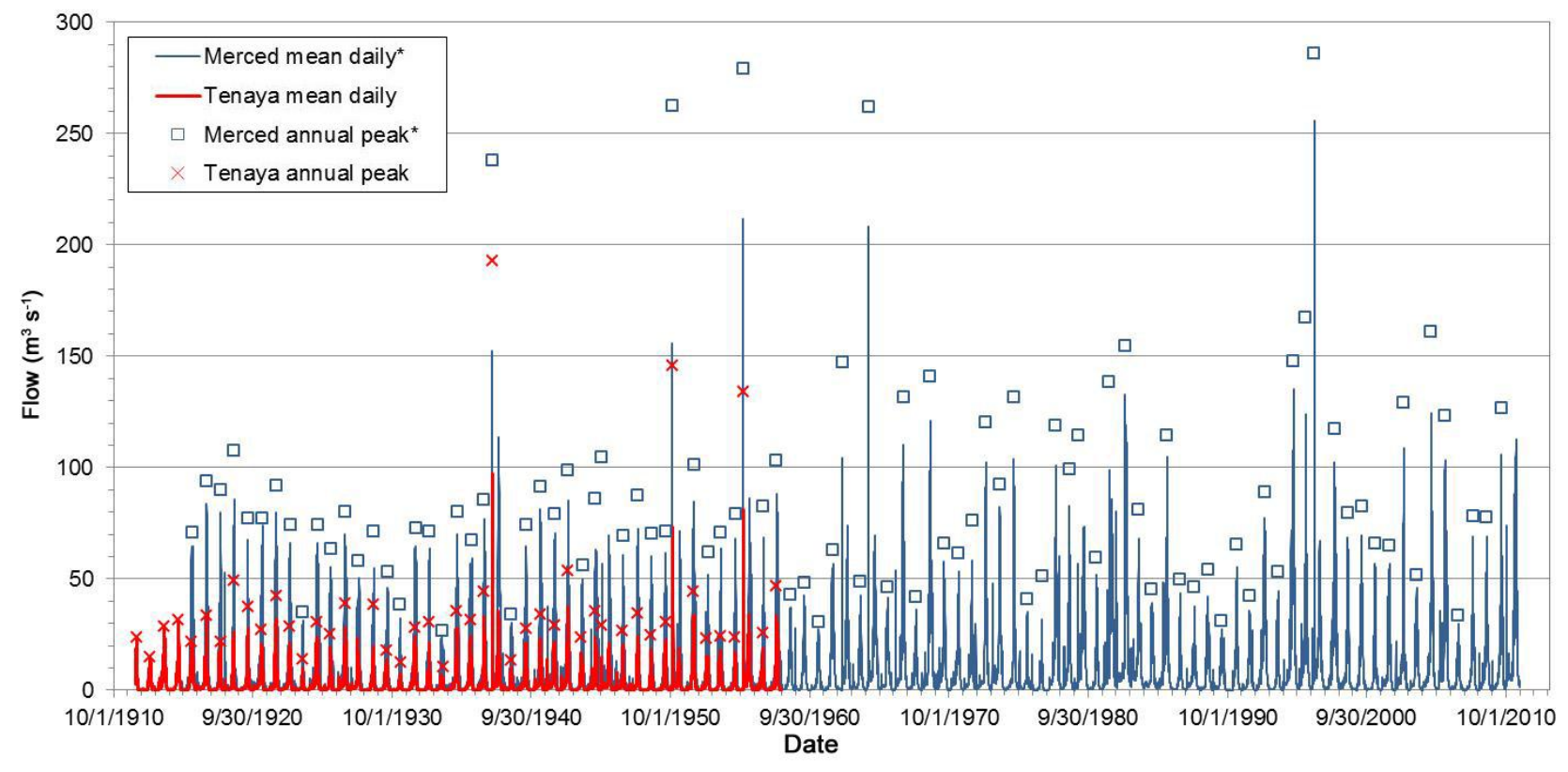

Figure 6. Comparison of flow data for the historical gage on Tenaya Creek (USGS gage 11265000) and Merced River at Happy Isles (USGS gage 11264500). Note that the largest peaks in WY1938, WY1951, WY1956, and WY1997 were primarily rain-on-snow floods in early winter and are much greater than typical snowmeltdominated floods (all other peaks). Note: * - Merced River discharge data shown here is from the USGS gage, Merced River at Happy Isles. 


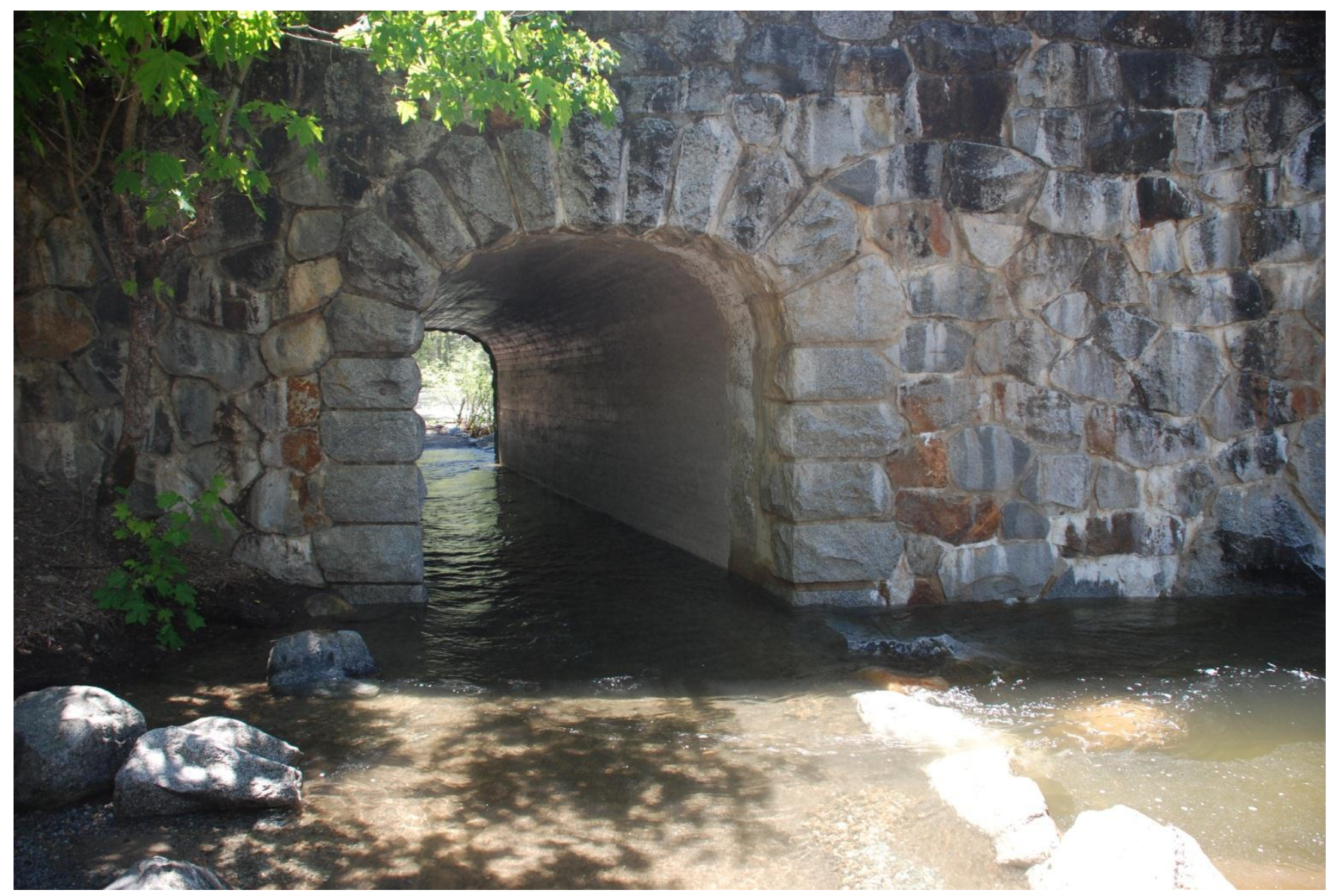

Figure 7. Photograph of flow through river right equestrian tunnel at Clark's Bridge, taken looking upstream. Figures 13 and 14 show the main bridge spans for Clark's and Ahwahnee Bridges. Photograph taken by YNP personnel, 6/7/2010. 


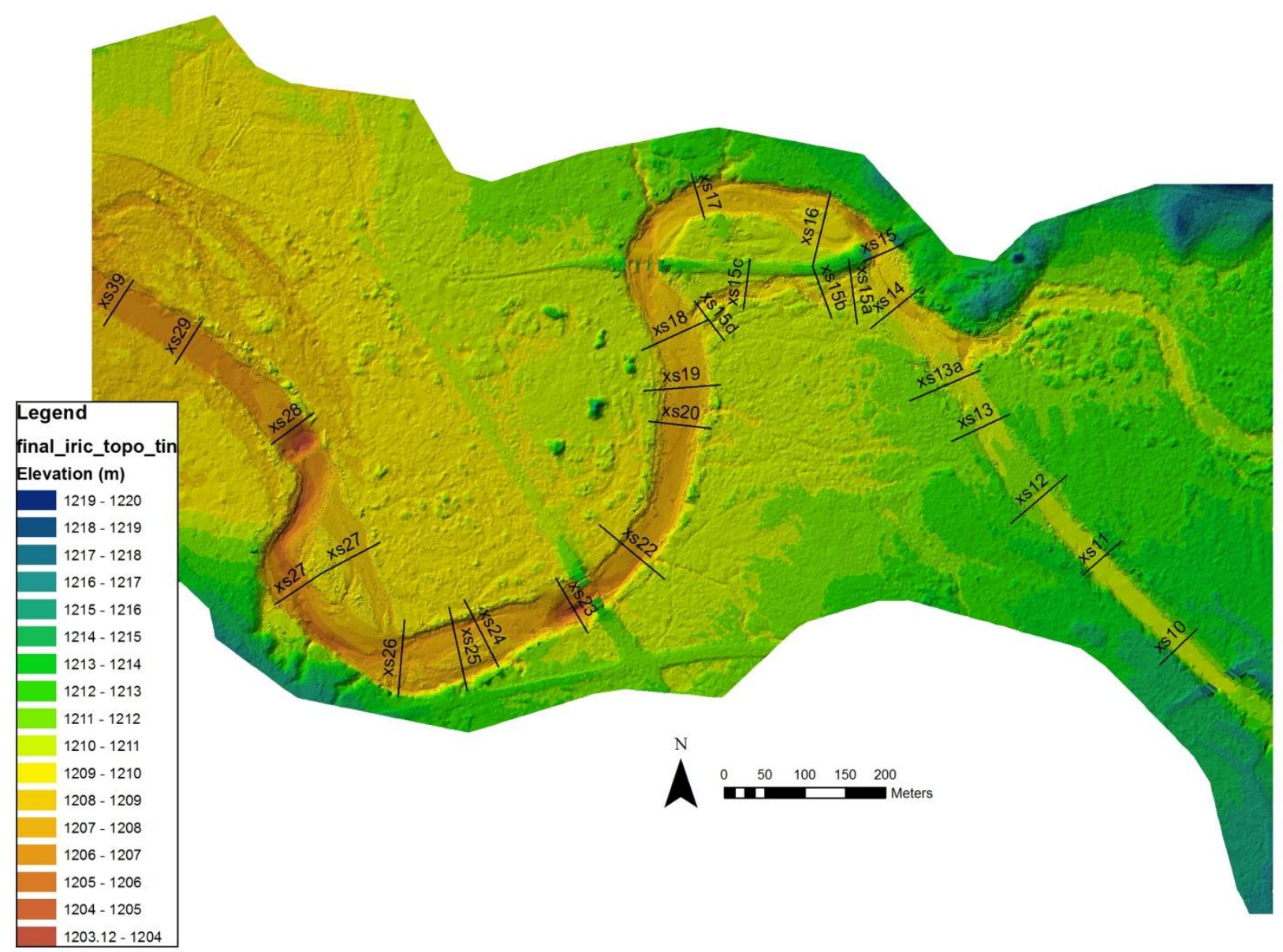

Figure 8. Map of Merced River in eastern Yosemite Valley, showing the locations of study cross-sections established by the YNP as part of an ongoing streambank monitoring program (YNP internal unpublished records). Some of the cross-sections were established as early as 1989, and are surveyed approximately every 3-5 years. 


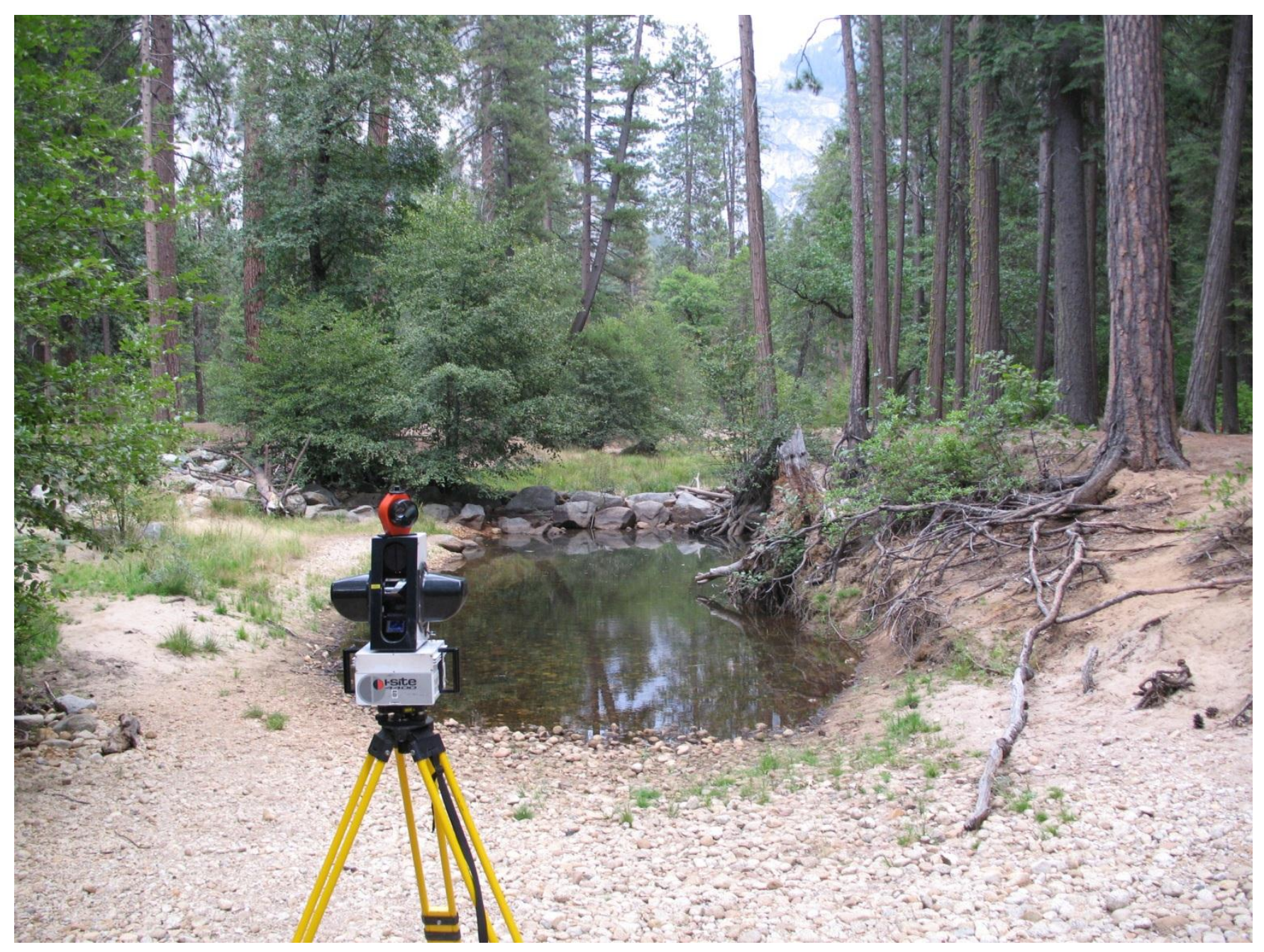

Figure 9. Photograph of the side channel and the ground-based LiDAR unit, Maptek I-Site 4400, looking upstream into the side channel between Sugar Pine and Ahwahnee Bridges. The road berm is on the left side of the photograph. Note the placed riprap in the side channel. Since the photograph was taken, the riprap has been enhanced with bio-engineering (plant stakings) on the berm-side of the channel (photograph by J. T. Minear, 9/22/2007). 


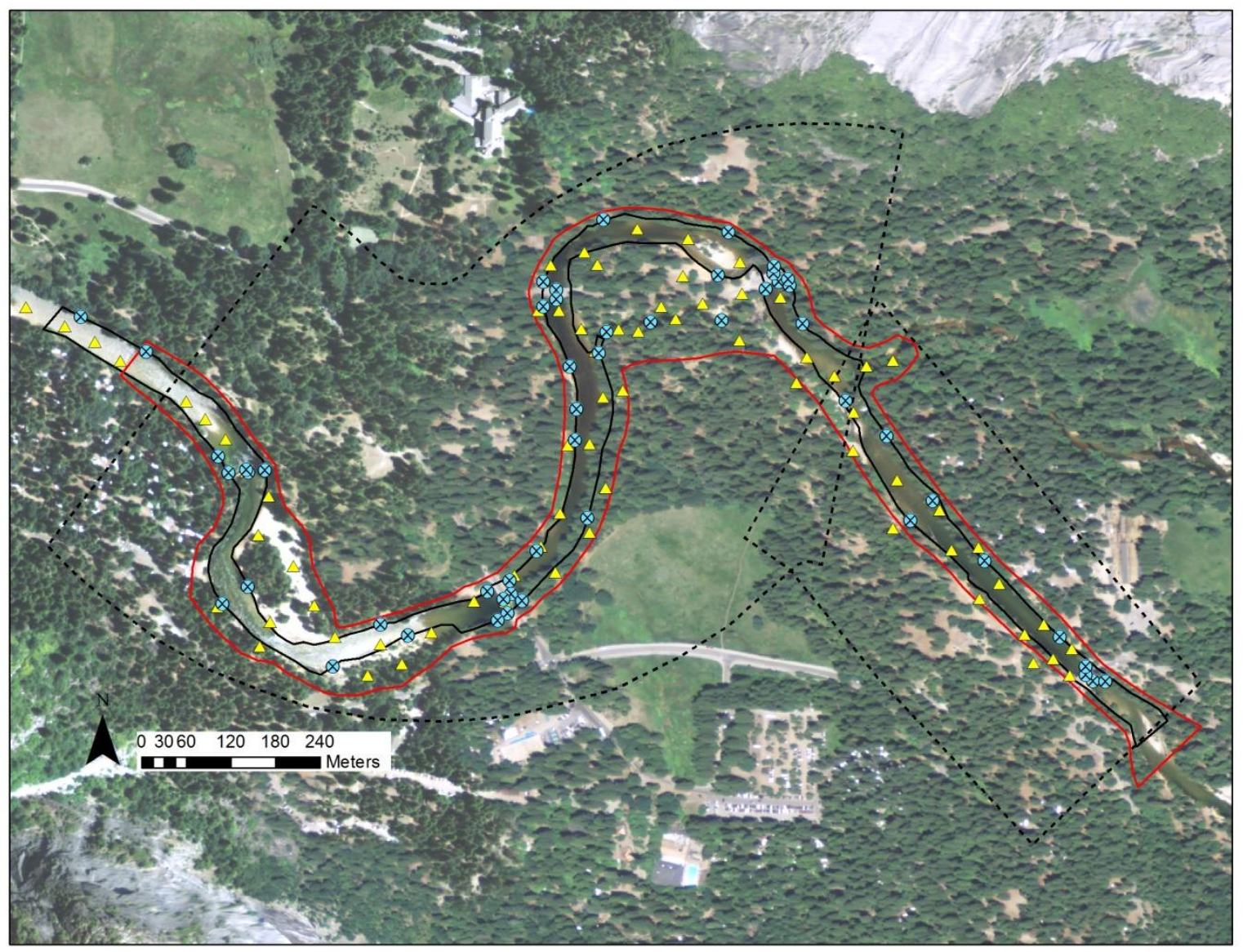

Figure 10. Map of the project site on the Merced River in eastern Yosemite Valley. Flow is right to left. Yellow triangles mark the instrument locations of the ground-based LiDAR and blue cross-marked circles denote the location of water-surface stage measurements in WY2010. The red outline is the polygon used to delineate the outer limit of the ground-based LiDAR points collected in 2007, and the black polygon is the base of bank determined from the ground-based LiDAR collected in 2007. The two dashed polygons are the extents of the FaSTMECH grids used in the flow models, with the downstream grid ( $1.85 \mathrm{~m} \times 2.4 \mathrm{~m}$ point spacing) being the main project area and the upstream grid $(1 \mathrm{~m} \times 1 \mathrm{~m})$ being used to evaluate the extent of floodplain flows exiting the Clark's Bridge area and entering the downstream grid domain. 


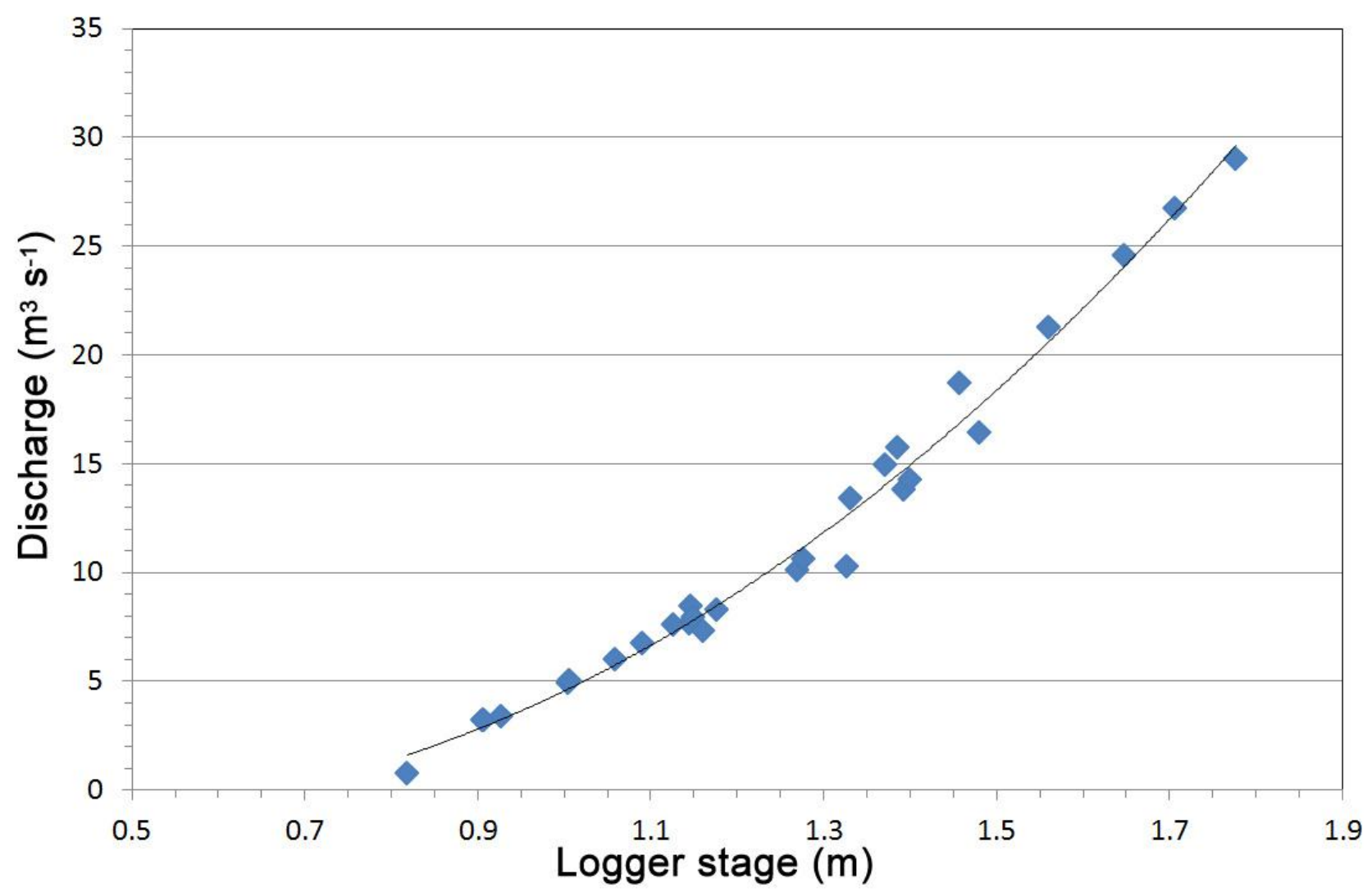

Figure 11. Stage-discharge relation developed by YNP for Tenaya Creek from discharge measurements collected by Balance Hydrologics in WY2006 and YNP in WY2009-2010 (YNP internal unpublished records). The maximum measured discharge is $29 \mathrm{~m}^{3} \mathrm{~s}^{-1}$, whereas the peak discharge in WY2010 is estimated at $54.5 \mathrm{~m}^{3} \mathrm{~s}^{-1}$. 


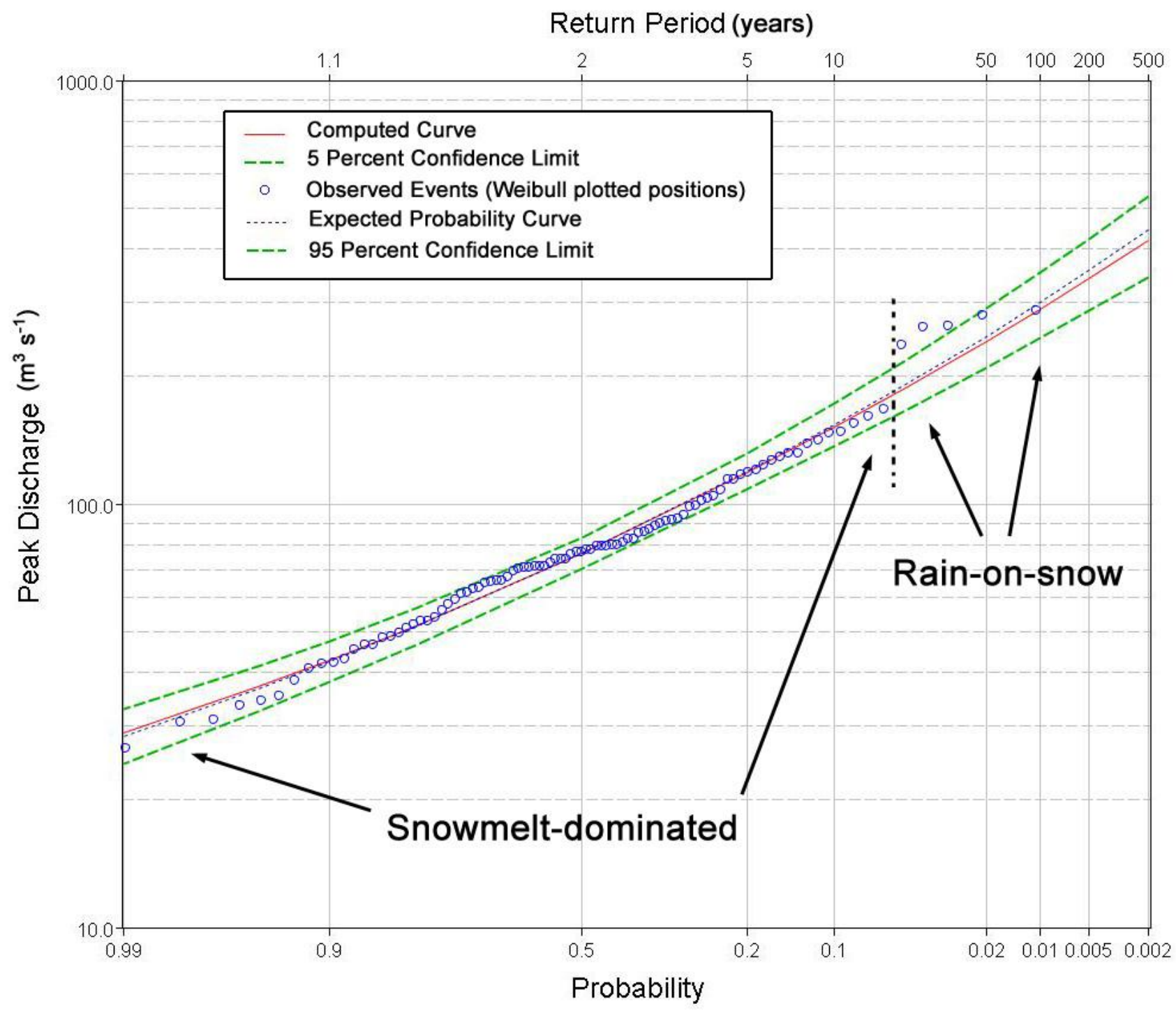

Figure 12. Flood probability plotted for the Merced River, using peak discharge data collected at the USGS Merced River at Happy Isles gage, 11264500. Note the two separate types of flows, with snowmelt-dominated peak flows making up the majority of the curve, and the five largest flows, occurring from rain-on-snow events, that are approximately twice as large. The break between the two different types of flows occurs between the 5and 4- percent annual exceedance probability floods. 


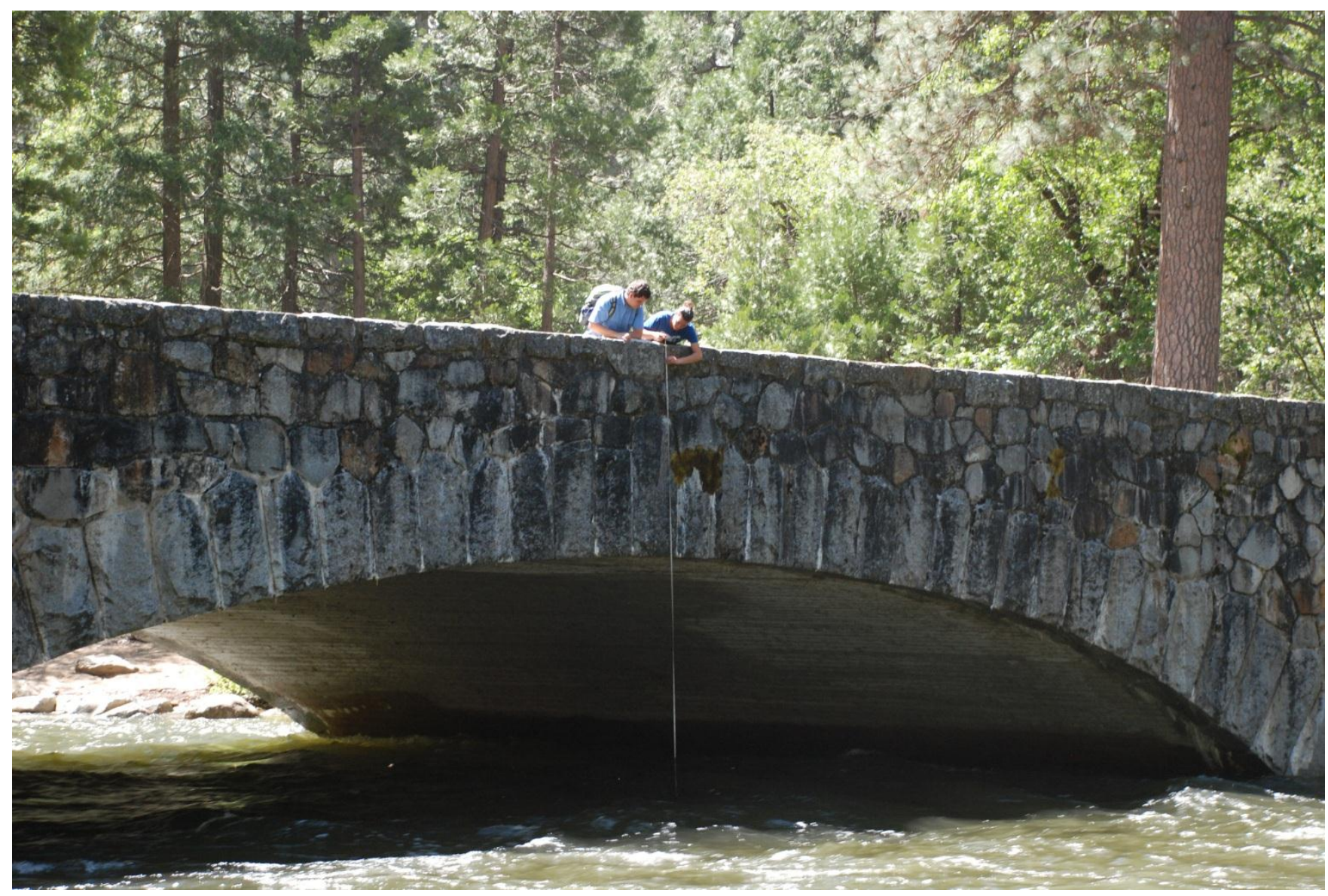

Figure 13. Photograph of a "tape-down" measurement of river stage during WY2010 on the downstream side of Clark's Bridge. Flow is left to right. Photograph taken by YNP personnel, 6/7/2010. 


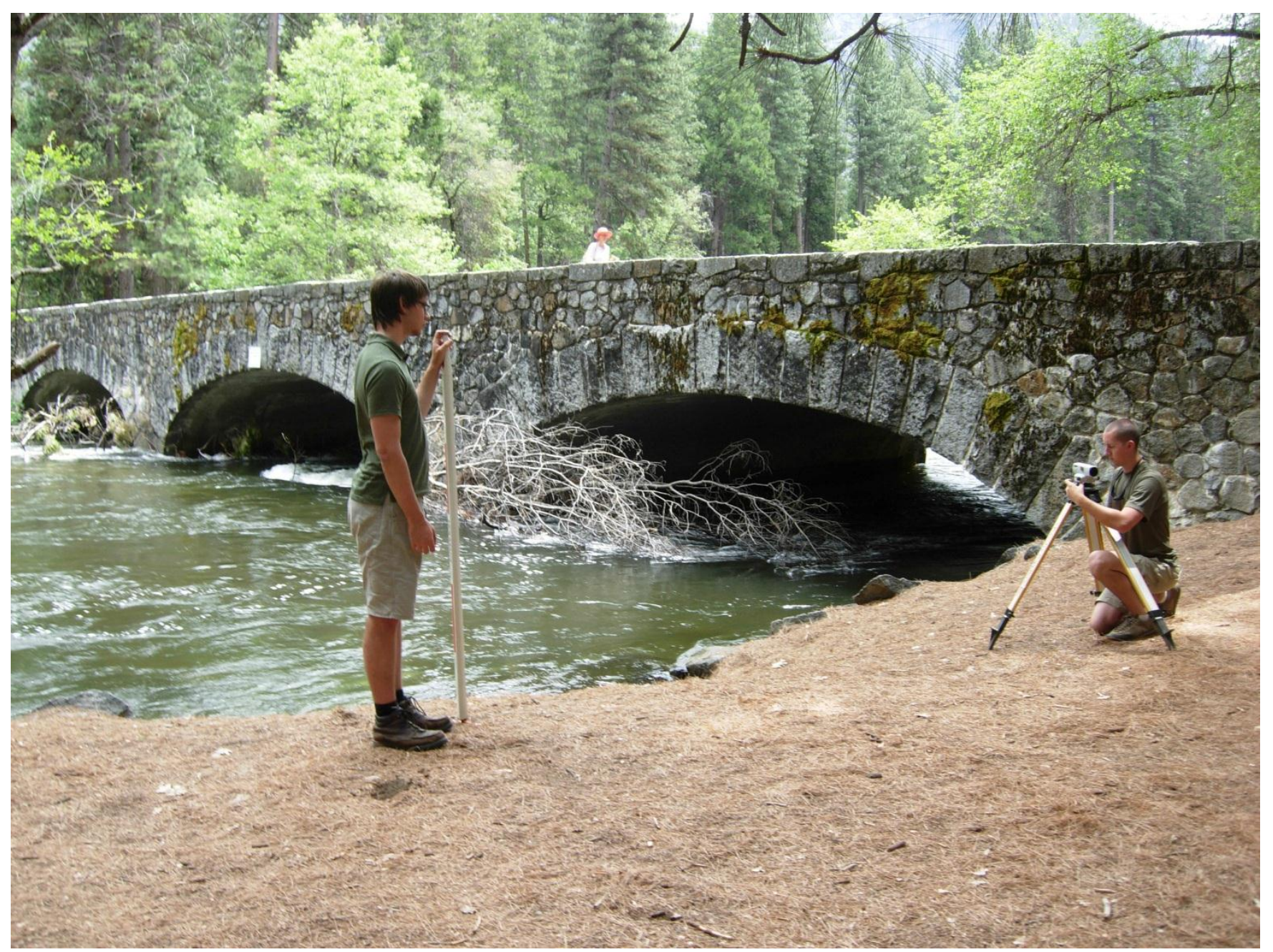

Figure 14. Photograph of water stage measurements during WY2010 showing wood accumulation at Ahwahnee Bridge during WY2010 snowmelt runoff. Photograph taken by YNP personnel, 6/4/2010. Flow is left to right. 


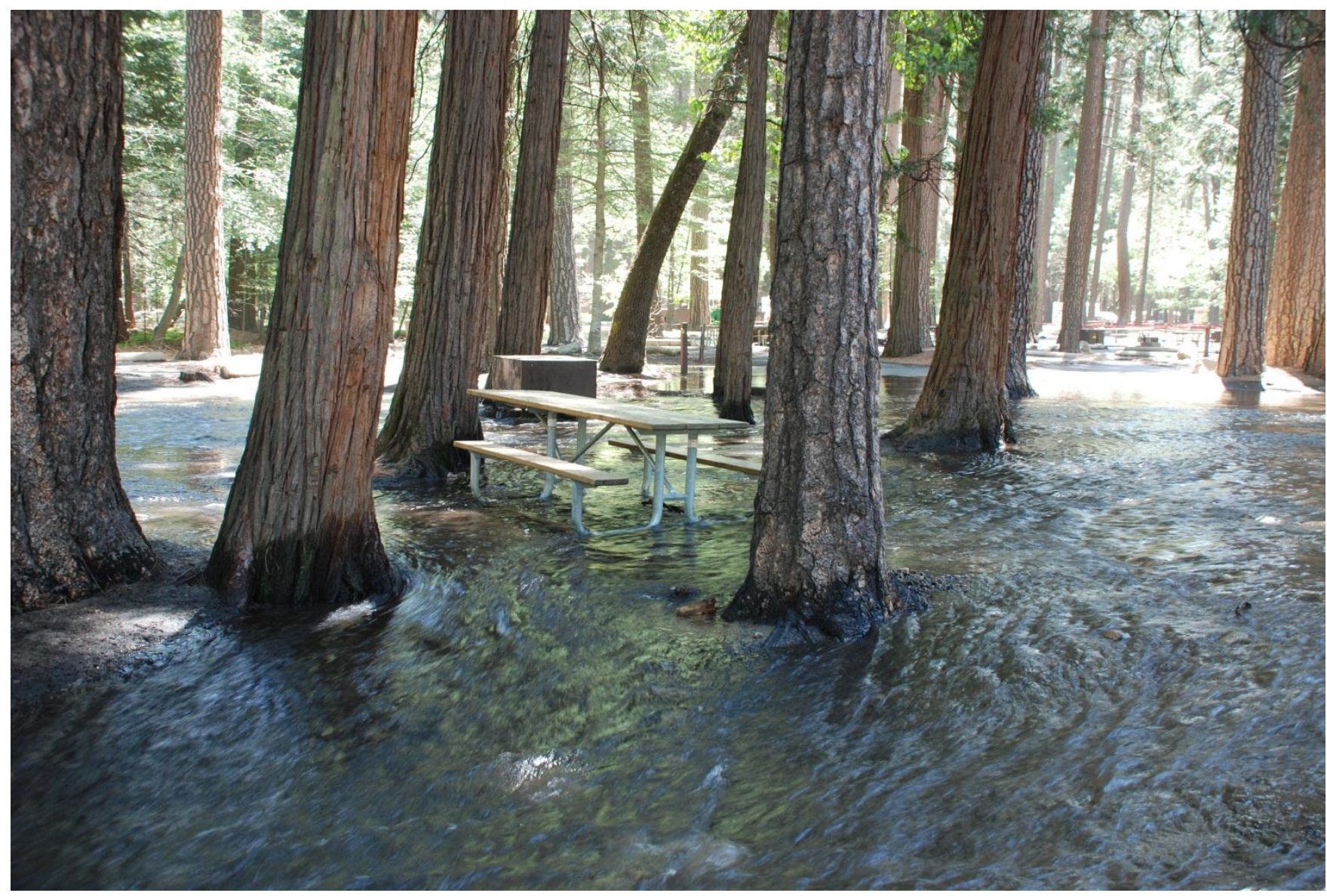

Figure 15. Photograph of water flowing several centimeters deep through North Pines Campground. Flow is right to left. Photograph by YNP personnel, taken 6/7/2010. 


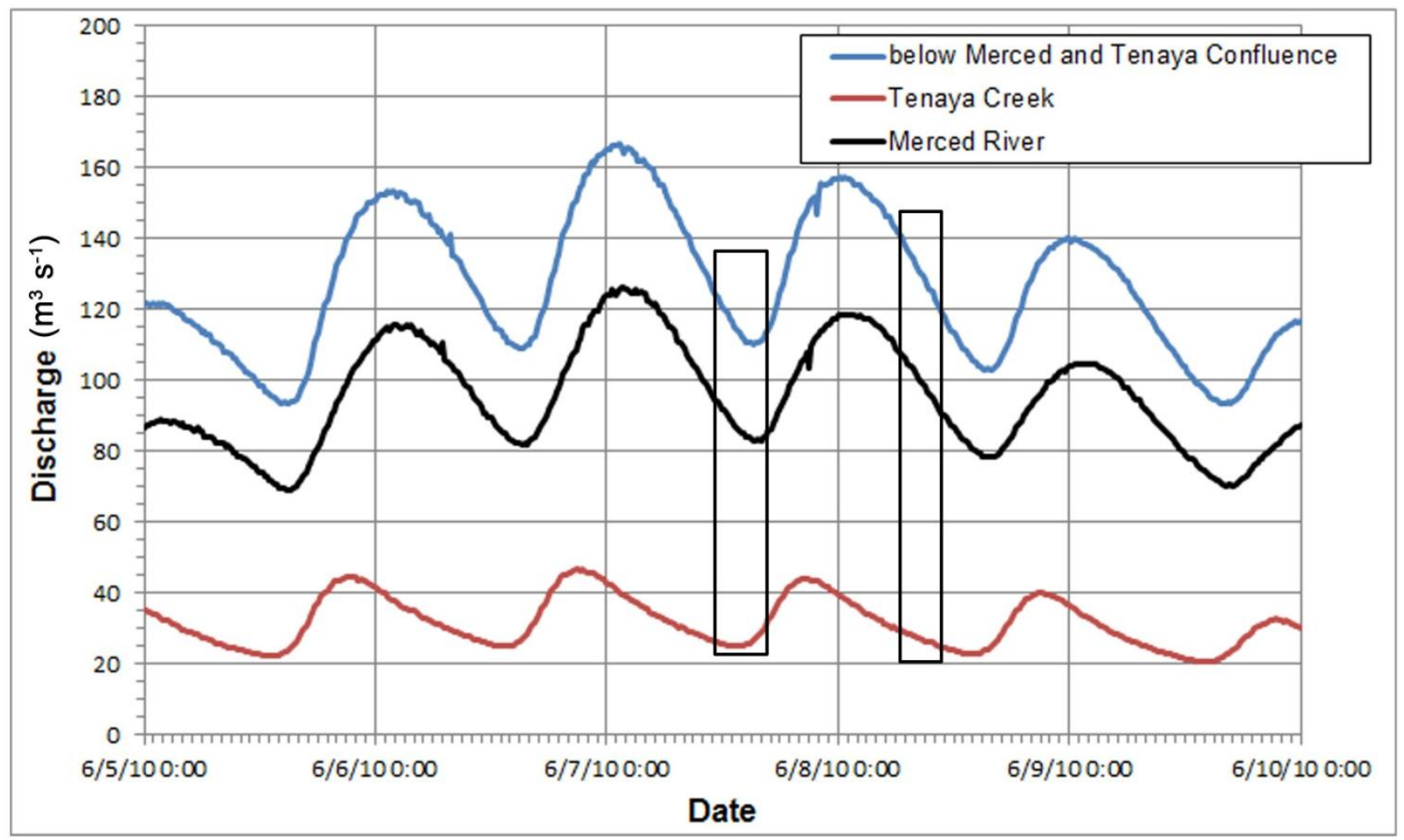

Figure 16. Graph of measured discharge for peak snowmelt runoff during WY2010 at Tenaya Creek (YNP gage), Merced River at Happy Isles (USGS gage 11264500) and the estimated discharge below the confluence of the Merced River and Tenaya Creek. The calculation of the flows below the confluence of Tenaya Creek and Merced River assumes a 15-minute travel-time from the YNP Tenaya Creek gage, and a 45-minute travel-time from the Merced River at Happy Isles USGS gage. The black boxes on the dates 6/7/2010 and 6/8/2010 are the periods over which stage measurements were performed by YNP throughout the study reach (see Table 5). Note that the diurnal flux was such that while the peak flow occurred on 6/7/2010, the stage measurements took place during the diurnal low-point during the day. The highest recorded stage measurements took place early on the morning of 6/8/2010 as the peak snowmelt flows during the night were receding. The midpoint of the flow during the highest stage measurements on 6/8/2010 (130.9 $\mathrm{m}^{3} \mathrm{~s}^{-1}$, approximately a 33-percent annual exceedance probability flood) was chosen as the calibration flow for the hydrodynamic model. 


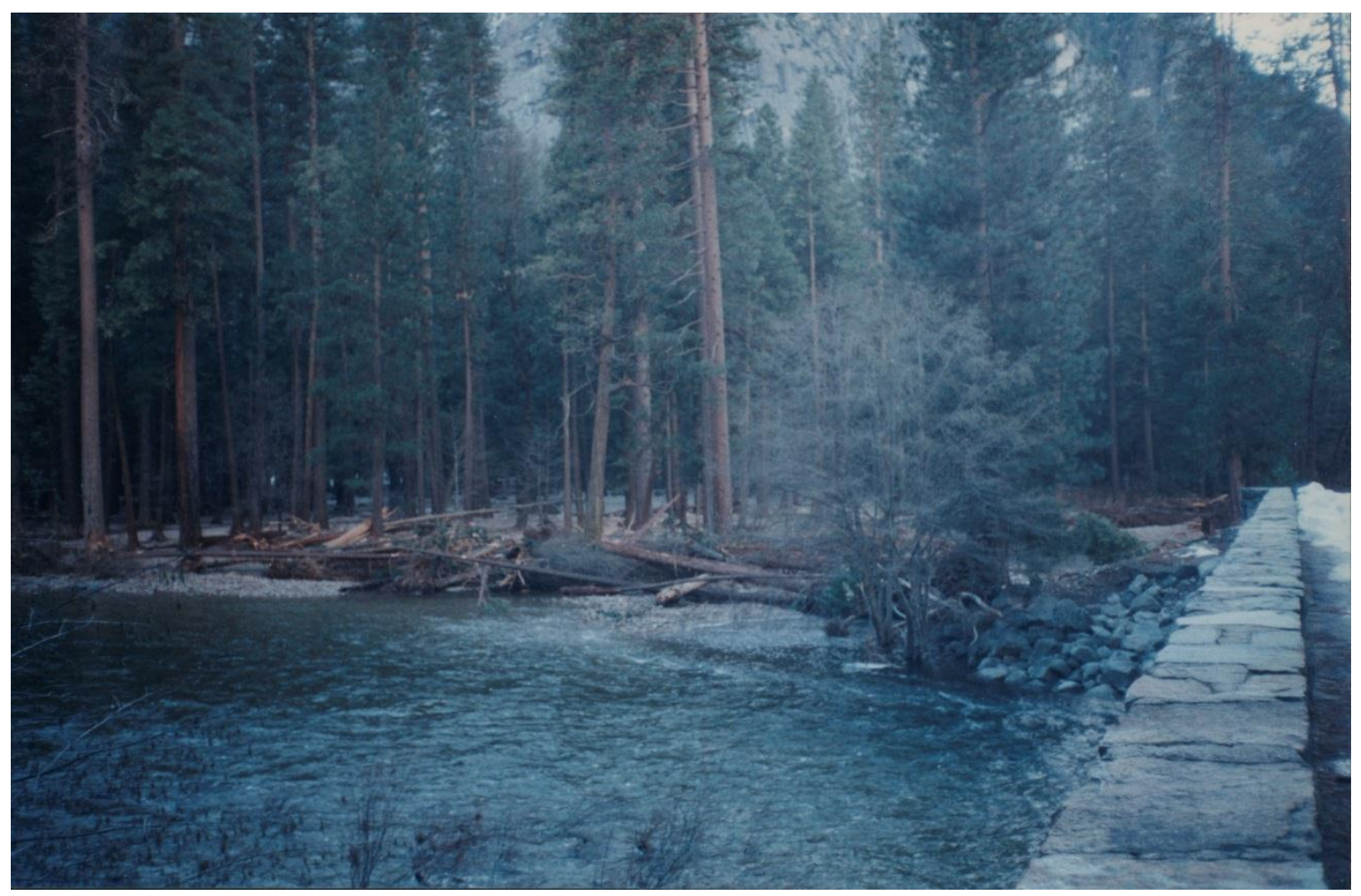

Figure 17. Photograph of the logjam at the head of the side channel cutoff between Sugar Pine and Ahwahnee Bridges immediately after it formed in January 1997. Photograph is taken from the upstream river right side of Sugar Pine Bridge looking across the Merced River towards the entrance to the side channel. Flow is left to right. Presently, riparian foliage makes it difficult to view the entire logjam and riparian trees have since grown into the jam. The diameter of some of the trees in the jam exceed $1 \mathrm{~m}$. Photograph taken by YNP personnel in January 1997, photograph courtesy of the Yosemite National Park Research Archive. 


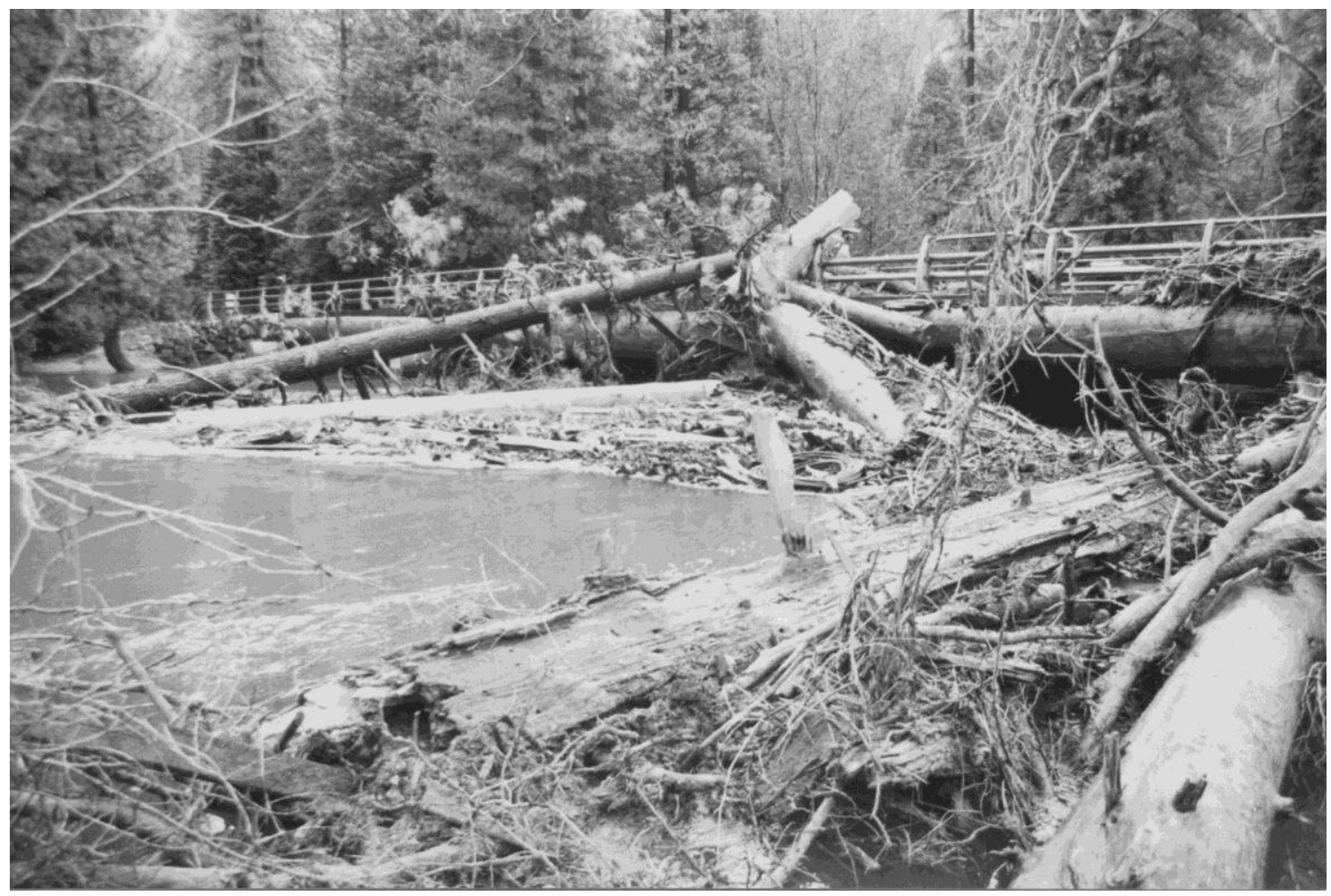

Figure 18. Photograph of large wood accumulated on El Capitan Crossover Bridge immediately following the 1997 flood. The large wood blocks most of the river right $1 / 3$ side of the bridge. Photograph is taken from the river right bank looking downstream towards the bridge. Photograph taken by YNP personnel in January 1997; photograph courtesy of the Yosemite National Park Research Archive. 


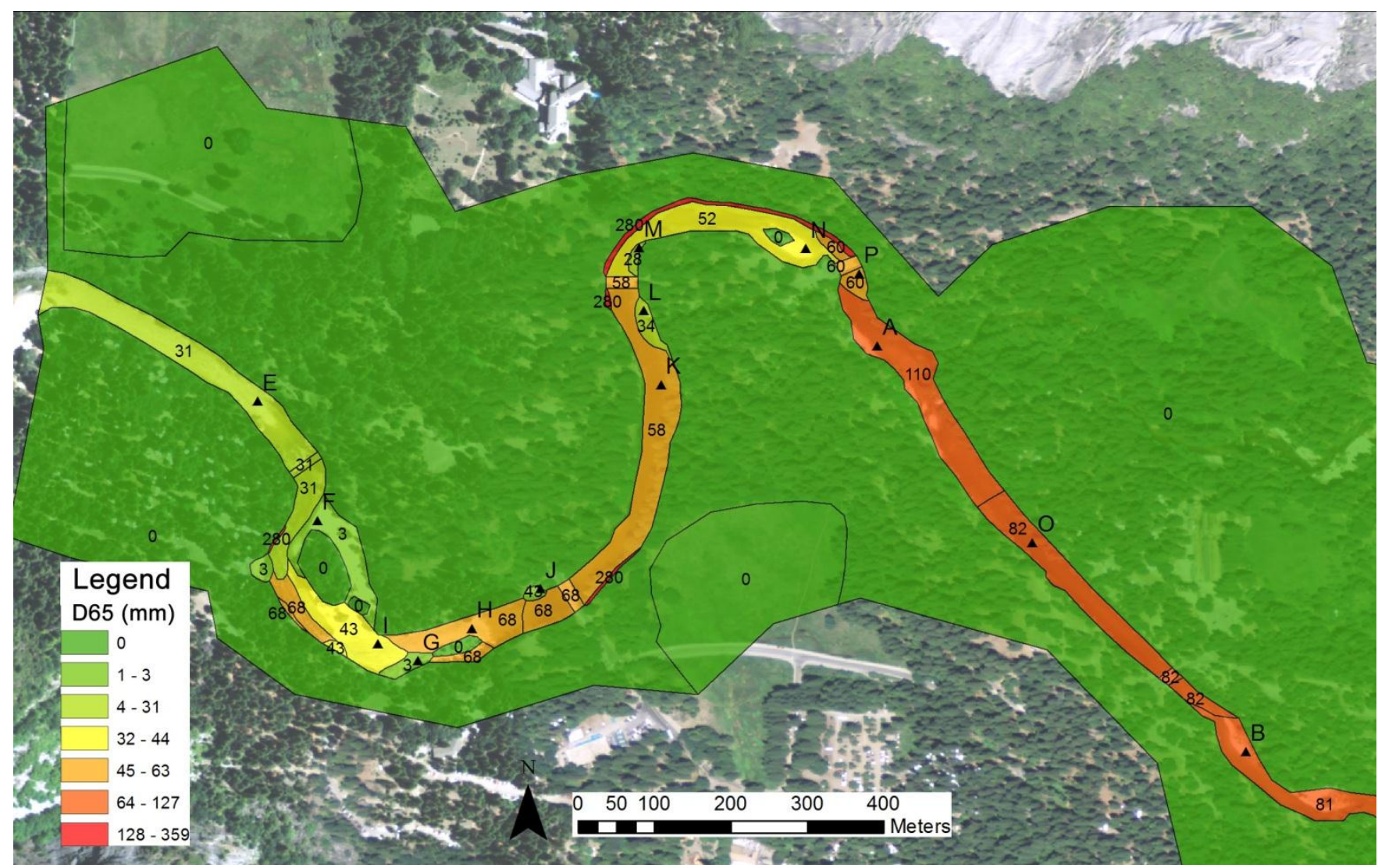

Figure 19. Map showing the location of Wolman pebble counts (black triangle, labeled with site name initial) and field-mapped geomorphic facies of D65 grain size. The D65 grain-size fraction was chosen for display because it was used in the approximation of roughness. D50 values of the facies can be found in figure 20 . The largest grains in the reach were riprap on the outside of banks, which were assigned a grain size $(280 \mathrm{~mm})$ on the basis of field observations and measurements of riprap in the ground-based LiDAR scans. Floodplain sites (marked in dark green and labeled with a zero for a placeholder) contain no grain-size information. 


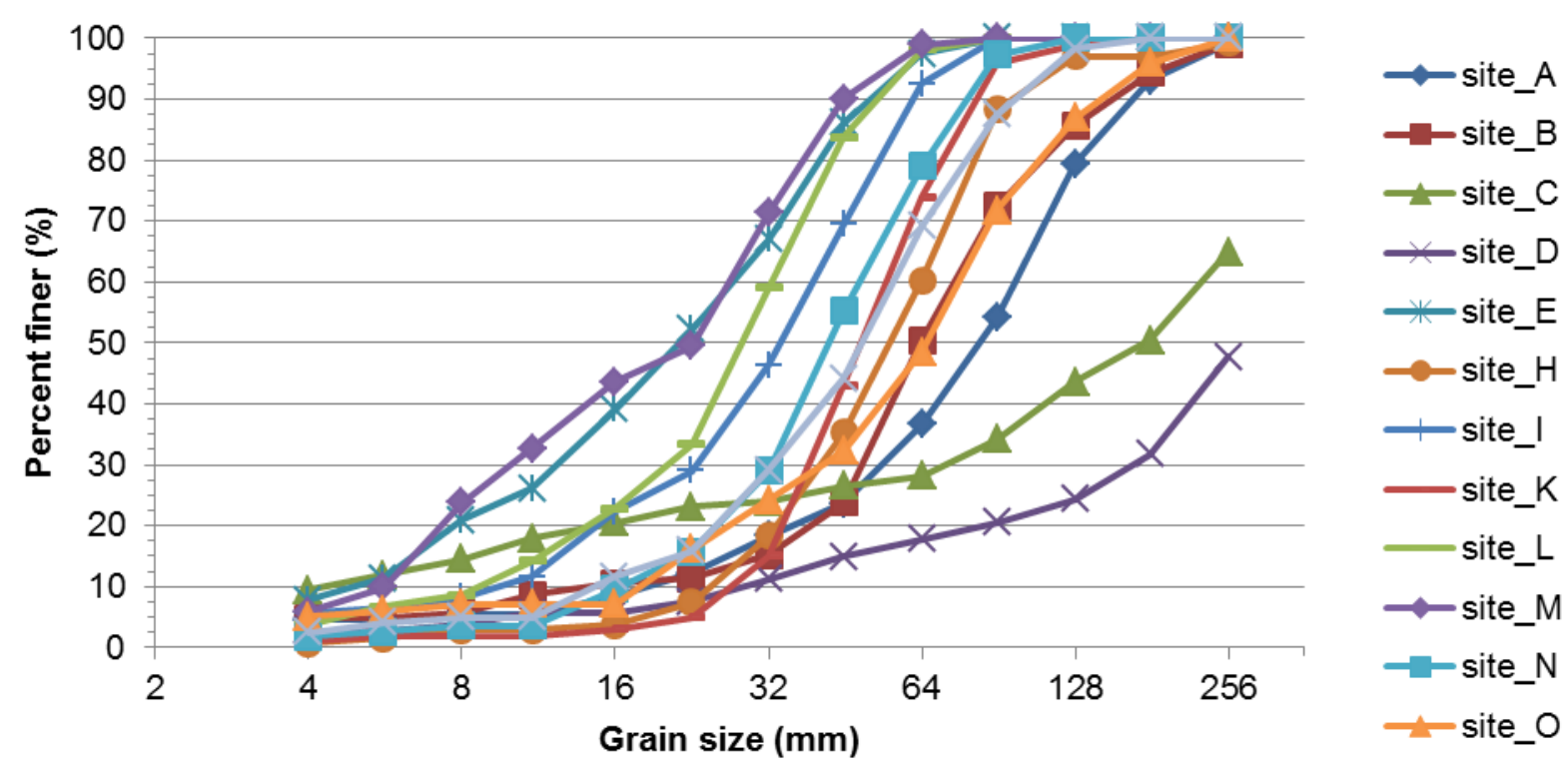

Figure 20. Graph of grain-size distributions from Wolman pebble counts for sampled locations in summer 2010. The locations of the pebble count sites can be found in Figure 19. Sites $C$ and $D$ are located upstream of the extent shown in Figure 19, and are located $20 \mathrm{~m}$ downstream of Happy Isles Bridge and $10 \mathrm{~m}$ upstream of the USGS Merced River at Happy Isles Bridge gage, respectively. 


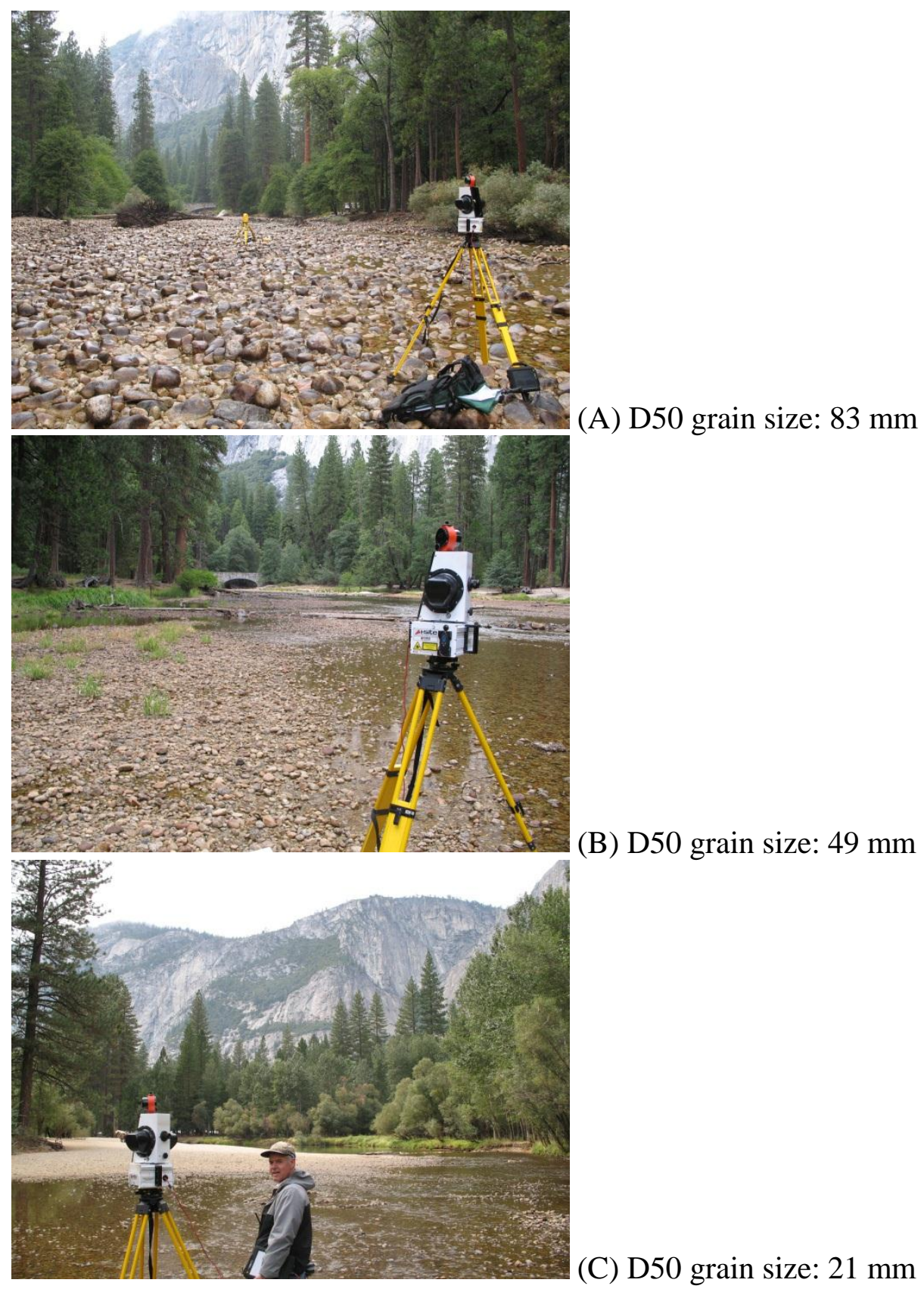

Figure 21. Photographs showing the variation of bed material size along the study reach during the ground-based LiDAR survey, September 20-24, 2007. Note the strong variation in grain size and the low flow that enabled excellent ground-based LiDAR coverage of a sizeable portion of the river bed. Photograph $(A)$ is taken near YNP study cross-section 13 (XS13 in fig. 8), on the Merced River just upstream of the Tenaya Creek confluence, view looking downstream towards Sugar Pine Bridge. Photograph $(B)$ is taken just downstream of where the side channel rejoins the main channel (near point $\mathrm{K}$ in fig. 19) downstream of Ahwahnee Bridge, looking upstream at the bridge. Photograph $(\mathrm{C})$ is taken in the lowest part of the study reach, near YNP study cross-section 29 (XS29 in fig. 8), looking downstream. All photographs taken by J.T. Minear. 


\section{Merced River Longitudinal Profile through East Yosemite Valley}

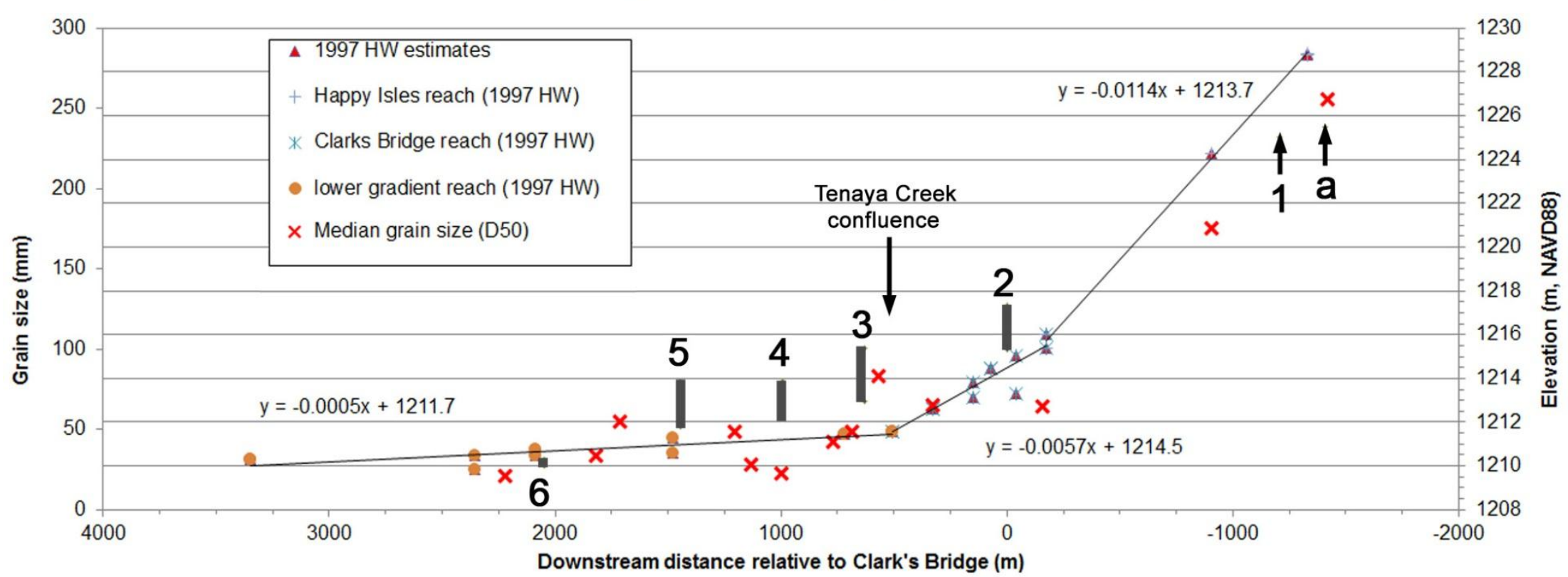

Figure 22. Longitudinal profile of the Merced River through eastern Yosemite Valley, showing the 1997 flood highwater marks and grain sizes measured from Wolman counts in WY2010. Grain size is shown on the left y-axis, all other points are shown on the right y-axis. The 1997 highwater (HW) marks are taken from a survey of water extents made following the January 1997 flood by YNP. The points on the longitudinal profile were interpolated between the river left and river right HW marks, and the linear regression slopes of the 1997 HW surface are shown for several sub-reaches. The locations of the USGS Merced River at Happy Isles gage (arrow "a"), and the Happy Isles Bridge (arrow "1") are marked along the longitudinal profile for reference, though the elevation is not accurate. The gray bars (numbers 2-6) demark the elevations for the top rail and top of the arch at the midpoint of the five bridges in the study reach, determined from the ground-based LiDAR measurements. The bridges from upstream to downstream are (same numbering as figure 4): Clark's (2), Sugar Pine (3), Ahwahnee (4), Stoneman (5), and Housekeeping (6). Housekeeping Bridge does not have a stone railing and here the thickness of the wooden deck was used; hence, the relatively small profile. Note the strong decrease in slope with distance downstream, decreasing from 0.011 slope near Happy Isles gage to 0.0005 slope near Housekeeping Bridge 


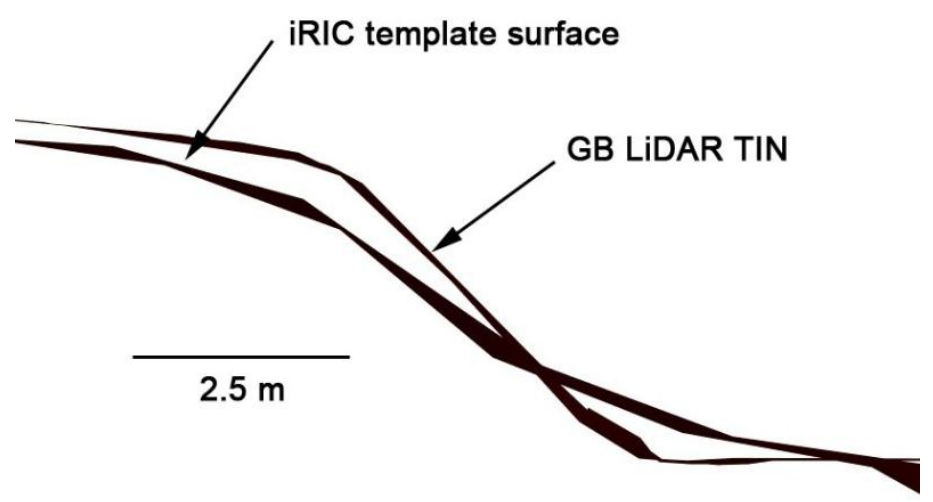

Figure 23. Cross-section view of an example of bank smoothing by the iRIC template compared to a triangulated irregular network (TIN) for a streambank downstream of Ahwahnee Bridge (view is looking upstream), using ground-based LiDAR topography data. Note the smoothing of the bank toe and crest with the iRIC template; a similar issue was observed within the aerial LiDAR data in the streambank areas (likely due to the filtering algorithm employed in the aerial LiDAR post-processing). To best preserve the bank features, the final topographic surface was created utilizing a combination of point datasets and represented as a TIN. 

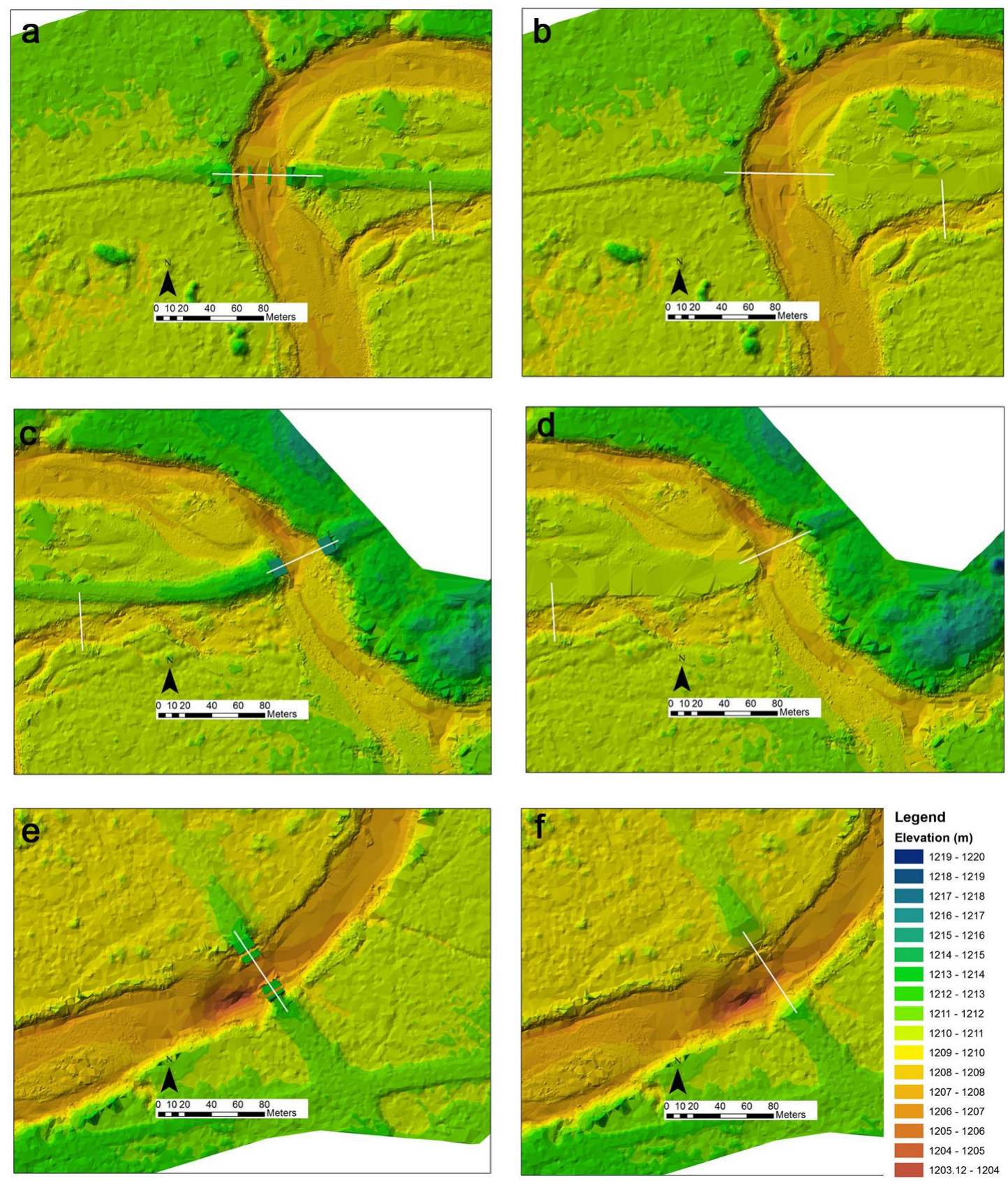

Figure 24. Topography used in the present-day and scenario FaSTMECH model runs. Topography in the left-hand panels $(a, c$, and $e)$ are present-day topography with all bridges present, whereas the right-hand panels $(b, d$, and f) are scenario conditions. The white lines in the panels are the evaluation cross-sections shown in Figure 5 , and all elevations correspond to the legend shown in the lower right. Panels (a) and (b) are at Ahwahnee Bridge with panel (a) showing present-day conditions, and panel (b) showing the Removed Ahwahnee and Sugar Pine Bridges and Berm scenario. Panels (c) and (d) are at Sugar Pine Bridge with panel (c) showing the present-day conditions, and panel (d) showing the Removed Ahwahnee and Sugar Pine Bridge and Berm scenario. Panels (e) and (f) are at Stoneman Bridge with panel (e) showing present-day conditions, and panel (f) showing the Removed Stoneman Bridge scenario. 


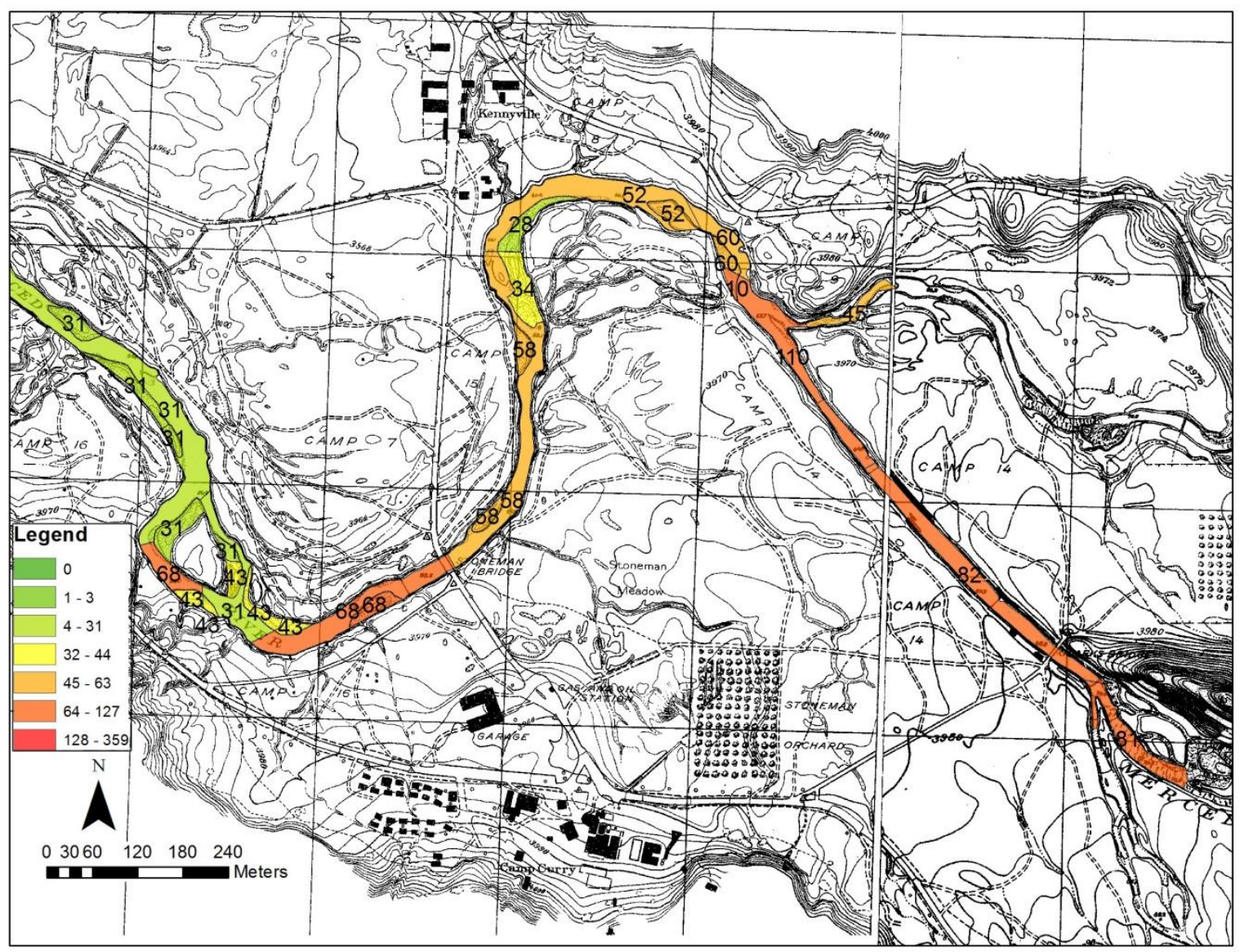

Figure 25. Map of 1919 USGS maps (published in 1921) and estimated historical D65 grain size (with legend in $\mathrm{mm}$ ). There are no measured historical grain size data available. To best represent the historical roughness in the study reach rather than utilizing a uniform roughness value, the historical D65 grain size was approximated by using the location and facies of current D65 grain-size values (figs. 19 and 20). Floodplain extents were removed from the above figure to illuminate the detailed topography contained in the 1919 USGS maps. 

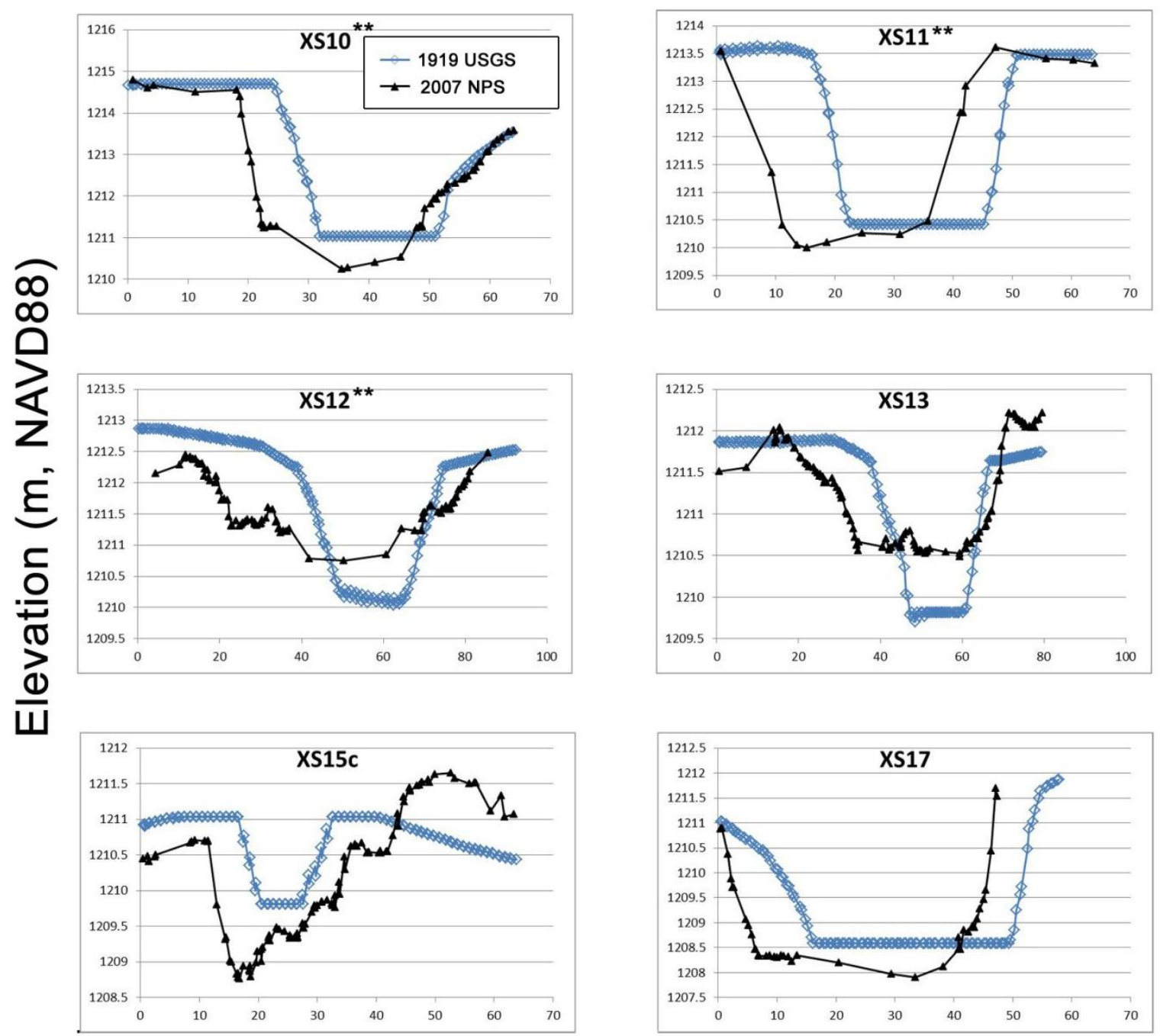

\section{Distance from left bank point $(m)^{*}$}

Figure 26. Comparison of cross-sections of the present-day-conditions surface used in FaSTMECH and the historical surface digital elevation model created from the 1919 USGS map. Note the primarily flat channel portion of the historical surface, which was due to the 2-foot contours of the historical topography data. In general, changes in the cross-sections trend towards widening of the stream channel, consistent with the findings of Madej and others (1991 and 1994), who used the same historical data at separate locations. Notes: * - Left bank point is the left bank benchmark (typically rebar) used by YNP in their repeat surveys; ** - these cross-sections are affected by the offset in the digitized map discussed in the text - it is likely that the shift in channel position observable in the cross-sections is due to the digitization offset rather than channel migration. 

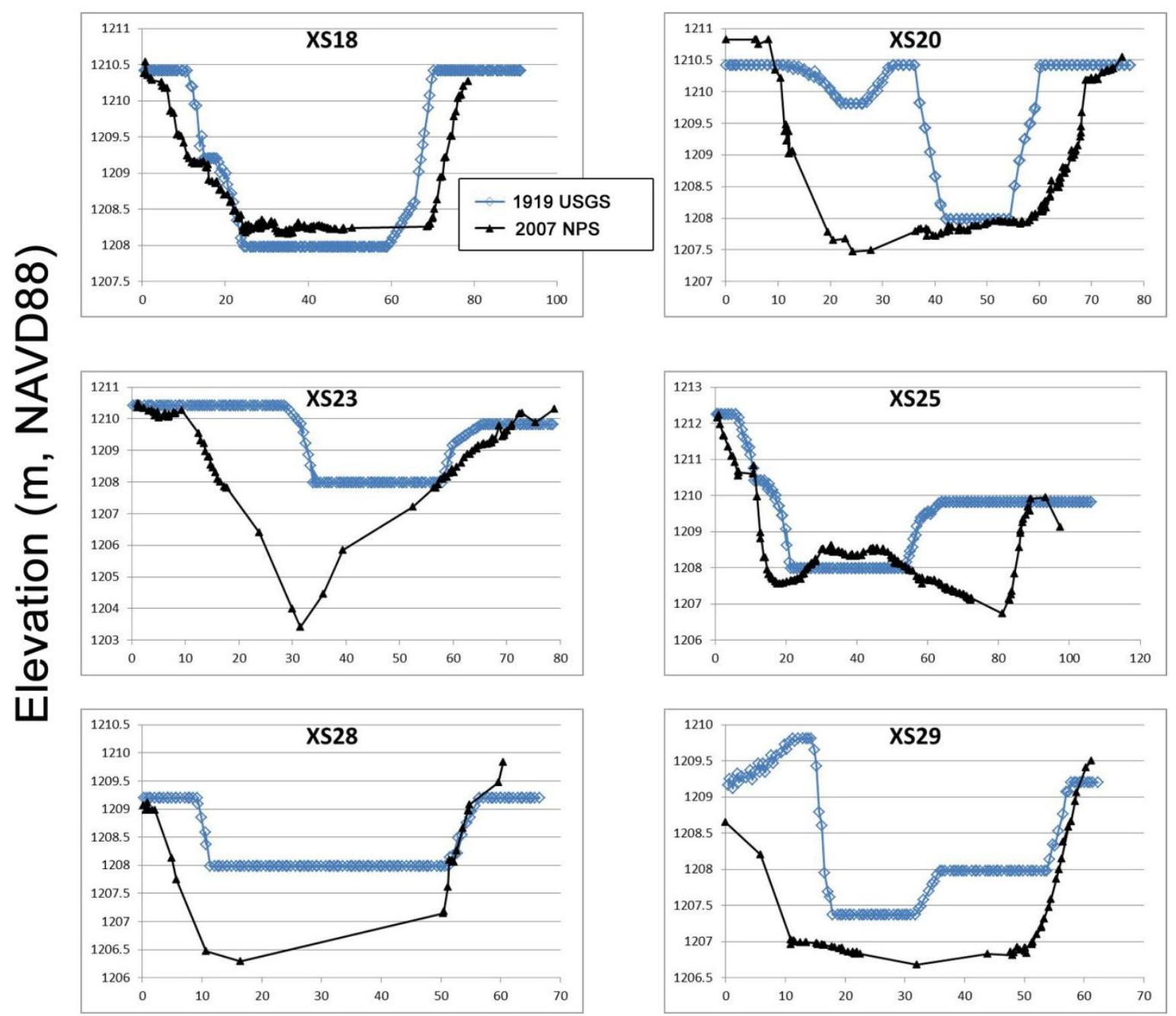

\section{Distance from left bank point $(\mathrm{m})^{\star}$}

Figure 26. (Continued) Comparison of cross-sections of the present-day-conditions surface used in FaSTMECH and the historical surface digital elevation model created from the 1919 USGS map. Note the primarily flat channel portion of the historical surface, which was due to the 2-foot contours of the historical topography data. In general, changes in the cross-sections trend towards widening of the stream channel, consistent with the findings of Madej and others (1991 and 1994), who used the same historical data at separate locations. Notes: * - Left bank point is the left bank benchmark (typically rebar) used by YNP in their repeat surveys; ** - these cross-sections are affected by the offset in the digitized map discussed in the text - it is likely that the shift in channel position observable in the cross-sections is due to the digitization offset rather than channel migration. 


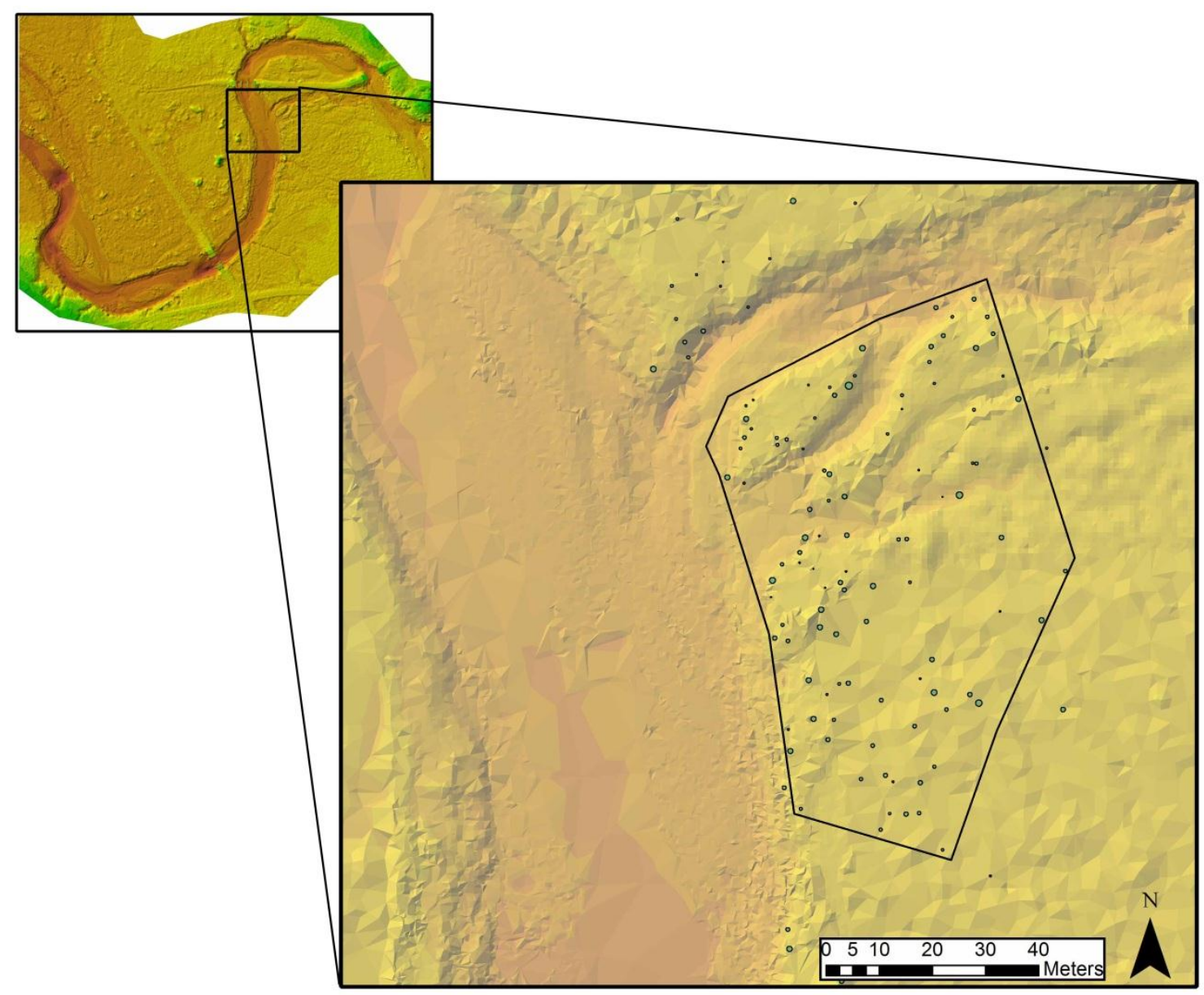

Figure 27. Map of the location of the stem plot of trees used in the estimate of floodplain roughness from large diameter trees. 


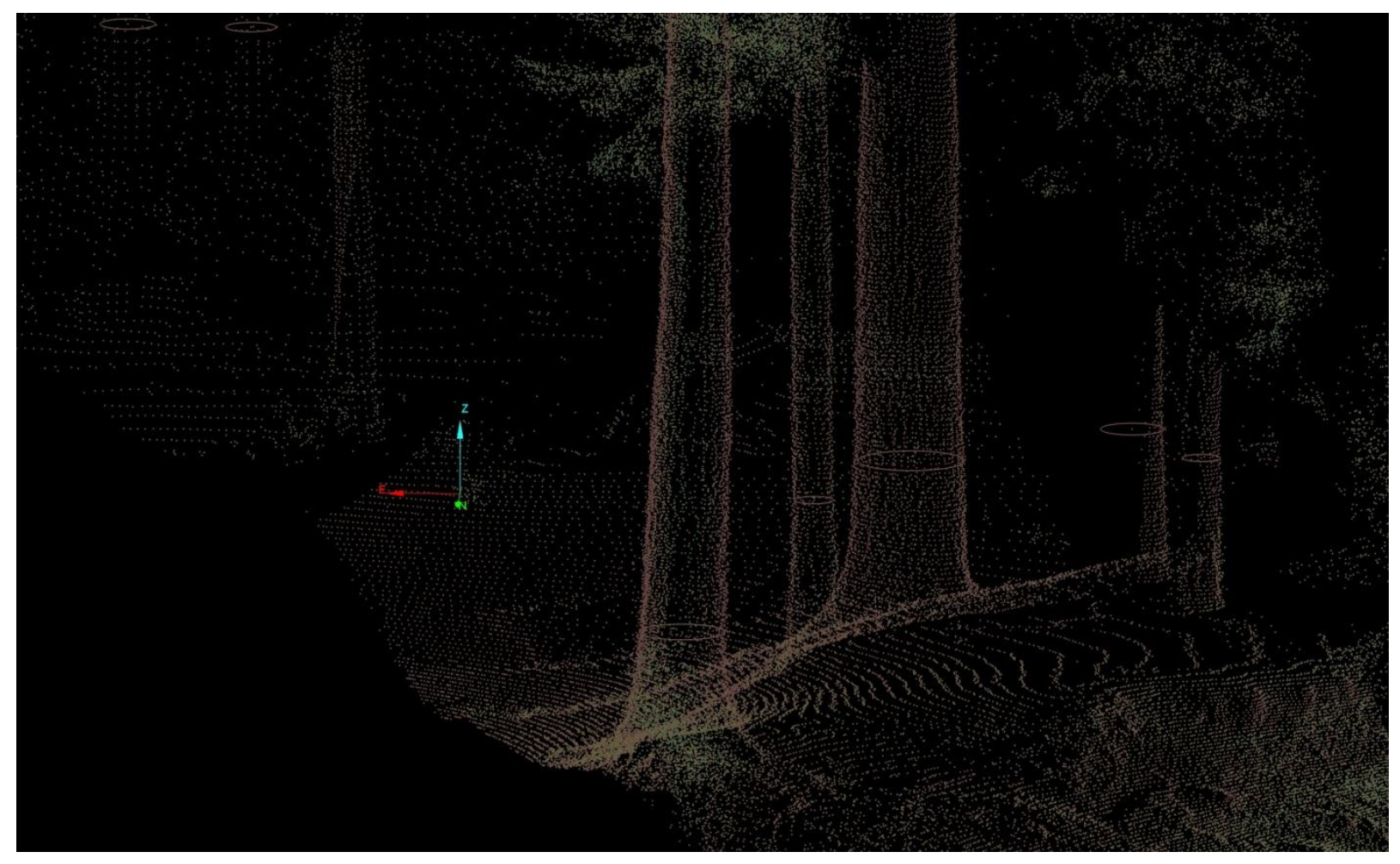

Figure 28. Oblique view of ground-based LiDAR point data at the site used to estimate floodplain roughness. The trees have been fitted with horizontal circles to estimate diameter at breast height.

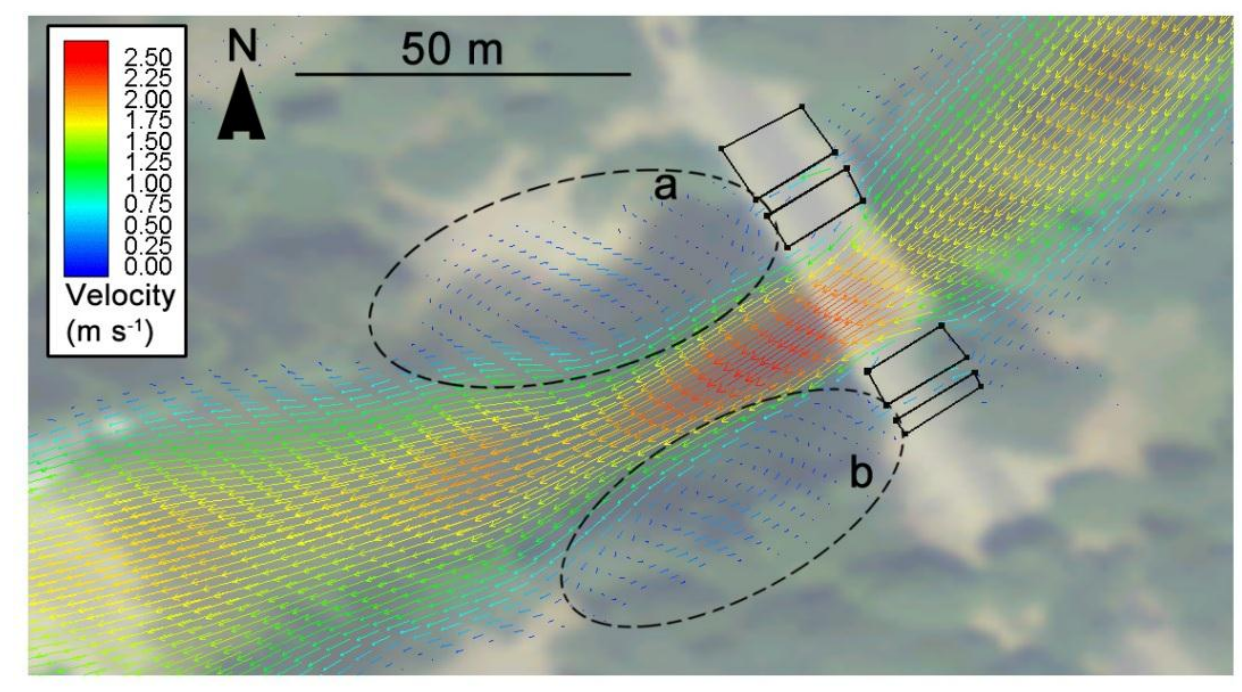

Figure 29. View of FaSTMECH velocity vector outputs downstream of Stoneman Bridge for the evaluation flow of $130.9 \mathrm{~m}^{3} \mathrm{~s}^{-1}$ using the $1 \mathrm{~m} \mathrm{x} 1 \mathrm{~m}$ grid. The number of vectors displayed has been reduced to one-fifth to better highlight the flow direction. The well-defined eddy circulation patterns are enclosed in dashed circles, 'a' and ' $b$ '. 

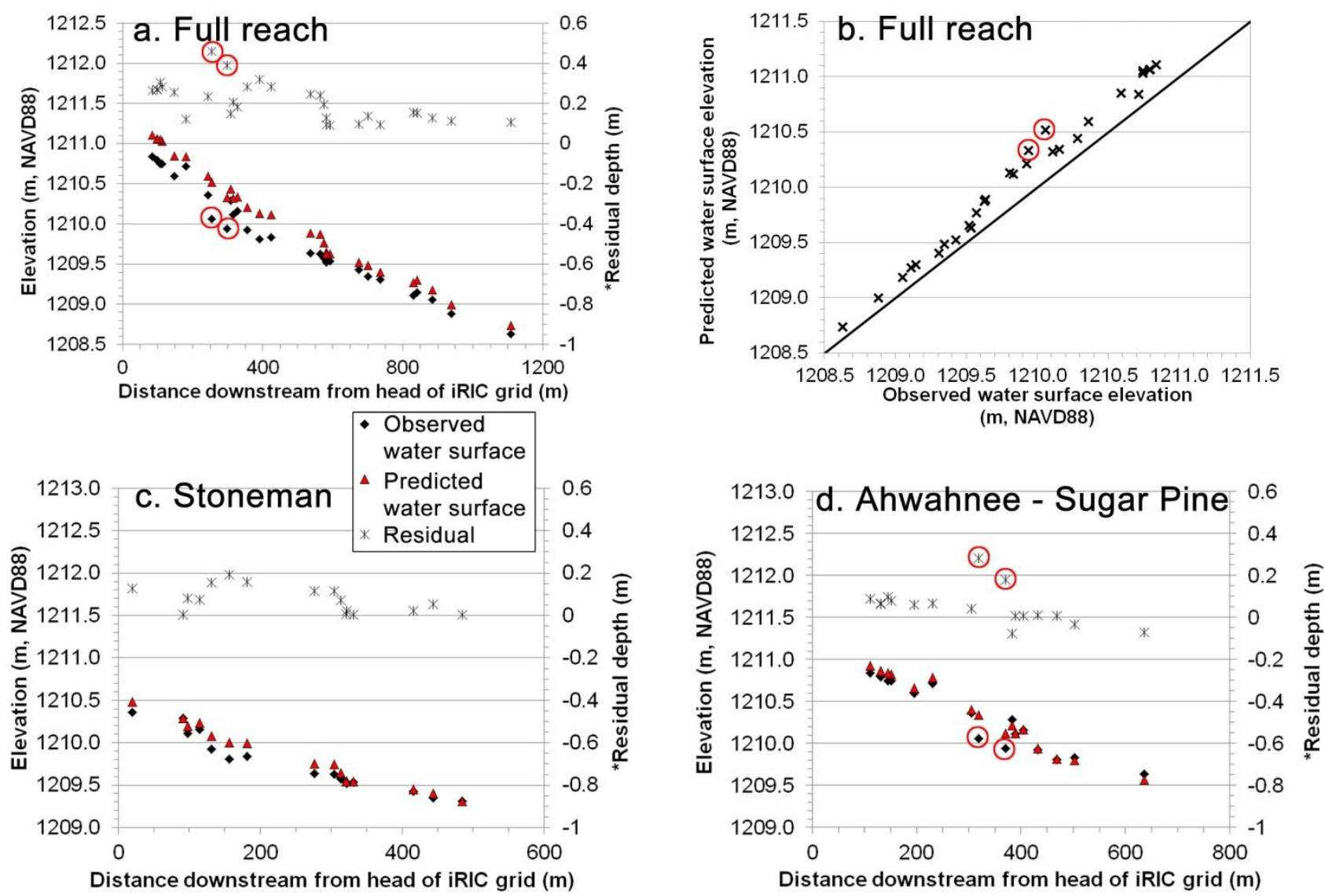

Figure 30. Predicted versus observed water-surface elevations for FaSTMECH evaluation runs at $130.9 \mathrm{~m}^{3} \mathrm{~s}^{-1}$ compared to measured water-surface elevations from June 8,2010 , for the $1.85 \mathrm{~m} \times 2.4 \mathrm{~m}$ grid $(\mathrm{a}, \mathrm{b})$, and the $1 \mathrm{~m} \times 1 \mathrm{~m}$ grids centered on Stoneman Bridge (c) and Ahwahnee / Sugar Pine Bridges (d). Two of the most strongly deviating observed water-surface measurements (more than $0.3 \mathrm{~m}$ from nearby observed points, circled in red) were from the side channel (at XS15C and XS15D in fig. 8). 

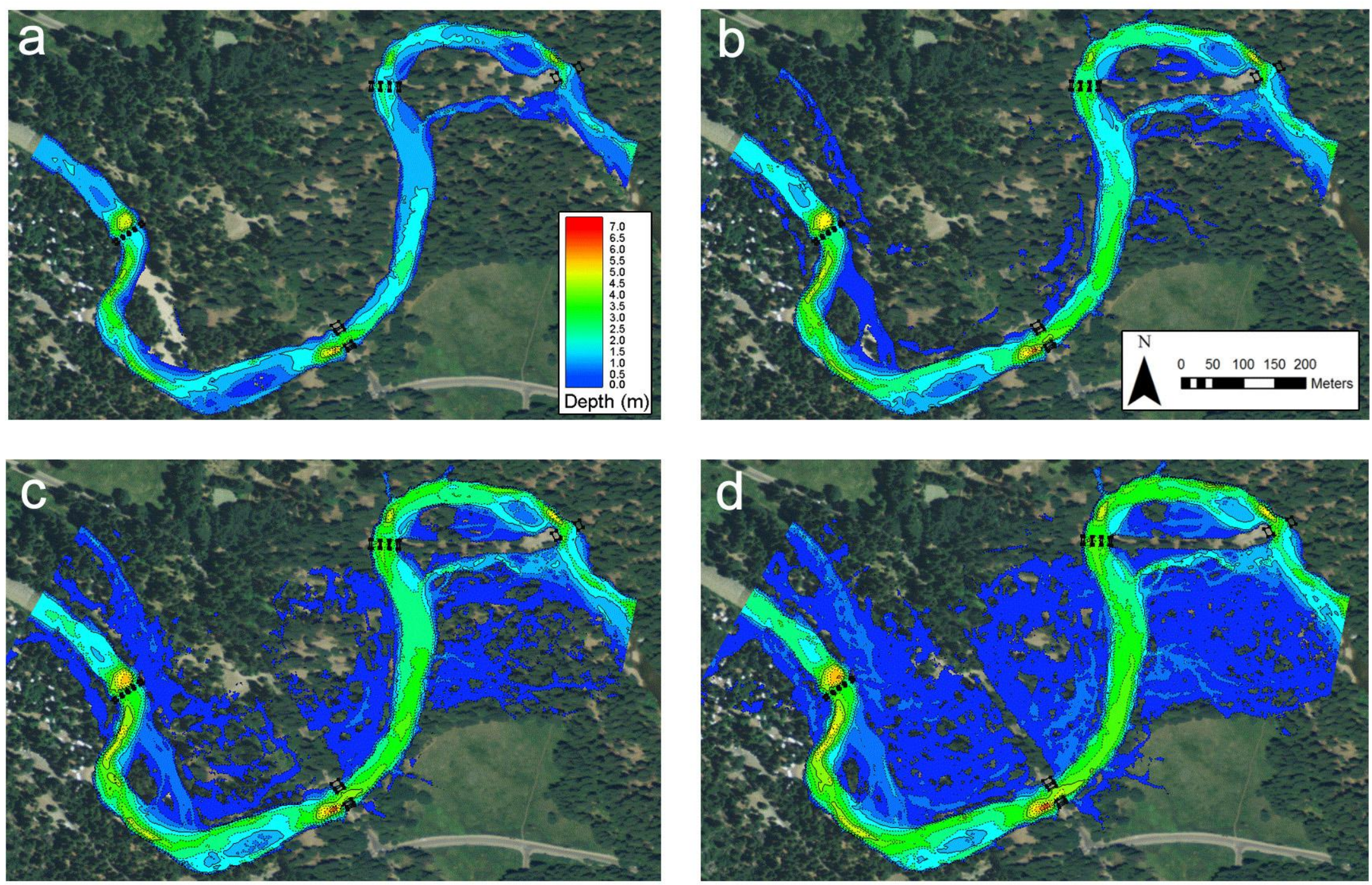

Figure 31. FaSTMECH model results of depth for the present-day full-reach model runs for 50-, 20-, 10-, and 5-percent annual exceedance probability floods (panels a, b, c, and d, respectively). The dotted contour lines are every $0.5 \mathrm{~m}$ in depth and solid lines are every $2 \mathrm{~m}$. 

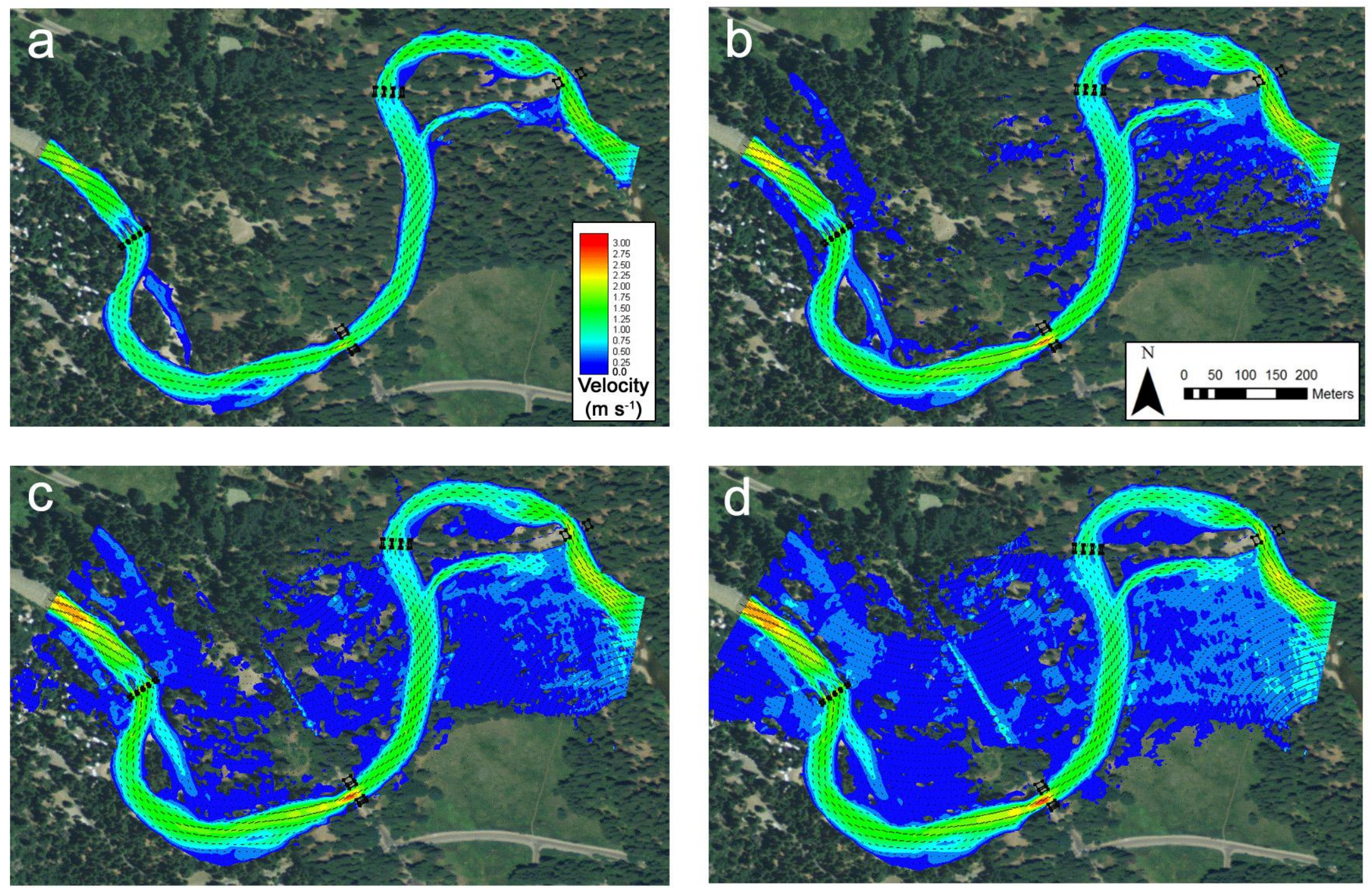

Figure 32. FaSTMECH model results of velocity for the present-day full-reach runs for 50-, 20-, 10-, and 5-percent annual exceedance probability floods (panels a, b, c, and d, respectively). The black lines are velocity vectors showing the relative strength and direction of flow. 


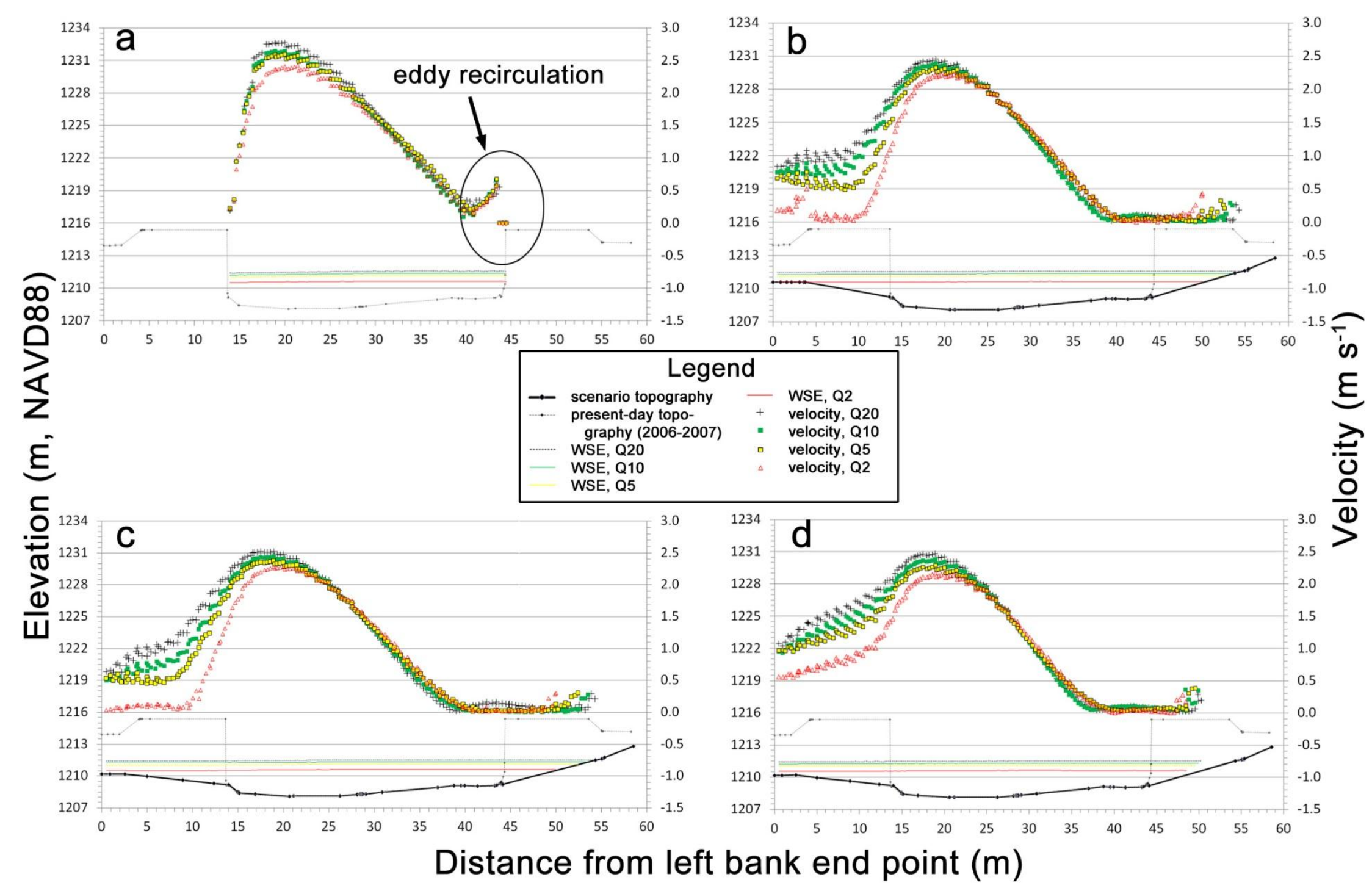

Figure 33. Cross-section view of FaSTMECH model results for present-day conditions and the scenarios evaluated at Sugar Pine Bridge (see fig. 5 for a location of the evaluation cross-section). Panel (a) is present-day conditions; panel (b) is Removed Sugar Pine Bridge scenario; panel (c) is the Removed Sugar Pine Bridge and Berm scenario; panel (d) is the Removed Sugar Pine and Ahwahnee Bridges and Berm scenario. In the legend, 'WSE' stands for water-surface elevation, and the various flows are denoted by their return interval. For example, 'Q20' is the 20-year return interval flow. The Q20, Q10, Q5, and Q2 floods are equivalent to the 5-, 10-, 20-, and 50-percent annual exceendance probability floods, respectively. 


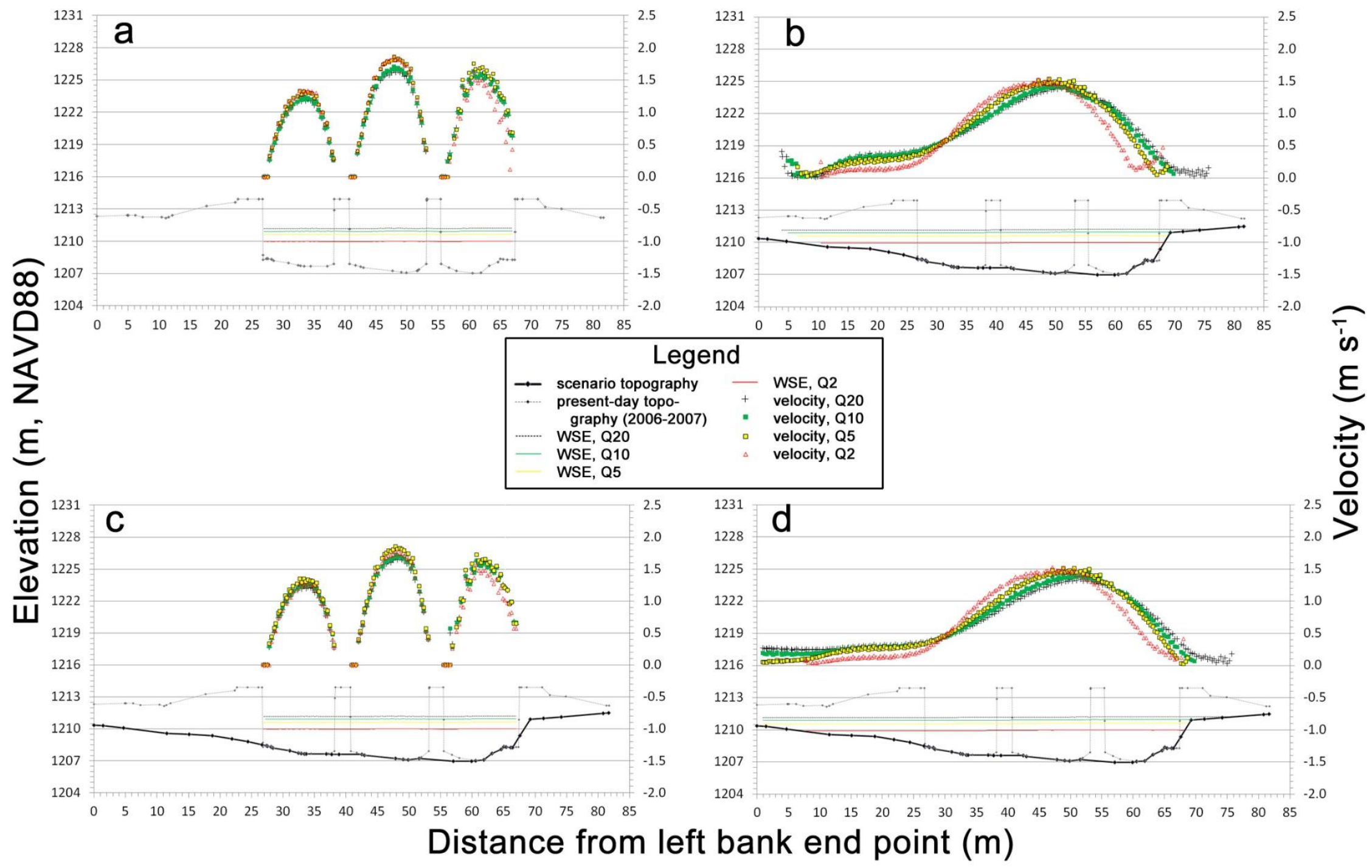

Figure 34. Cross-section view of FaSTMECH model velocity and depth results for present-day conditions and the scenarios evaluated at Ahwahnee Bridge (see fig. 5 for a location of the evaluation cross-section). Panel (a) is present-day conditions; panel (b) is Removed Ahwahnee Bridge scenario; panel (c) is the Removed Sugar Pine Bridge scenario; panel (d) is the Removed Sugar Pine and Ahwahnee Bridges and Berm scenario. The Removed Sugar Pine Bridge and Berm scenario is indistinguishable from panel (c). In the legend, 'WSE' stands for water-surface elevation, and the various flows are denoted by their return interval. For example, 'Q20' is the 20-year return interval flow. The Q20, Q10, Q5, and Q2 floods are equivalent to the 5-, 10-, 20-, and 50-percent annual exceendance probability floods, respectively. 


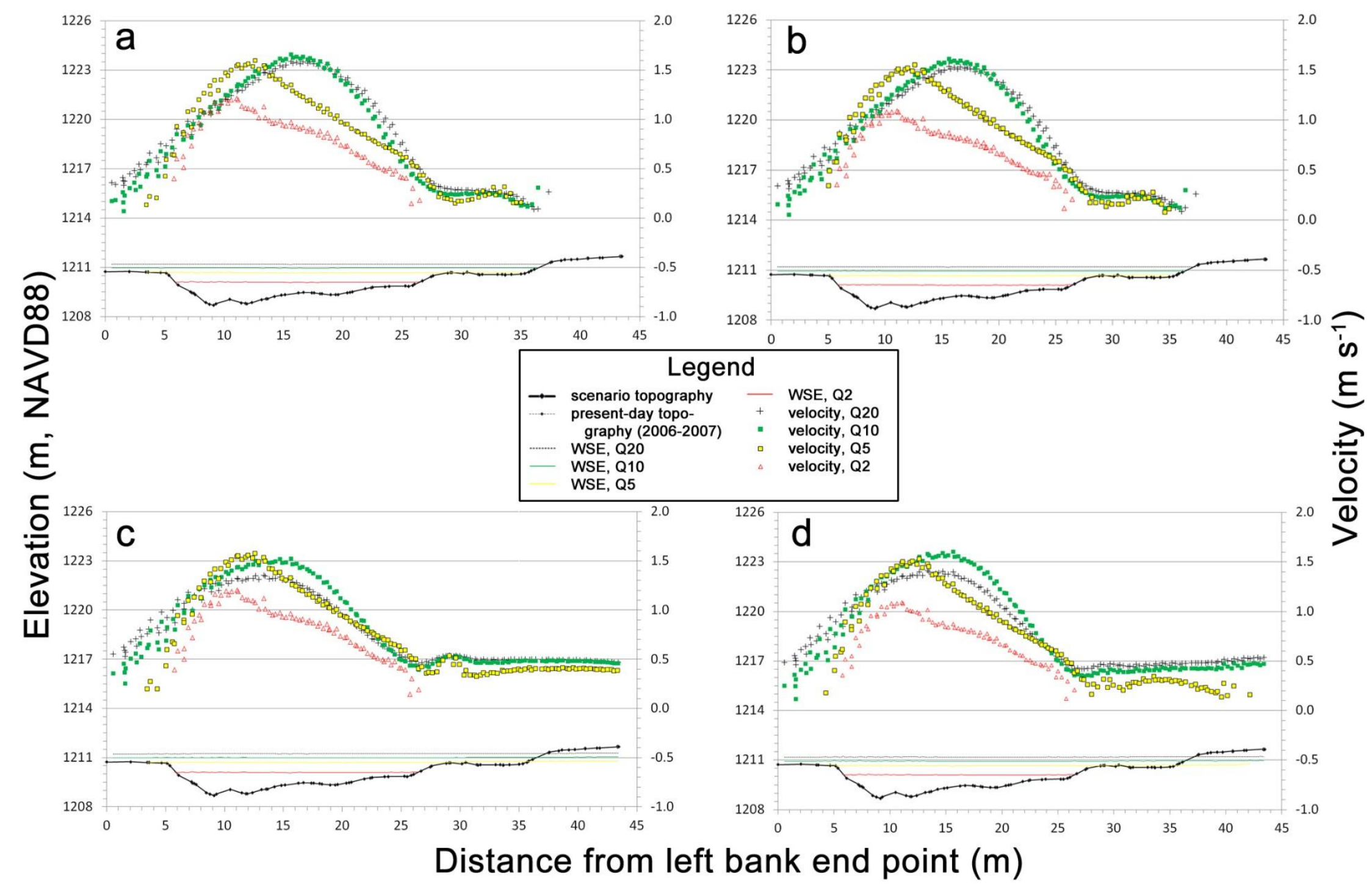

Figure 35. Cross-section view of FaSTMECH model velocity and depth results for present-day conditions and the scenarios evaluated at the side channel (see fig. 5 for a location of the evaluation cross-section). Panel 'a' is present-day conditions; panel 'b' is the Removed Sugar Pine Bridge scenario; panel 'c' is the Removed Sugar Pine Bridge and Berm scenario; panel 'd' is the Removed Sugar Pine and Ahwahnee Bridges and Berm scenario. The Removed Ahwahnee Bridge is not included because it is indistinguishable from panel 'a'. In the legend, 'WSE' stands for water-surface elevation, and the various flows are denoted by their return interval. For example, 'Q20' is the 20-year return interval flow. The Q20, Q10, Q5, and Q2 floods are equivalent to the 5-, 10-, 20-, and 50-percent annual exceendance probability floods, respectively. 

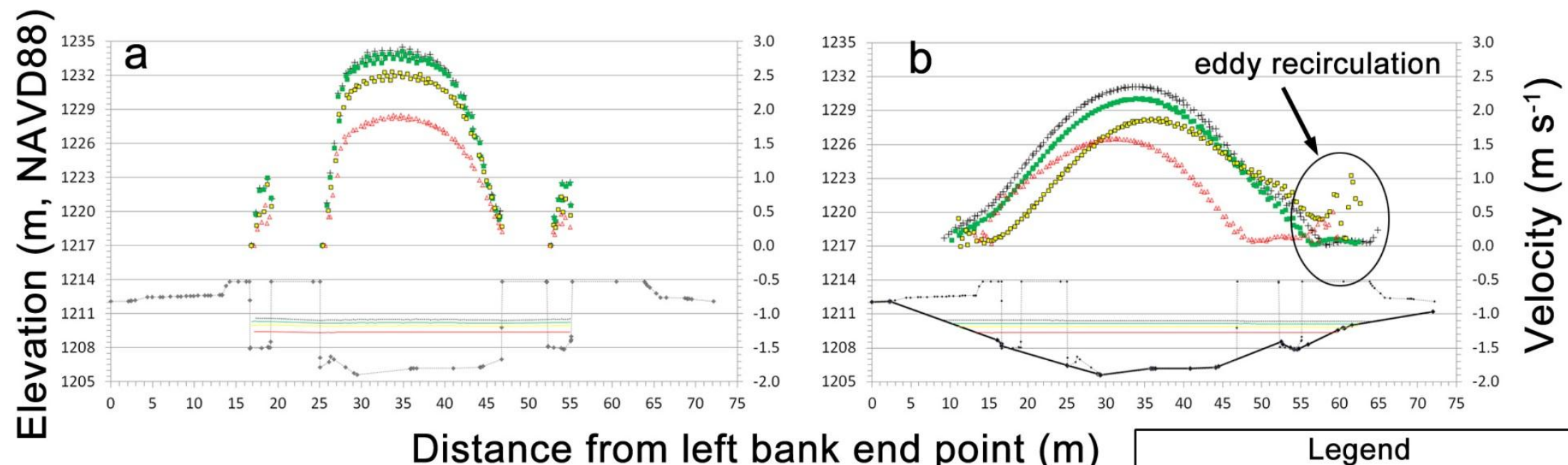

Distance from left bank end point $(\mathrm{m})$

\begin{tabular}{|c|c|c|c|}
\hline \multicolumn{4}{|c|}{ Legend } \\
\hline$\rightarrow$ & $\begin{array}{l}\text { scenario topography } \\
\text { present-day topo- }\end{array}$ & . & $\begin{array}{l}\text { WSE, Q2 } \\
\text { velocity, Q20 }\end{array}$ \\
\hline ......... & WSE, Q20 & 口 & velocity, Q5 \\
\hline & WSE, Q10 & $\triangle$ & velocity, Q2 \\
\hline & WSE, Q5 & & \\
\hline
\end{tabular}

Figure 36. Cross-section view of FaSTMECH model velocity and depth results for present-day conditions and the Removed Stoneman Bridge scenario evaluated at Stoneman Bridge (see fig. 5 for a location of the evaluation cross-section). Panel 'a' is present-day conditions; panel 'b' is the Removed Stoneman Bridge scenario. All other bridge removal scenarios are not distinguishable from panel 'a'. In the legend, 'WSE' stands for water-surface elevation, and the various flows are denoted by their return interval. For example, 'Q20' is the 20-year return interval flow. The Q20, Q10, Q5, and Q2 floods are equivalent to the 5-, 10-, 20-, and 50-percent annual exceendance probability floods, respectively. 


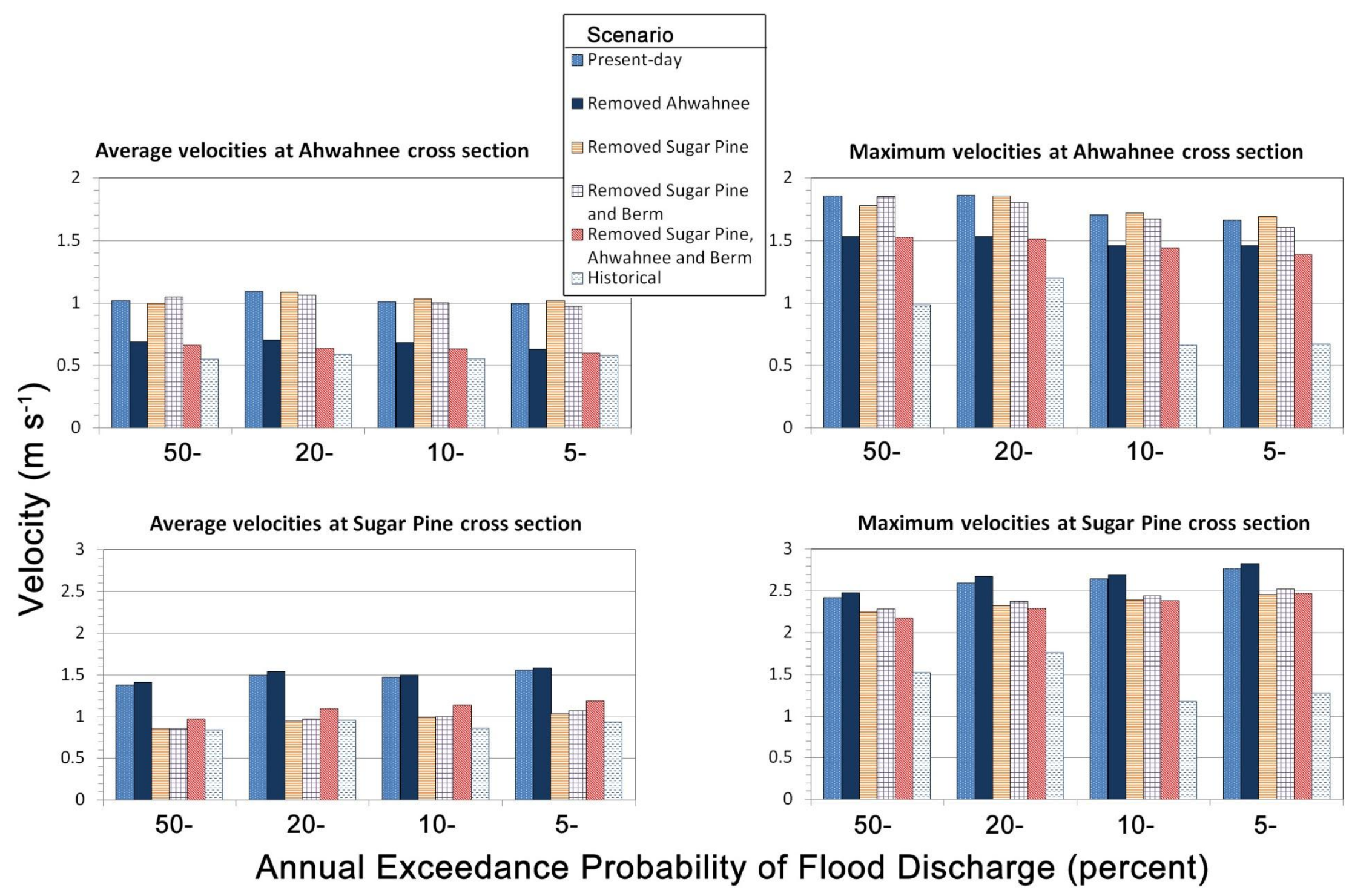

Figure 37. Summary graphs of FaSTMECH velocity results for the modeled scenarios evaluated at Ahwahnee and Sugar Pine cross-sections (located in fig. 5). The two graphs on the left are average velocities; the graphs on the right are maximum velocities. Note that the graphs have the same $y$-axis and that for comparison the results also include the cross-sections not directly influenced by a particular scenario (results from Ahwahnee cross-section are included in the results for the scenario, Removed Sugar Pine Bridge). The 'Historical' scenario was created from a series of digitized 1919 USGS maps and other inputs that are explained in the text. 


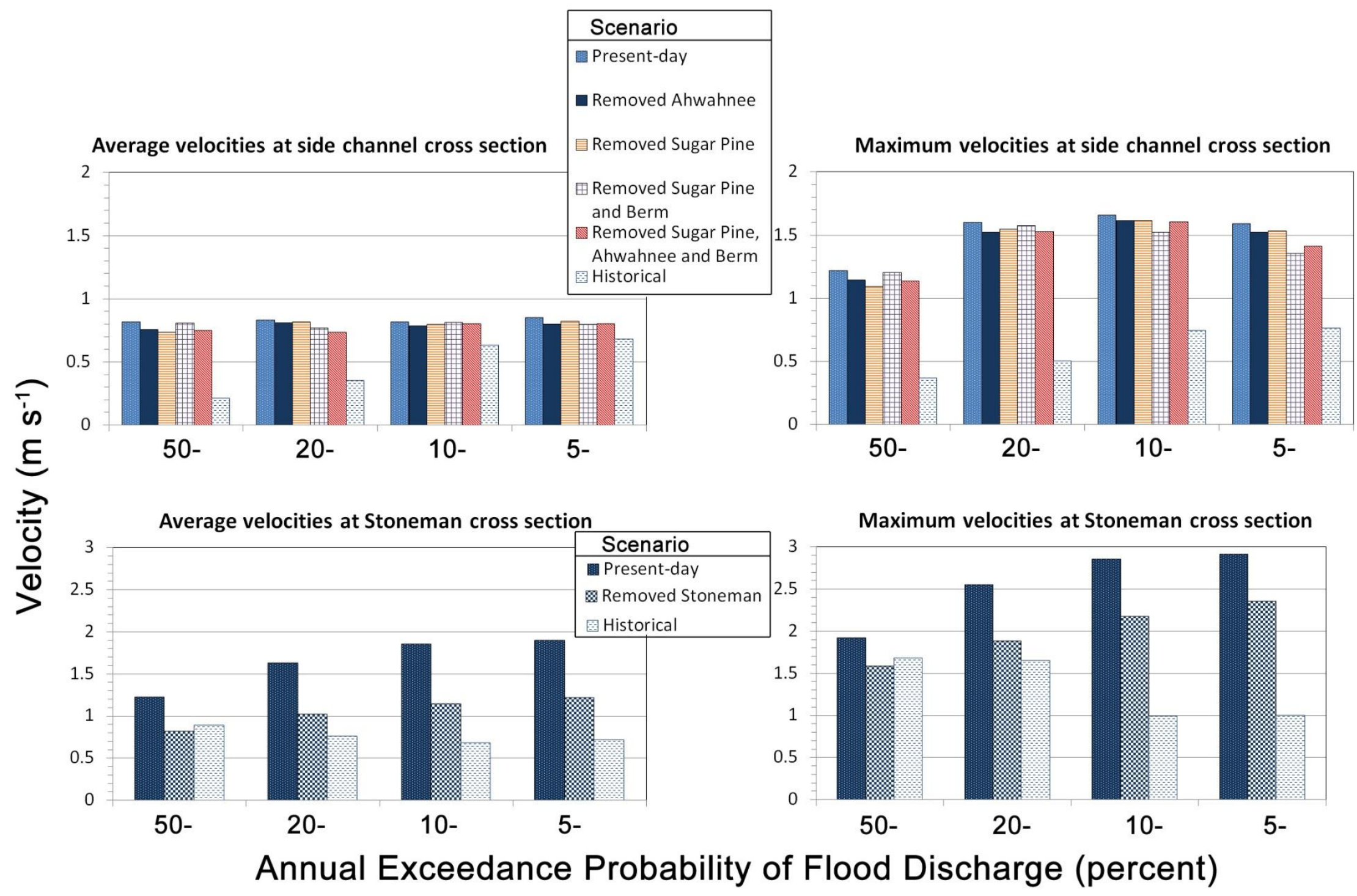

Figure 38. Summary graphs of FaSTMECH velocity results for the side channel and Stoneman cross-sections (see fig. 5 for the cross-section location). The 'Historical' scenario was created from a series of digitized 1919 USGS maps and other inputs that are explained in the text. 

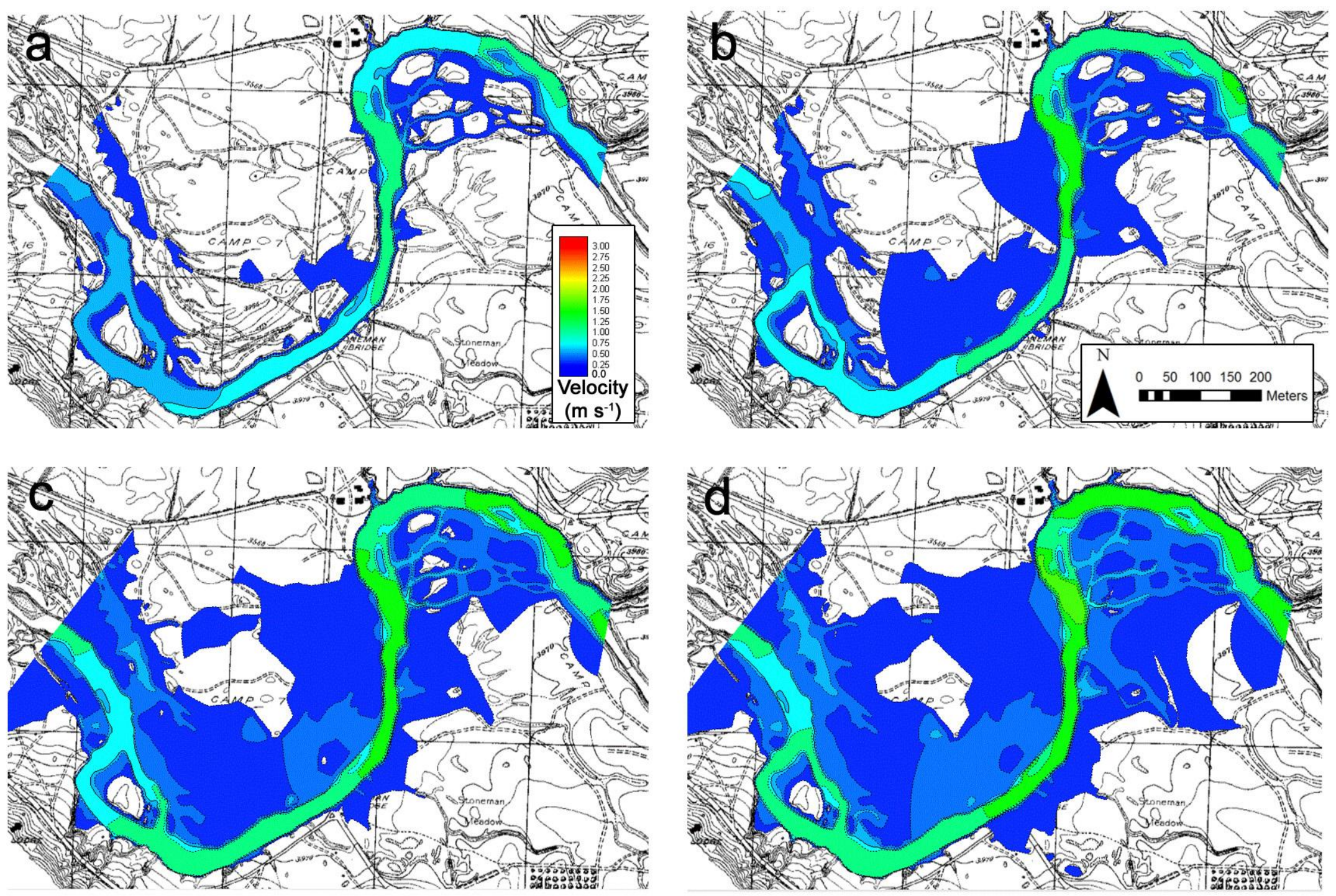

Figure 39. Maps of FaSTMECH model results of depth for historical conditions in the study reach for 50-, 20-, 10-, and 5-percent annual exceedance probability floods (panels a, b, c, and d, respectively). The dotted contour lines are every $0.5 \mathrm{~m}$ in depth and the solid lines are every $2 \mathrm{~m}$. 

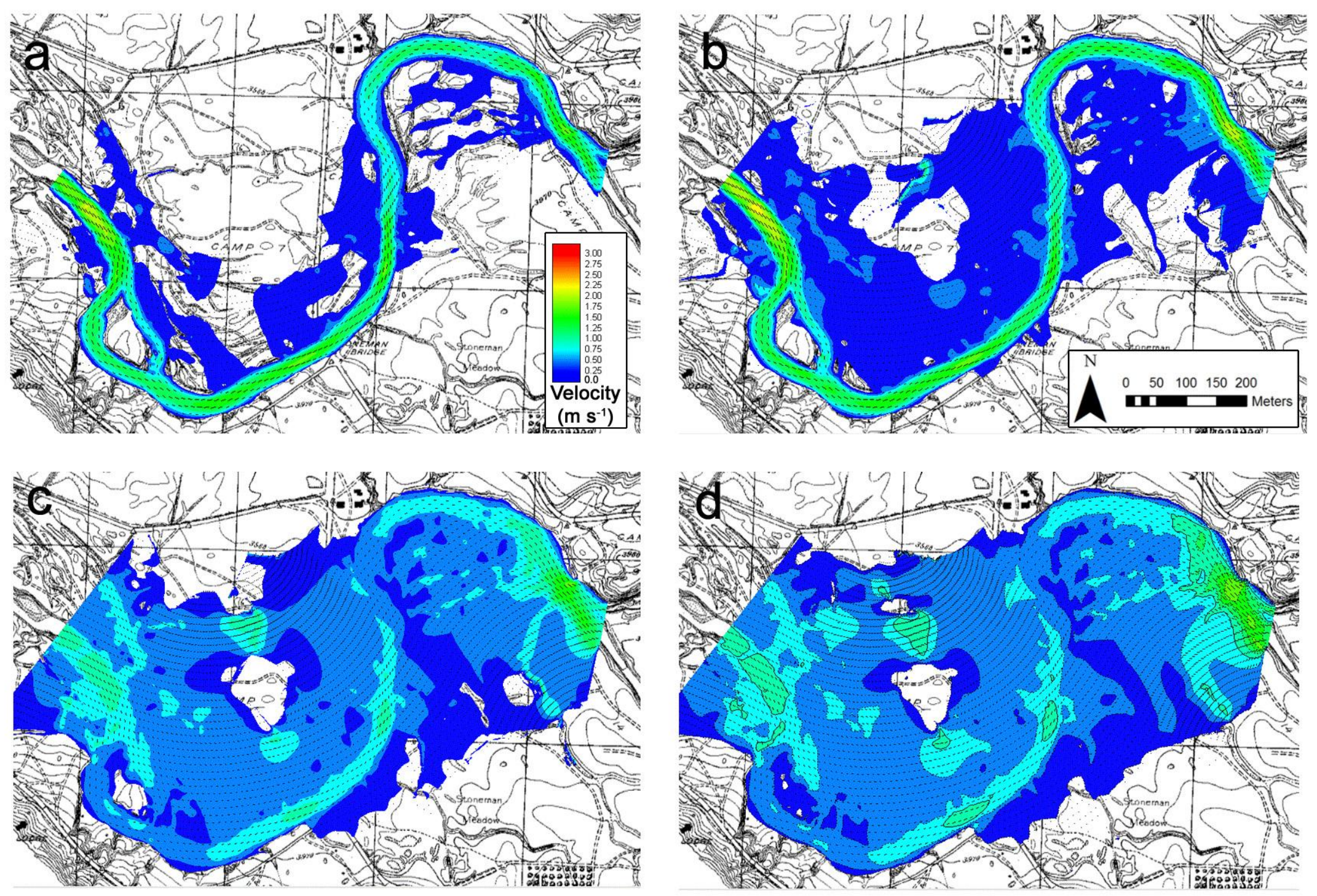

Figure 40. Maps of FaSTMECH model results of velocity for historical conditions in the study reach for 50-, 20-, 10-, and 5-percent annual exceedance probability floods (panels a, b, c, and d, respectively). The black lines are velocity vectors showing the relative flow strength and direction. 


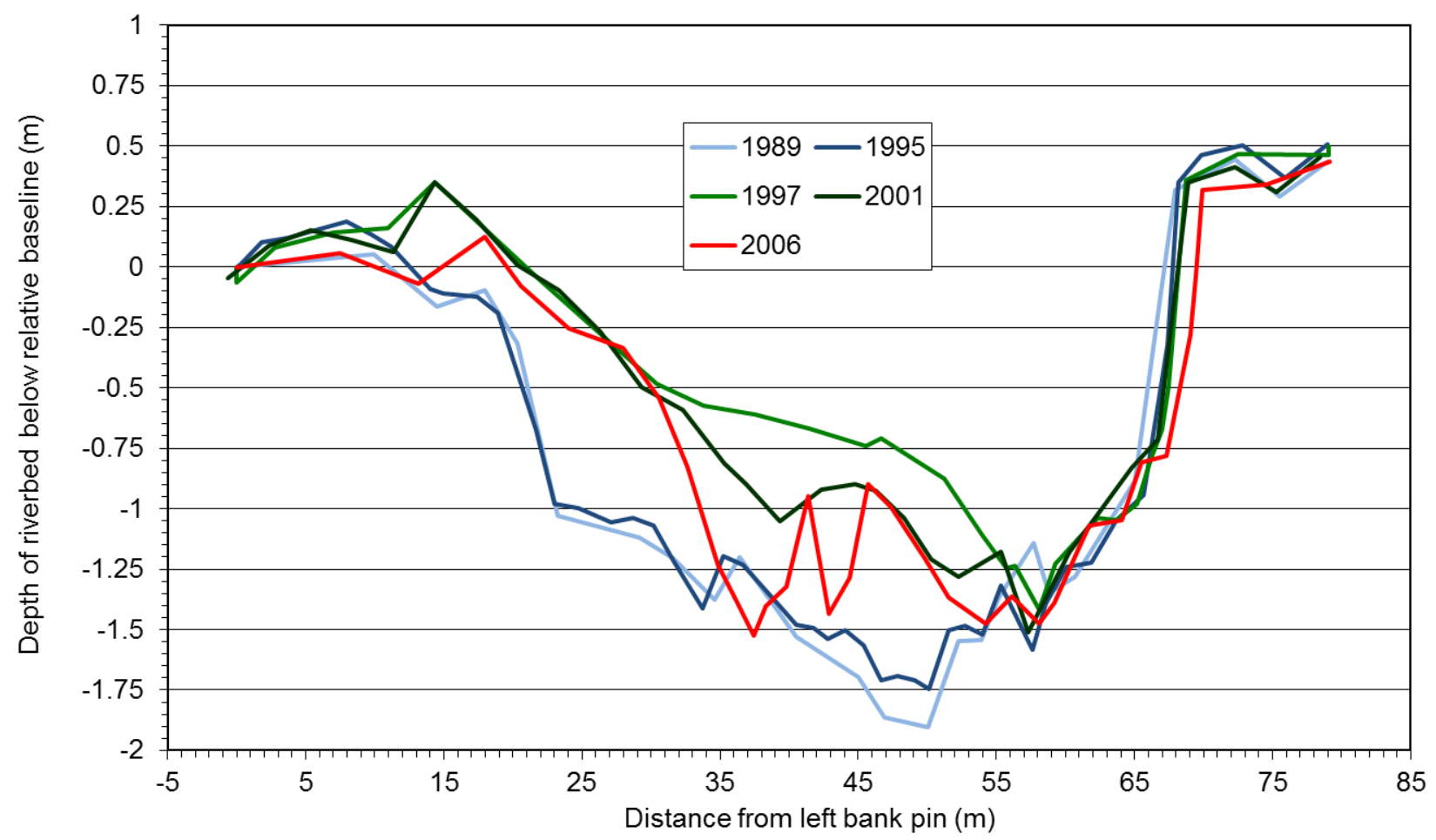

Figure 41. Cross-section view of YNP study cross-section XS 13 (see fig. 8 for location). Note the decrease in channel capacity from 1989 to 1997 , followed by an increase in channel capacity from 1997 to 2006. Channel capacity is tabulated in table 7.

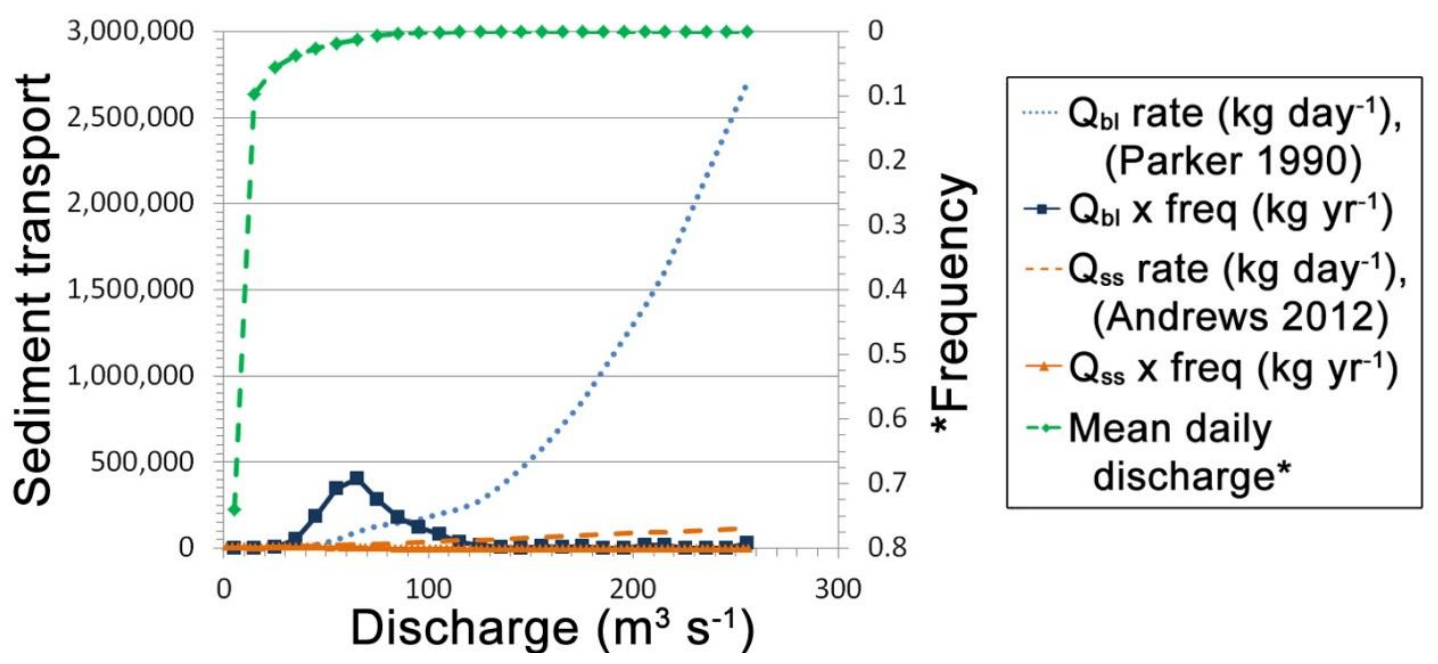

Figure 42. Calculated magnitude-frequency of bedload and suspended-sediment transport at YNP study crosssection 13 (XS 13 - see fig. 8 for location). 'Qb' is bedload discharge, ' $Q_{s s}$ ' is suspended-sediment discharge. Note that the frequency of mean daily discharge is plotted on the secondary axis and that the legend contains the units for the y-axis. 


\section{Tables}

Table 1. Description of model scenarios developed for this study

\begin{tabular}{|l|l|}
\hline \multicolumn{1}{|c|}{ Short name (as listed in figures) } & \multicolumn{1}{c|}{ Description } \\
\hline Present-day & Present-day conditions \\
\hline Historical & Historical conditions based on 1919 USGS map \\
\hline Removed Sugar Pine & $\begin{array}{l}\text { Identical to present-day conditions but with Sugar Pine Bridge } \\
\text { removed }\end{array}$ \\
\hline Removed Ahwahnee & $\begin{array}{l}\text { Identical to present-day conditions but with Ahwahnee Bridge } \\
\text { removed }\end{array}$ \\
\hline Removed Stoneman & $\begin{array}{l}\text { Identical to present-day conditions but with Stoneman Bridge } \\
\text { removed }\end{array}$ \\
\hline Removed Sugar Pine and Berm & $\begin{array}{l}\text { Same as Removed Sugar Pine scenario and additionally has } \\
\text { the present-day elevated road berm between Sugar Pine and } \\
\text { Ahwahnee Bridges removed }\end{array}$ \\
\hline $\begin{array}{l}\text { Removed Sugar Pine, Ahwahnee and } \\
\text { Berm }\end{array}$ & $\begin{array}{l}\text { Same as Removed Sugar Pine or Berm scenario and also } \\
\text { includes a removed Ahwahnee Bridge }\end{array}$ \\
\hline
\end{tabular}

Table 2. Gaging stations used in this study

\begin{tabular}{|l|l|l|c|}
\hline \multicolumn{1}{|c|}{ Name } & \multicolumn{1}{c|}{ Site ID } & \multicolumn{1}{c|}{ Dates of operation } & Drainage Area (km²) \\
\hline $\begin{array}{l}\text { Merced River at Happy } \\
\text { Isles Bridge near } \\
\text { Yosemite }\end{array}$ & USGS 11264500 & Aug. 1915 to present & 469 \\
\hline $\begin{array}{l}\text { Merced River at Pohono } \\
\text { Bridge }\end{array}$ & USGS 11266500 & Oct. 1916 to present & 831 \\
\hline $\begin{array}{l}\text { Tenaya Creek near } \\
\text { Yosemite Village }\end{array}$ & USGS 11265000 & May 1912 to Sept. 1958 & 121 \\
\hline Tenaya Creek* & YNP location* & March 2006 to present & About 121 \\
\hline
\end{tabular}

* - YNP Tenaya Creek gage location is no in the same location as the historical USGS gage on Tenaya Creek (11265000, Tenaya Creek near Yosemite Village).

Table 3. Accuracy assessment of YNP 2007 topographic survey data.

\begin{tabular}{|c|c|c|c|c|c|c|}
\hline \multirow{3}{*}{ Location } & \multirow[b]{2}{*}{$\begin{array}{l}\text { total distance per } \\
\text { survey loop: }\end{array}$} & \multirow{2}{*}{$\begin{array}{l}\text { number } \\
\text { of } \\
\text { stations }\end{array}$} & \multicolumn{4}{|c|}{ Closure Error } \\
\hline & & & horizontal & $\begin{array}{c}\text { approx. } \\
\text { horizontal } \\
\text { accuracy level }\end{array}$ & vertical & $\begin{array}{c}\text { approx. } \\
\text { vertical accuracy } \\
\text { level }\end{array}$ \\
\hline & $\mathrm{m}$ & \# & $\mathrm{m}$ & & $\mathrm{m}$ & \\
\hline Loop 1 & 528 & 6 & 0.378 & $1: 1,000$ & 0.017 & $1: 2,500$ \\
\hline Loop 2 & 468.2 & 8 & 0.167 & $1: 2,500$ & 0.114 & Less than $1: 1,000$ \\
\hline Loop 3 & $1,682.7$ & 14 & 1.035 & $1: 1,000$ & 0.099 & Less than $1: 1,000$ \\
\hline
\end{tabular}


Table 4. Results of flood frequency analysis for eastern Yosemite Valley.

\begin{tabular}{|l|c|c|c|}
\hline $\begin{array}{c}\text { Annual } \\
\text { exceedance } \\
\text { probability }\end{array}$ & $\begin{array}{c}\text { USGS gage 11264500, } \\
\text { Merced River at Happy } \\
\text { Isles Bridge near } \\
\text { Yosemite } \\
(\mathbf{1 9 1 6 - 2 0 1 0 )}\end{array}$ & $\begin{array}{c}\text { USGS gage } \\
\text { 11265000, Tenaya } \\
\text { Creek near } \\
\text { Yosemite Village } \\
(\mathbf{1 9 1 2 - 1 9 5 8 )}\end{array}$ & $\begin{array}{c}\text { at confluence of Merced } \\
\text { River and Tenaya Creek }\end{array}$ \\
\hline percent & $\mathbf{m}^{3} \mathbf{s}^{-1}$ & $\mathbf{m}^{\mathbf{3}} \mathbf{s}^{-1}$ & $\mathbf{m}^{3} \mathbf{s}^{-1}$ \\
\hline 50 & 76.5 & 27.8 & 104.3 \\
\hline 20 & 118.6 & 46.7 & 165.3 \\
\hline 10 & 151.9 & 65.9 & 217.8 \\
\hline 5 & 188.2 & 91.0 & 279.2 \\
\hline
\end{tabular}

Gage information is listed in Table 2. *-see text for details. 
Table 5. YNP WY2010 water stage survey data.

* - discharge estimated using stage-discharge curve in fig. $5 .{ }^{* *}$ - discharge at confluence of Merced River and Tenaya Creek estimated using a 45-minute lag from Happy Isles gage and a 15-minute lag from the Tenaya Creek gage.

\begin{tabular}{|c|c|c|c|c|c|c|c|c|}
\hline \multicolumn{6}{|c|}{ WY2010 water stage survey } & $\begin{array}{l}\text { Happy Isles } \\
\text { gage }\end{array}$ & $\begin{array}{c}\text { Tenaya } \\
\text { Creek gage }\end{array}$ & $\begin{array}{c}\text { Estimated } \\
\text { discharge at } \\
\text { confluence }\end{array}$ \\
\hline date & start time & end time & $\begin{array}{l}\text { midpoint } \\
\text { time }\end{array}$ & total time & $\begin{array}{c}\text { \# of } \\
\text { stage } \\
\text { meas. }\end{array}$ & $\begin{array}{c}\left(\mathrm{m}^{3} \mathrm{~s}^{-1}, \text { at }\right. \\
\text { midpoint } \\
\text { time })\end{array}$ & $\begin{array}{c}\left(\mathrm{m}^{3} \mathrm{~s}^{-1}, \text { at }\right. \\
\text { midpoint } \\
\text { time })\end{array}$ & $\begin{array}{c}\left(\mathrm{m}^{3} \mathrm{~s}^{-1}, \text { at midpoint }\right. \\
\text { time) }\end{array}$ \\
\hline $5 / 21 / 2010$ & $8: 55$ & $14: 15$ & $11: 45$ & $5: 20$ & 18 & 42.76 & 15.79 & 58.55 \\
\hline $5 / 28 / 2010$ & 9:07 & $14: 46$ & $11: 37$ & $5: 39$ & 26 & 16.28 & 6.85 & 23.13 \\
\hline $6 / 4 / 2010$ & $12: 20$ & $16: 55$ & $14: 34$ & $4: 35$ & 59 & 64.28 & 24.20 & 88.48 \\
\hline 6/7/2010 & $11: 11$ & $16: 42$ & $14: 15$ & $5: 31$ & 47 & 86.65 & 24.67 & 111.32 \\
\hline $6 / 8 / 2010$ & $6: 25$ & $10: 49$ & $8: 30$ & $4: 24$ & 42 & 103.36 & 27.51 & 130.87 \\
\hline $6 / 10 / 2010$ & $9: 59$ & 13:01 & $11: 36$ & 3:02 & 48 & 74.47 & 19.54 & 94.02 \\
\hline $7 / 29 / 2010$ & $11: 41$ & $17: 17$ & $14: 08$ & $5: 36$ & 32 & 5.35 & na & na \\
\hline
\end{tabular}

Table 6. Downstream stage elevations used as inputs to the FaSTMECH 2D model.

\begin{tabular}{|c|c|c|}
\hline Discharge & $\begin{array}{c}\text { Water surface elevation } \\
\text { (present-day conditions and } \\
\text { scenarios) }\end{array}$ & $\begin{array}{c}\text { Water surface elevation } \\
\text { (historical) }\end{array}$ \\
\hline $\mathbf{m}^{\mathbf{3} \mathbf{s}^{-1}}$ & $\mathbf{m}, \mathbf{N A V D 8 8}$ & $\mathbf{m}, \mathbf{N A V D 8 8}$ \\
\hline 104.3 & $1,208.48$ & $1,209.24$ \\
\hline 130.9 & $1,208.63$ & na \\
\hline 165.3 & $1,208.84$ & $1,209.54$ \\
\hline 217.8 & $1,209.06$ & $1,209.74$ \\
\hline 279.2 & $1,209.28$ & $1,209.97$ \\
\hline
\end{tabular}


Table 7. Input parameters for bedload transport calculations.

\begin{tabular}{|l|l|l|}
\hline \multicolumn{1}{|c|}{ Input } & \multicolumn{1}{c|}{ Value } & \multicolumn{1}{c|}{ Source } \\
\hline Cross-section topography & $\begin{array}{l}\text { Present-day topography at YNP study } \\
\text { cross-section 13 (XS13 in fig. 8) with } \\
\text { floodplain topography from final } \\
\text { FaSTMECH surface }\end{array}$ & YNP cross-section database and this study \\
\hline Grain size distribution & Site A in Figures 19 and 20 & This study \\
\hline Slope & 0.0033 & $\begin{array}{l}\text { Field measurement and FaSTMECH } \\
\text { simulation - this study }\end{array}$ \\
\hline Roughness (Manning's $n$ ) & In-channel: 0.035; floodplain: 0.085 & This study \\
\hline
\end{tabular}

Table 8. Evaluation of equestrian tunnels at Stoneman Bridge for two flows, the 50- and 5-percent annual exceedance probability floods.

\begin{tabular}{|l|c|c|c|c|c|}
\hline \multicolumn{1}{|c|}{ Feature } & $\begin{array}{c}\text { FaSTMECH } \\
\text { model } \\
\text { discharge }\end{array}$ & $\begin{array}{c}\text { Unit } \\
\text { discharge }\end{array}$ & Width & Discharge & $\begin{array}{c}\text { Percent of total } \\
\text { discharge }\end{array}$ \\
\cline { 2 - 6 } & $\boldsymbol{m}^{\mathbf{3}} \boldsymbol{s}^{-1}$ & $\boldsymbol{m}^{-1}$ & $\boldsymbol{m}$ & $\boldsymbol{m}^{\mathbf{3}} \boldsymbol{s}^{-1}$ & percent \\
\hline RR equestrian tunnel & 104 & 0.48 & 3 & 1.44 & 1.4 \\
\hline RL equestrian tunnel & 104 & 0.50 & 2.7 & 1.35 & 1.3 \\
\hline Main channel & 104 & 4.64 & 21.9 & 101.62 & 97.3 \\
\hline $\begin{array}{l}\text { Combined (tunnels + main } \\
\text { channel) }\end{array}$ & 104 & na & na & 104.41 & 100 \\
\hline & 279 & 1.81 & 3 & 5.44 & 1.9 \\
\hline RR equestrian tunnel & 279 & 1.90 & 2.7 & 5.13 & 1.8 \\
\hline RL equestrian tunnel & 279 & 9.53 & 21.9 & 208.67 & 74.7 \\
\hline Main channel & 279 & na & na & 219.25 & 78.5 \\
\hline $\begin{array}{l}\text { Combined (tunnels + main } \\
\text { channel) }\end{array}$ & & & & & \\
\hline
\end{tabular}

"RR" refers to "River right", "RL" refers to "River left" (viewing downstream).

Table 9. Change through time at YNP Merced River study cross-section 13 at "Tenaya Bar".

\begin{tabular}{|c|c|c|}
\hline \multirow{2}{*}{ Year } & $\begin{array}{c}\text { Channel } \\
\text { Area* }\end{array}$ & $\begin{array}{c}\text { Percent Change relative to } 1989 \\
\text { Area }\end{array}$ \\
\cline { 2 - 3 } & \multicolumn{1}{c|}{$\boldsymbol{m}^{\mathbf{2}}$} & percent \\
\hline 1989 & 61.4 & 100.0 \\
\hline 1995 & 60.9 & 99.2 \\
\hline 1997 & 33.8 & 55.0 \\
\hline 2001 & 39.4 & 64.2 \\
\hline 2006 & 47.3 & 77.0 \\
\hline
\end{tabular}

${ }^{*}$ measured below top of left bank 